\title{
Nuclear receptor signal transduction in C. elegans
}

\author{
Adam Antebi ${ }^{\S}$
}

Max Planck Institute for Biology of Ageing and Cologne Excellence Cluster on Cellular Stress Responses in Aging Associated Diseases (CECAD), University of Cologne, Cologne, Germany; Department of Molecular and Cellular Biology, Huffington Center on Aging, Baylor College of Medicine, Houston, TX 77030, USA

\section{Table of Contents}

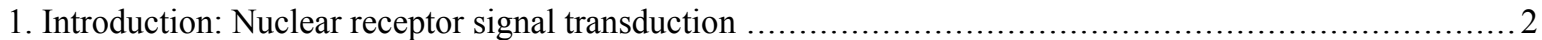

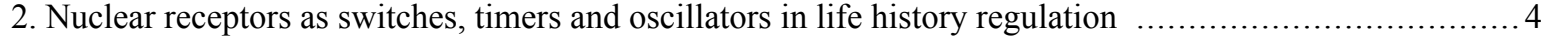

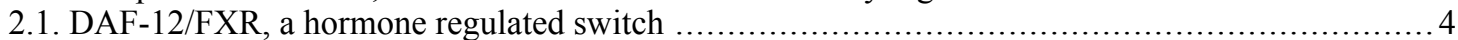

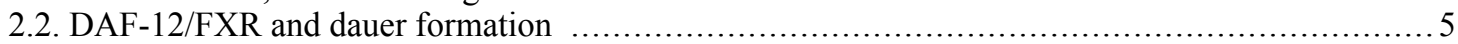

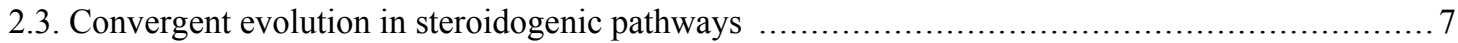

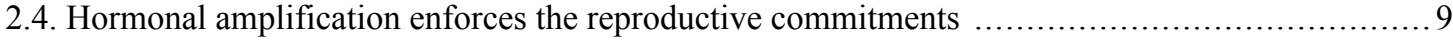

2.5. DAF-12 regulates L2/L3 transitions in developmental timing circuits ............................ 10

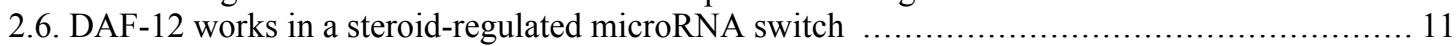

2.7. DAF-12 regulates life span in response to signals from the reproductive system .................... 13

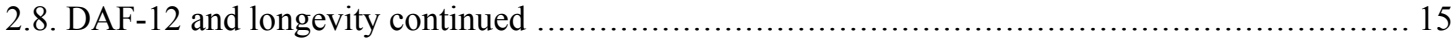

2.9. DA/DAF-12 signaling in parasitic and other nematodes ............................................ 15

2.10. NHR-8/LXR regulates cholesterol, bile acid, and fatty acid metabolism .......................... 15

2.11. UNC-55/COUP, a switch in neuronal developmental timing circuits ............................... 16

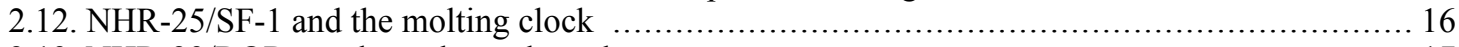

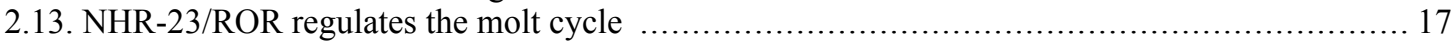

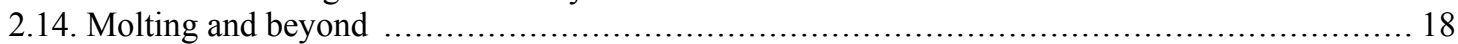

3. Nuclear receptors as regulators of cell fate and organogenesis ............................................. 19

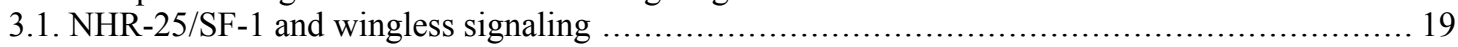

3.2. NHR-67/TLL controls cell fate through EGF, FGF, and Notch signaling ............................. 20

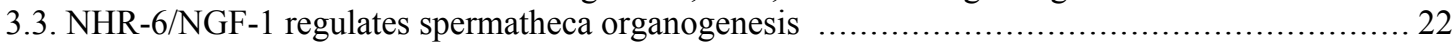

4. Nuclear receptors in nutrient sensing, metabolism, and energy homeostasis .............................. 22

4.1. NHR-91 regulates blast cell progression in response to nutrients ................................ 22

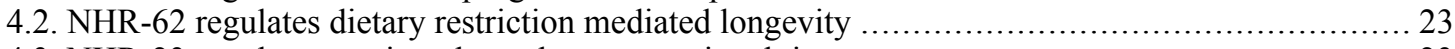

4.3. NHR-23 regulates nutrient dependent maturational time …...................................... 23

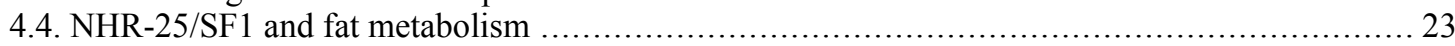

*Edited by Iva Greenwald. Last revised July 23, 2014. Publishedl-XQHD, 2015. This chapter should be cited as: Antebi A. Nuclear receptor signal transduction in C. elegans (-XQHप⿴囗十口), WormBook, ed. The C. elegans Research Community, WormBook, doi/10.1895/wormbook.1.64.2, http://www.wormbook.org.

Copyright: $\subset 2015$ Adam Antebi. This is an open-access article distributed under the terms of the Creative Commons Attribution License, which permits unrestricted use, distribution, and reproduction in any medium, provided the original author and source are credited.

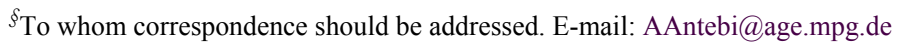


4.5. NHR-49/PPAR regulates fat metabolism and the nutrient response ................................ 24

4.6. NHR-49/PPAR affects life span and the adult reproductive diapause ............................. 25

4.7. NHR-49/PPAR transcriptional complexes .................................................. 25

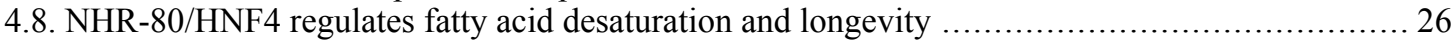

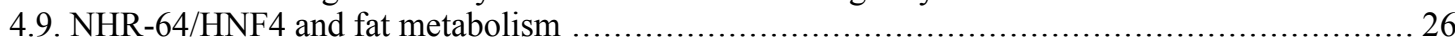

4.10. NHR-76 integrates biogenic amine signaling to mediate lipolysis ................................ 27

4.11. NHR-69/HNF4 regulates insulin secretion and dauer formation .............................. 27

4.12. NHR-31/HNF4 controls fluid balance ....................................................... 28

4.13. NHR-114 affects germ cell integrity in response to diet ........................................ 29

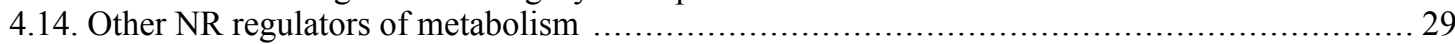

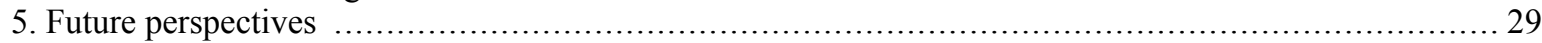

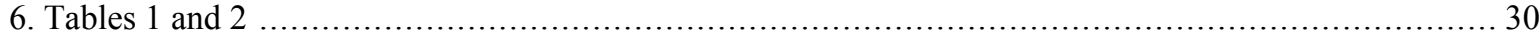

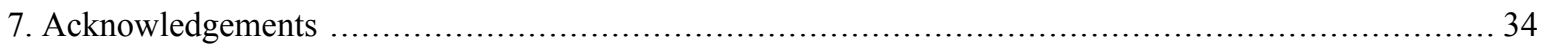

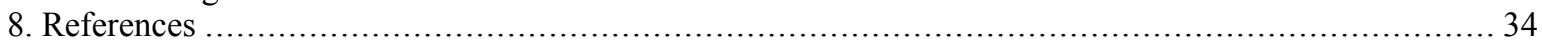

\begin{abstract}
Nuclear receptors are transcription factors that often respond to small molecule metabolites and fat-soluble compounds to regulate gene expression. They broadly govern development, reproduction, metabolism, and homeostasis in diverse metazoan species and their dysregulation is associated with numerous diseases. Work in $C$. elegans has shed light on the seminal role of nuclear receptors in life history regulation, stem cell progression, developmental timing, cell fate specification, nutrient sensing, metabolism, and longevity. Here we highlight recent advances on the best-studied nuclear receptors in the worm, and how they illuminate metazoan biology.
\end{abstract}

\title{
Abbreviations:
}

NR: nuclear receptor; LBD: ligand binding domain, DA: dafachronic acid; IIS: insulin/IGF signaling; AC: anchor cell; ARD: adult reproductive diapause; LC: linker cell; MUFA: monounsaturated fatty acid; PUFA: polyunsaturated fatty acid; TAG: triacyl glycerides; VU: ventral uterine; DR: Dietary restriction.

\section{Introduction: Nuclear receptor signal transduction}

A remarkable invention of metazoan evolution, nuclear receptors (NR) are ligand gated transcription factors that typically bind small molecule metabolites such as fatty acids, vitamins, and steroids to directly regulate gene transcription. They are well poised to coordinate multicellular metabolism, development, reproduction, and homeostasis across diverse tissues. A conserved architecture and mechanism underlies their signaling abilities (Mangelsdorf et al., 1995). The DNA binding domain consists of two zinc fingers near the N-terminus, which contact the double helix and form a dimerization interface. The ligand binding domain (LBD) resides at the C-terminus, and binds cognate ligand as well as co-activator and co-repressor complexes that instruct its activity. Typically class 1 receptors, such as the classical steroid receptors (e.g., estrogen, androgen, glucocorticoid receptors), are ligand activated, while so-called class 2 receptors (e.g., PPARs, vitamin D receptor, thyroid receptor) function as transcriptional activators in the presence of ligand, but as repressors in the absence of ligand (Figure 1). Various post-translational modifications including phosphorylation, acetylation, ubiquitylation, and sumoylation can also modulate their activities (Anbalagan et al., 2012). Some NRs constitutively bind ligand (e.g., HNF4 $\alpha$ binds fatty acids), and are instead gated by associated proteins or modifications (Gonzalez, 2008). Other NRs have no identified ligands, and are therefore termed orphan receptors. 


\section{LIGAND BOUND NR}

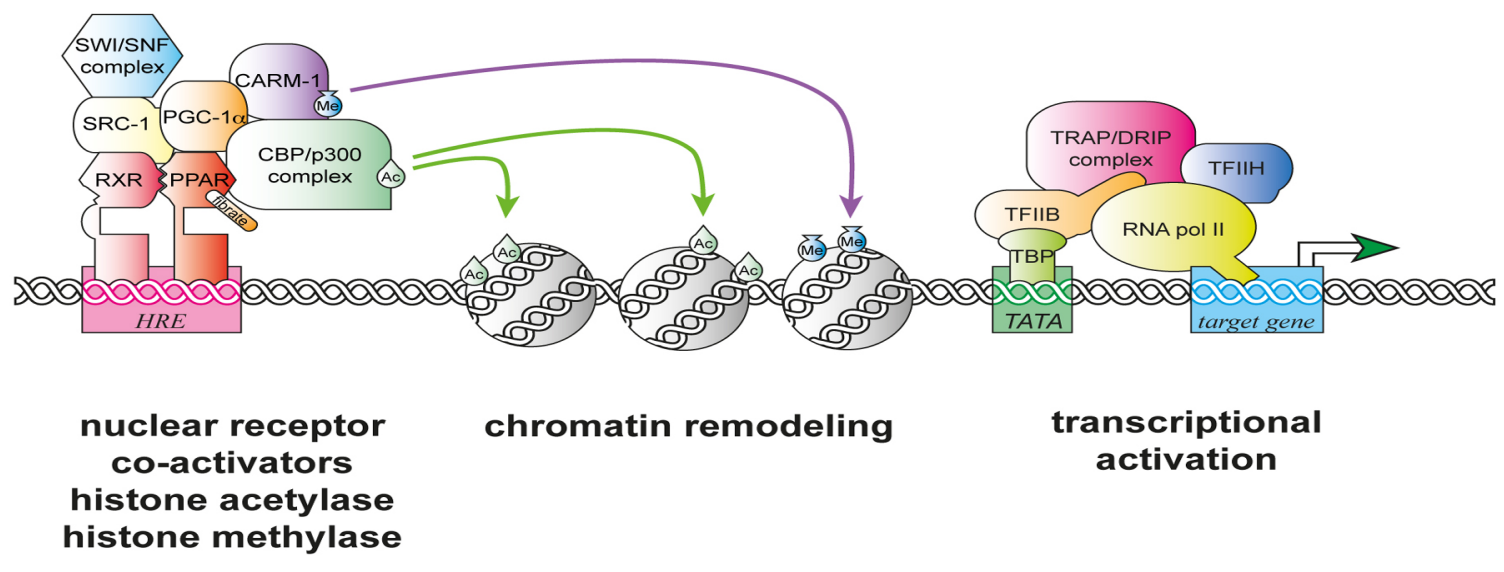

\section{UNLIGANDED NR}

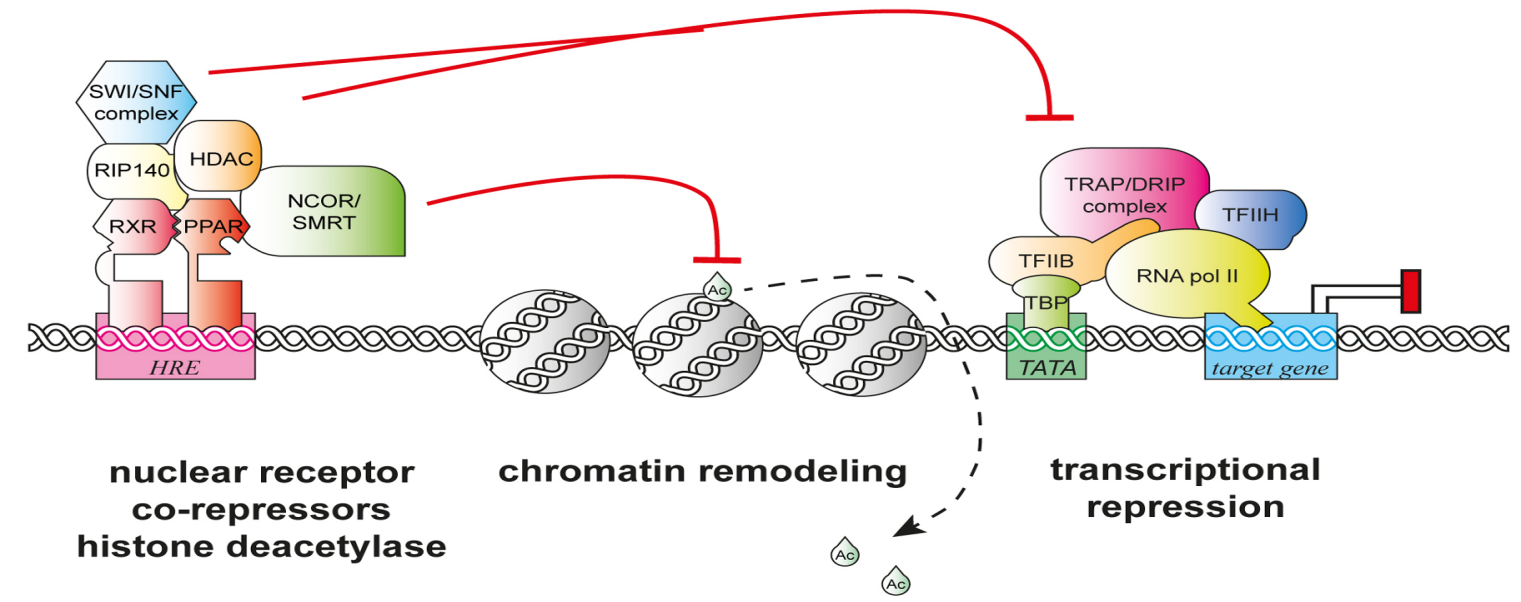

Figure 1. NRs assemble activation and repressive complexes. Typical type 2 NRs such as PPAR $\gamma$ bind to hormone response elements (HRE), and when ligand bound (e.g., fibrates) activate transcription by recruiting co-activator complexes (PGC-1, SRC-1), histone acetylase complexes (p300), methylase complexes (e.g., CARM), chromatin remodeling complexes (SWI/SNF), and mediator subunits (TRAP/DRIP). In the absence of their ligands, NRs recruit co-repressor complexes (NCoR, RIP140) to repress transcription through the recruitment of histone deacetylases (HDAC), histone demethylases, and other repressive components, and to inhibit TRAP/DRIP complexes. Adapted from http://themedicalbiochemistrypage.org/signal-transduction.php\#corepressors by Michael W King, PhD | C 1996-2014 themedicalbiochemistrypage.org, LLC.

Humans harbor 48 NRs including the classical steroid receptors, thyroid receptors, vitamin D receptor, and retinoic acid receptors, SF1, GCNF, ROR, COUP, which primarily govern development, immunity, and reproduction. Major regulators of lipid, glucose, and xenobiotic metabolism include PPARs, LXR, LRH, HNF4, FXR, PXR, and CAR (McKenna and O'Malley, 2010a, McKenna and O'Malley, 2010b). C. elegans boasts a remarkable 284 receptors: 269 of them represent a vast expansion and diversification of the HNF4 family (Robinson-Rechavi et al., 2005). The remaining 15 are more evolutionarily conserved, and include homologs of VITD/LXR/FXR (daf-12, $n h r-8, n h r-48)$, SF1 ( $n h r-25)$, ROR (nhr-23), COUP (unc-55), HNF4 (e.g., nhr-64, $n h r-69)$, Rev-Erb (nhr-85, sex-1), TLX (nhr-67), PNR (fax-1), NGF-1 (nhr-6), GCNF (nhr-91), and TR2/4 (nhr-41) (Table 1, Section 6). Notably missing from $C$. elegans are clear structural orthologs of the classical steroid and ecdysteroid receptors, the PPARs, thyroid receptors, as well as retinoic acid and heterodimeric receptor RXR. Nevertheless evidence suggests that analogous physiologic functions have arisen through convergent evolution (Table 2, Section 6). The expanded NR superfamily is not unique to C. elegans, but also characteristic of closely related nematodes such as C. rameni and C. briggsae (Haerty et al., 2008), as well as species more evolutionarily 
diverged such as Pristionchus pacificus (Dieterich et al., 2008), suggesting an ancestral role in nematode physiology.

Because of $C$. elegans' cellular simplicity and powerful genetics, the study of NR signaling in the worm has provided unprecedented insights into events in vivo, from the subcellular to organismal level, from synaptic remodeling to longevity - vantages not always easily achieved in mammalian models. Since our 2006 chapter, Nuclear hormone receptors in $C$. elegans, a wealth of information on the C. elegans receptors has been uncovered. An emergent view is that these NRs play key roles in timers and oscillators, working as feedback regulated switches in circuits governing developmental timing, the molt cycle clock, dauer formation, longevity, and other aspects of life history. They also extensively interface with other signaling pathways to mediate fate choice and organogenesis. Finally they serve as key homeostatic regulators or switches in nutrient sensing and metabolism. In this review, we highlight the best studied of these receptors, and attempt to place them in biological context.

\section{Nuclear receptors as switches, timers and oscillators in life history regulation}

All animals develop through successive life stages to reproductive maturity, and ultimately age and die, collectively comprising the life history of the species. Coordinate progression through the life stages requires a precise integration of extrinsic environmental cues together with intrinsic metabolic, cellular, and physiologic processes. As ligand and nutrient responsive transcription factors, NRs play a particularly important role in orchestrating animal life history, by integrating environmental and physiologic information, coordinating metabolic and cellular events throughout the body, and triggering the succession of life stages.

C. elegans life history, like many species depends very much on environment. In favorable environmental conditions, $C$. elegans develops from embryo through four larval stages L1-L4 separated by molts to reproductive maturity, produces large broods of 300 animals, and then lives another 3 weeks (Byerly et al., 1976; Klass, 1977). In unfavorable conditions, such as food deprivation, animals arrest at several diapause states including the L1 diapause, the L3 dauer diapause, and an adult reproductive diapause, which are stress resistant and long lived (Cassada and Russell, 1975; Johnson et al., 1984; Angelo and Van Gilst, 2009). Upon return to ample nutrients and favorable conditions, worms will resume growth and reproduction. Several conserved NRs, including DAF-12, NHR-8, UNC-55, NHR-25, and NHR-23, function as key regulators of C. elegans life history. These NRs govern diapause stages and developmental timing circuits, catalyze transitions through life stage programs, and drive the molt cycle timer. They also often influence reproduction, metabolism, and longevity. Below we highlight their roles in these circuits.

\subsection{DAF-12/FXR, a hormone regulated switch}

DAF-12 is the most intensively studied NR in C. elegans and has served as an important paradigm for metazoan NR signal transduction in vivo. DAF-12 is most homologous to vertebrate farnesoid-X (FXR), liver-X, and vitamin-D receptors (Antebi et al., 2000), which regulate metabolism, development, and homeostasis in a wide variety of contexts (Table 1). Vertebrate homologs are gated by cognate bile acids (Makishima et al., 1999; Parks et al., 1999), oxysterols (Janowski et al., 1996), and vitamin-D (McDonnell et al., 1987), respectively, but also share the ability to be regulated by bile acid-like steroids, suggesting an ancestral role of such molecules (Song and Liao, 2000; Jurutka et al., 2005; Zhi et al., 2012). DAF-12 is also regulated by bile acid-like steroids, in this case called the dafachronic acids (DA) as well as cholestenoic acid, which activate transcription with high affinity (Held et al., 2006; Motola et al., 2006), and to date is the sole C. elegans receptor whose ligand has been unequivocally determined. Found in the nucleus of all somatic cells, DAF-12 regulates a wide swath of C. elegans biology, including the dauer diapause, developmental timing, metabolism, and longevity, coupling environmental and physiologic information to reproductive development, detailed below (Antebi et al., 2000). 


\subsection{DAF-12/FXR and dauer formation}

Under food scarcity, thermal stress and overcrowding, C. elegans will arrest and enter the dauer diapause, an alternate third larval stage specialized for survival and dispersal (Cassada and Russell, 1975; Fielenbach and Antebi, 2008; see also the WormBook chapter Dauer). Dauer larvae are extremely stress resistant, sexually immature, and long lived. Yet when returned to ample food, will mature to reproductive adults, revealing incredible plasticity in regulation of reproduction and longevity. Genetic screens for mutants that affect dauer formation identified dauer-formation constitutive (Daf-c) and dauer-formation defective loci (Daf-d) that either always, or never, enter the dauer stage (Riddle et al., 1981). Genetic epistasis experiments place daf-12 at the end of the dauer pathways (Riddle et al., 1981; Vowels and Thomas, 1992; Thomas et al., 1993; Gottlieb and Ruvkun, 1994). Various daf-12 mutants show opposite phenotypes: null mutants are Daf-d and somewhat short lived, whereas ligand-insensitive LBD mutants are Daf-c and modestly long lived, indicating that DAF-12 is instructive in the dauer decision (Riddle et al., 1981; Antebi et al., 1998; Gerisch et al., 2001; Fisher and Lithgow, 2006).

The molecular and cellular architecture of dauer formation reveals an intricate coupling of environmental information to a conserved endocrine network. Environmental inputs include ascarosides as signals of population density, unidentified food cues, and temperature (Golden and Riddle, 1984a; Golden and Riddle, 1984b; Butcher et al., 2007), which are perceived and integrated by ciliated sensory neurons (Perkins et al., 1986; Bargmann and Horvitz, 1991) and transduced through cGMP signaling (Vowels and Thomas, 1992; Birnby et al., 2000). Sensory perception regulates production and neurosecretion of TGF- $\beta$ (Ren et al., 1996), and insulin-like-peptides (Li et al., 2003), which work through their respective signal transduction pathways to control steroidal hormone signaling (Gerisch and Antebi, 2004; Mak and Ruvkun, 2004). This core endocrine network is modulated by a myriad of signaling inputs including serotonin (Sze et al., 2000), acetylcholine (Lee et al., 2014), neuropeptide-Y-like (Cohen et al., 2009), ALK (Reiner et al., 2008), TOR (Jia et al., 2004), AMPK (Apfeld et al., 2004), Wnt (Essers et al., 2005; Goh et al., 2012), Notch (Ouellet et al., 2008), ER stress signaling (Kulalert and Kim, 2013), and others. Despite the complexity of inputs, the essential core signaling reduces to a binary decision: that in favorable circumstances, TGF- $\beta$ and insulin/IGF signaling (IIS) are upregulated and stimulate production of the DAs in steroidogenic cells (Fielenbach and Antebi, 2008). Liganded DAF-12 then prevents dauer formation, and promotes reproductive development in tissues throughout the body (Figure 2). Conversely, under adverse circumstances, TGF- $\beta$ and IIS are downregulated, resulting in suppression of DA production. Unliganded DAF-12 forms a repression complex with the DIN-1/SHARP co-repressor, thereby specifying the long-lived dauer diapause (Ludewig et al., 2004; Fielenbach and Antebi, 2008). Thus, DAF-12 functions as a hormone-regulated switch governing reproduction or survival. 


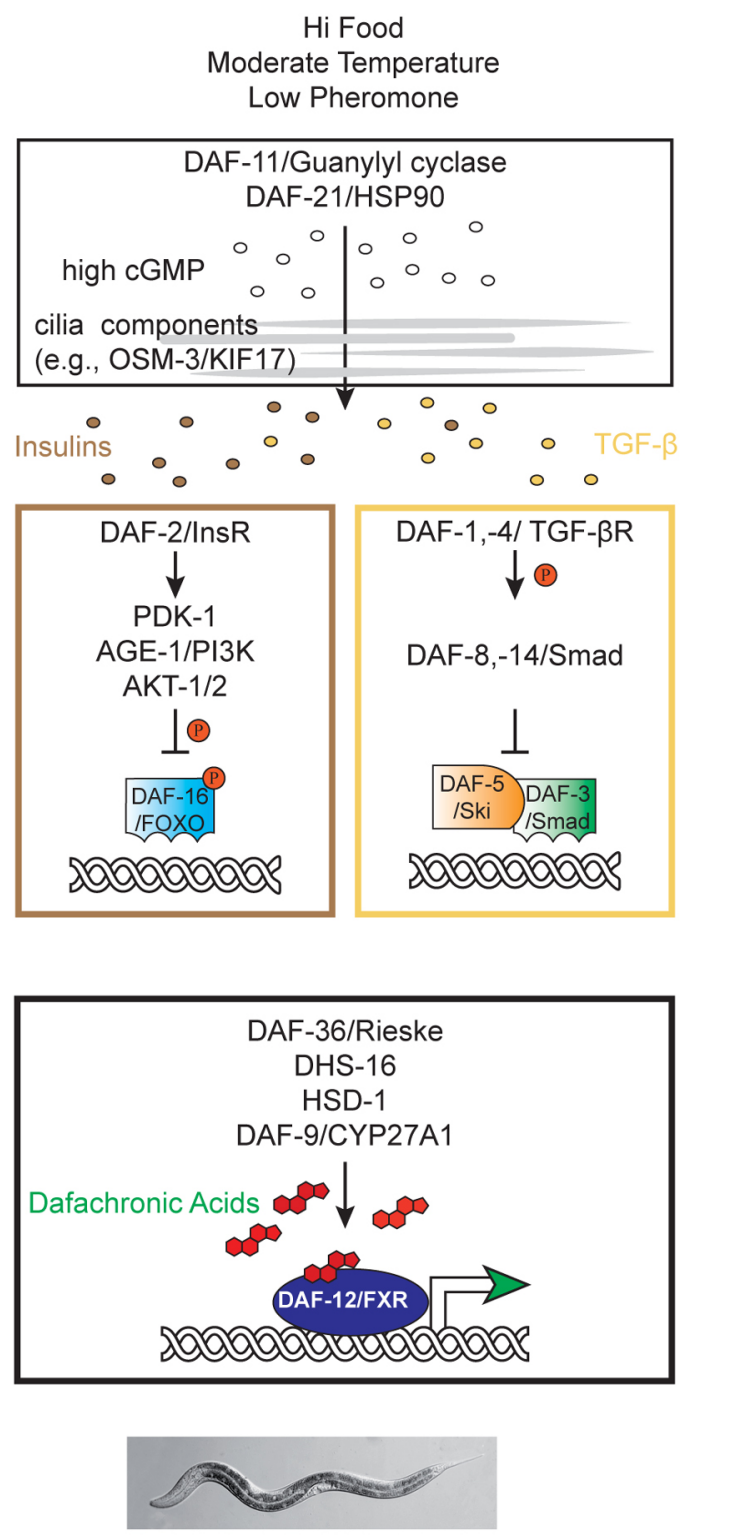

Reproductive Development
Low Food

Hi Temperature

Hi Pheromone

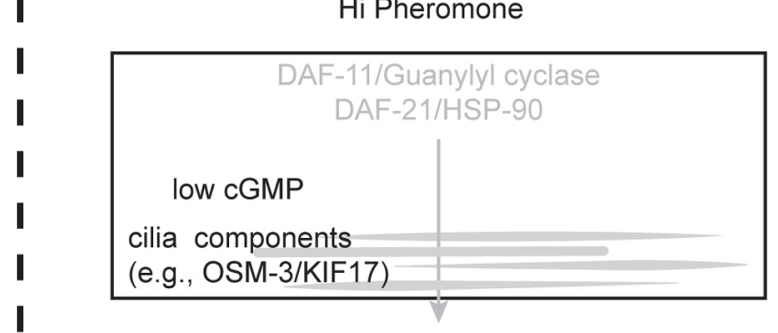

I

I
I
I
I
I
I
I
I

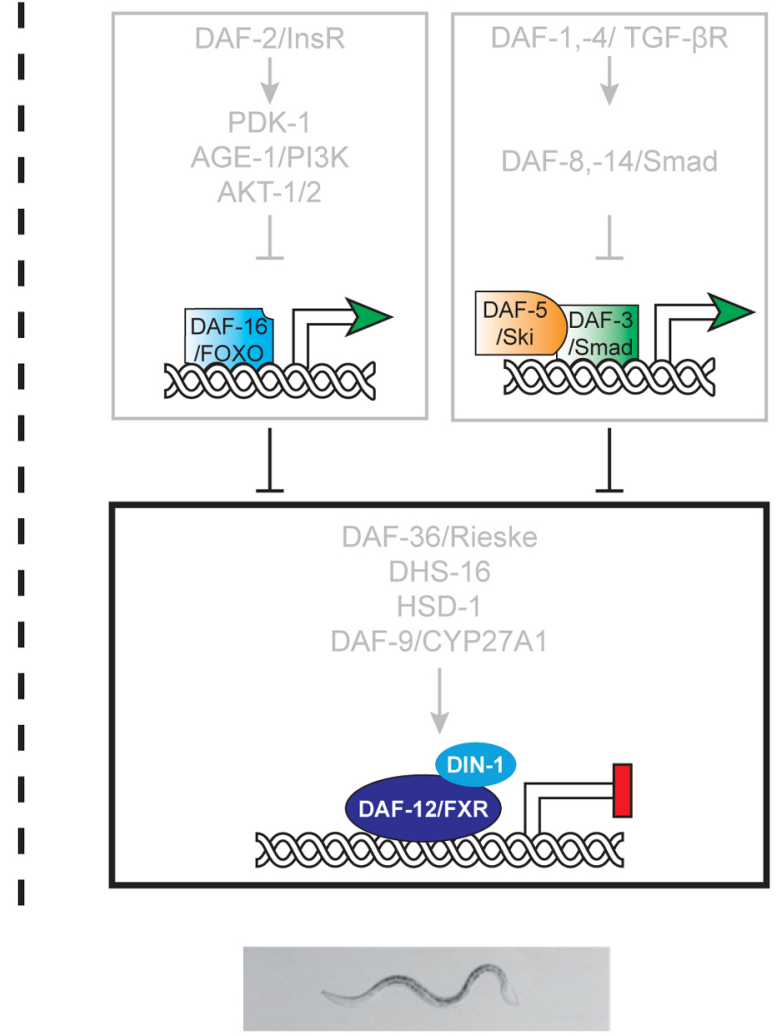

I

Dauer Development

Figure 2. DAF-12 works at the convergence of the dauer pathways to mediate the choice between dauer arrest versus reproductive development. In favorable environments, cues detected by ciliated sensory neurons (grey lines) result in the activation of the DAF-11/guanylyl cyclase and the production of cGMP. Thereafter, TGF- $\beta$ and insulin-like peptides are secreted from neurons and impinge on their respective signal transduction pathways in target tissues and steroidogenic cells. Inactivation of DAF-16/FOXO by the PI3K/AKT kinase cascade as well as inhibition of DAF-3/Smad-DAF-5/Ski complexes by DAF-8/DAF-14 SMADs stimulate biosynthesis of the DAs from cholesterol. Liganded DAF-12 assembles putative co-activator complexes, bypassing dauer, and allowing L3 and later programs.

In unfavorable environments, cues detected by ciliated sensory neurons result in the inactivation of the DAF-11/guanylyl cyclase and decreased synthesis of cGMP. Consequently, production of TGF- $\beta$ and Insulin-like peptides is suppressed, as are their respective signal transduction pathways in target tissues. Activation of DAF-16/FOXO as well DAF-3/Smad and DAF-5/Ski complexes inhibit production of the DAs. Unliganded DAF-12 together with DIN-1 form a co-repressor complex, promoting the dauer diapause, and preventing reproductive programs.

Apparently the dauer endocrine network has a conserved physiologic function in regulating reproduction and longevity across taxa. Both IIS and TGF- $\beta$ pathways govern ecdysteroidogenesis in insect metamorphosis, and steroidogenesis in mammalian puberty (Tennessen and Thummel, 2011) (Figure 3). TGF- $\beta$, IIS, and steroidal signaling and other dauer signaling pathways have been implicated in regulation of $C$. elegans adult longevity (Kenyon et al., 1993; Hsin and Kenyon, 1999; Gerisch et al., 2001; Jia et al., 2002; Shaw et al., 2007). IIS regulates longevity in flies, mice and humans (Clancy et al., 2001; Tatar et al., 2001; Holzenberger et al., 2003; Willcox et al., 2008), while various steroids have been implicated to affect life span in flies and perhaps mammals (Keisala et al., 
2009; Kenyon, 2010; Mooijaart et al., 2007; Simon et al., 2003). It will be important to explore whether other pathways that govern reproduction and survival also impact mammalian longevity.

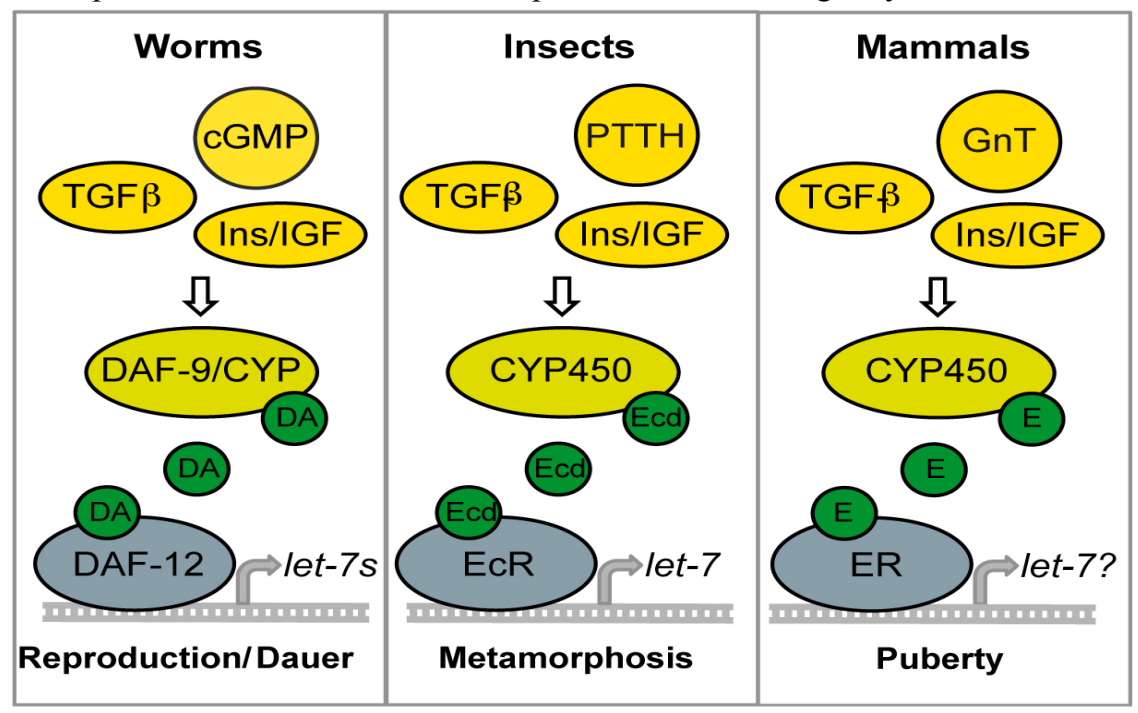

Figure 3. Conserved endocrine pathways for maturation. In $C$. elegans, cGMP, TGF- $\beta$, and IIS activate steroidal signaling to promote maturation through let- $7 s$ expression. Reduction of these endocrine pathways result in maturational arrest and longevity (i.e., dauer). Similarly in flies the convergence of PTTH (prothoraciotropic hormone), TGF- $\beta$, and IIS activate ecdysone signaling resulting in metamorphosis and maturation. Ecdysteroid signaling activates let-7 microRNAs in some tissues. Downregulation of IIS and ecdysone is associated with longevity. In mammals, gonadotropins, TGF- $\beta /$ Activin, and IIS stimulate maturational steroids. Steroid receptors may also be involved in promoting let-7 and other maturational microRNAs. Reduced IIS is associated with mammalian longevity.

\subsection{Convergent evolution in steroidogenic pathways}

Until recently relatively little was known about steroidogenic pathways in worms. Mutants were originally identified as having a similar spectrum of phenotypes as daf-12 ligand-insensitive LBD mutants, including Daf-c and retarded gonadal migration phenotypes. Initial genetic and biochemical experiments suggested that the DAs were synthesized from cholesterol (which must be obtained through the diet) through two proposed biosynthetic branches to produce active DAF-12 ligands, called $\Delta^{7}$-DA and $\Delta^{4}$-DA (Figure 4) (Motola et al., 2006; Rottiers et al., 2006). Since then, these models have undergone revision as new activities have been revealed. 


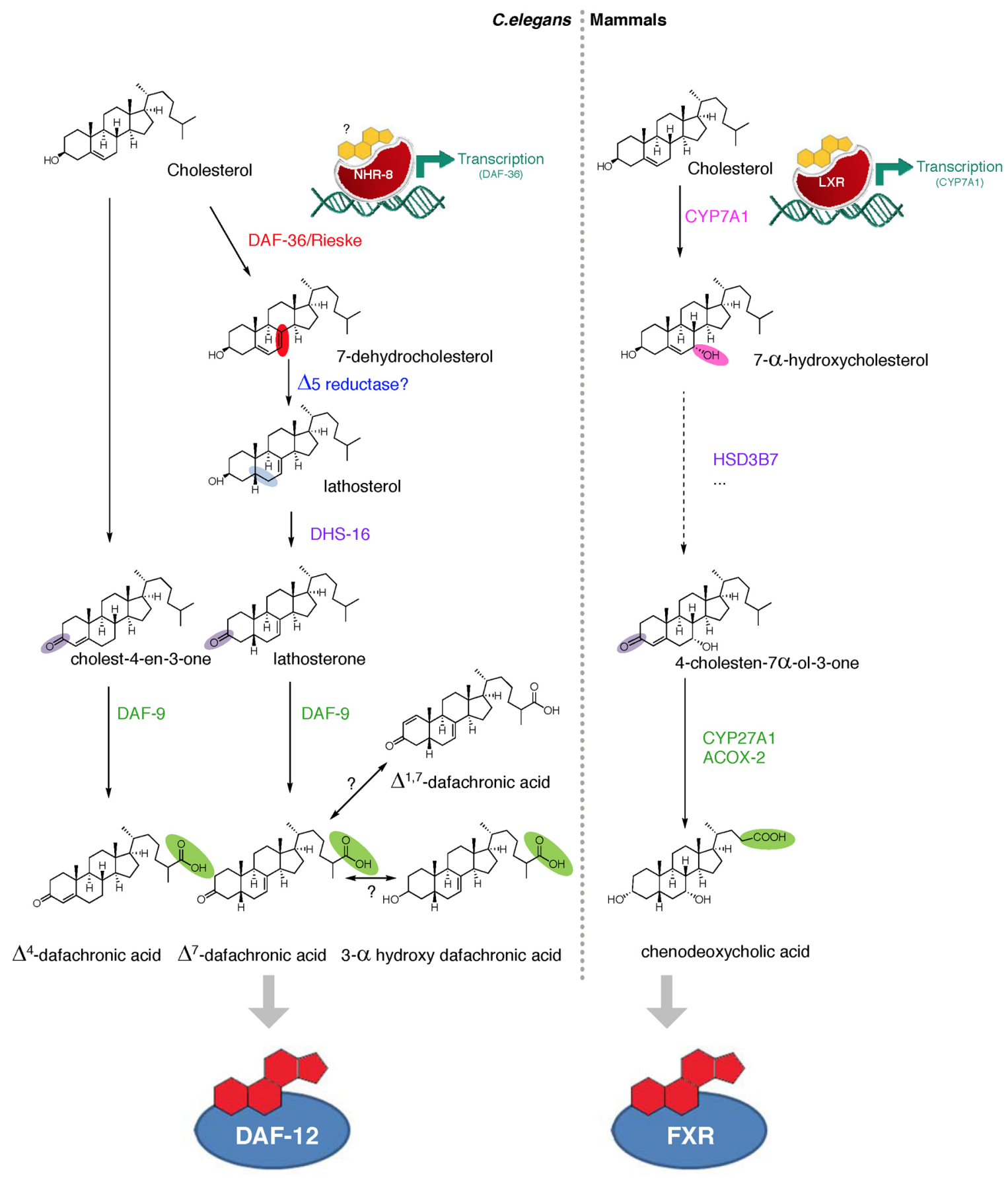

Figure 4. Bile acid-like biosynthetic pathways show conserved features between worms and mammals. In C. elegans, dietary cholesterol is modified via a series of enzymes to give the various DAs, including $\Delta 4$-DA, $\Delta 7$-DA, $\Delta 1,7$-DA, and 3-alphahydroxy-DA. (Modifications highlighted in color). DAs regulate DAF-12, a worm homolog of the bile acid receptor FXR. A related C. elegans receptor, NHR-8, regulates the first step in DA synthesis, the conversion of cholesterol to 7-dehydrocholesterol by the DAF-36/Rieske oxygenase. Ligands for NHR-8 are unknown but surmised to be sterols. In mammals, major bile acids such as chenodeoxycholic acid regulate the transcriptional activity of mammalian FXR. In response to its oxysterol ligands, LXR controls cholesterol and bile acid flux, regulating the first step in the pathway, the conversion of cholesterol to 7-hydroxycholesterol by CYP7A1. Several similarities are seen in the chemistry of bile acid-like steroid production in worms and mammals.

The $\Delta^{7}$ branch is best understood (Figure 4). The first step entails the conversion of cholesterol to 7-dehydrocholesterol by the DAF-36/Rieske oxygenase (Rottiers et al., 2006; Wollam et al., 2011; Yoshiyama-Yanagawa et al., 2011). A similar $\Delta^{7}$ desaturation is catalyzed by the orthologous neverland/Rieske oxygenase in the first step of insect ecdysteroid biosynthesis (Yoshiyama et al., 2006; Yoshiyama-Yanagawa et al., 2011). During mammalian bile acid production, CYP7A1/cytochrome P450 hydroxylates the cholesterol backbone 
at the 7-position in the first step (Russell, 2003), revealing an analogous chemistry. In C. elegans, an unknown $\Delta 5$ reductase thereafter leads to the production of lathosterol, which is oxidized to the 3-keto steroid, lathosterone, by the short chain dehydrogenase DHS-16, analogous to mammalian HSD3B7 (Wollam et al., 2012). The last step in the $\Delta^{7}$ pathway involves sequential oxidation of the cholesterol side chain to the carboxylic acid moiety by DAF-9/cytochrome P450 (Motola et al., 2006), bearing similar chemistry to that carried out by CYP27A1 in mammalian bile acid synthetic pathways (Russell, 2003). Indeed, a compound called dafadine, which phenocopies daf-9 loss of function when fed to worms, biochemically inhibits both DAF-9 and CYP27A1 activity (Luciani et al., 2011). These studies reveal remarkable convergence in the biochemical activities of bile acid synthetic pathways from worm to human.

Less is known about nematode $\Delta^{4}$ production. Although proposed as an endogenous ligand derived from 4-cholestene-3-one, spectroscopic analysis failed to detect $\Delta^{4}$-DA in vivo, perhaps because of vanishingly small amounts or instability (Mahanti et al., 2014). The 3-hydroxysteroid dehydrogenase, $h s d-1$, had been proposed to work in the $\Delta^{4}$ branch (Patel et al., 2008), but available evidence argues against this hypothesis, and suggests instead that $h s d-1$ may produce alternative DA-like ligands or function as a cholesterol $\Delta^{7}$ desaturase specifically within the XXX neuroendocrine cells (Wollam et al., 2012; Mahanti et al., 2014). Accordingly, hsd-1 mutants exhibit phenotypes and genetic interactions distinct from other hormone biosynthetic genes with respect to dauer formation, gonadal migration, and longevity (Patel et al., 2008; Dumas et al., 2010). More recently, several new DA-related compounds have been discovered through 2D-NMR and MS analysis, including an abundant and potent $\Delta^{1,7}$-DA, as well as a less prevalent and less potent 3-alpha hydroxy DA (Figure 4) (Mahanti et al., 2014). In the future it will be important to determine where and how these different DAs are made, and whether the different DAs have distinct functions and transcriptomes.

\subsection{Hormonal amplification enforces the reproductive commitments}

Interestingly, DA production is distributed in various tissues throughout the organism. The DAF-36/Rieske oxygenase is expressed primarily within the intestine (Rottiers et al., 2006), DHS-16/3-hydroxysteroid dehydrogenase is expressed in the pharynx, head neurons, and hypodermis (Wollam et al., 2012), HSD-1 in the XXX neuroendocrine cells (Patel et al., 2008), and DAF-9/CYP27A1 in XXX neuroendocrine cells, hypodermis, and spermatheca (Gerisch et al., 2001; Jia et al., 2002). Distributed synthesis implies that there must be mechanisms involved to transport precursors from one tissue to the other. Why hormone biosynthesis is organized in this non-autonomous fashion is unknown, but speculatively it may generate tissue-specific ligands, or help coordinate the dauer decision across the organism.

Indeed, the choice between dauer and reproductive development converts noisy and variable environmental information into an all-or-none binary organismal decision. Although how this is achieved is not completely understood, it seems to rely largely on tight regulation of DA production, which involves both feed forward and feedback mechanisms that ensure this decision is robust (Gerisch and Antebi, 2004; Mak and Ruvkun, 2004; Schaedel et al., 2012). daf-9/CYP27A1 regulation is critical in this regard where its function in the neuroendocrine XXX cells and within the hypodermal syncitium apparently serves as a relay to coordinate the organismal response (Gerisch et al., 2001; Jia et al., 2002). It is hypothesized that the dauer pathways comprise a three state regulatory system to mediate this choice (Figure 5) (Gerisch and Antebi, 2004; Schaedel et al., 2012). Under favorable conditions, insulin and TGF- $\beta$ signaling converge upon hormone production within the XXX neuroendocrine cell, which results in a DA signal that can be amplified in the hypodermis through upregulation of daf-9, thus locking in reproductive commitments. Moderate thermal stress, pheromone level, or modest downregulation of TGF- $\beta$, IIS, or steroidal signaling, also visibly upregulate hypodermal daf-9, presumably increasing DA to sustain reproductive development. Factors required for this upregulation include daf-12, as well as $t t x-1$, tax-2, pkc-1, and $h s f-1$ genes functioning in thermotaxis neurons, revealing a complex regulatory network linked to temperature cues (Lee and Kenyon, 2009; Monje et al., 2011; Barna et al., 2012). In unfavorable dauer inducing conditions, DA production falls below a threshold, hypodermal amplification is suppressed, and animals undergo dauer development. Shift experiments performed with DA (which promotes non-dauer development) and ascarosides (which oppositely promote dauer development) suggest that the dauer decision transpires within a critical time window of 12-18 hours post-hatch within the L1/early L2 stage and that sustained and elevated DA exposure is critical for rapid and complete reproductive development (Golden and Riddle, 1984a; Schaedel et al., 2012). Surprisingly, ascaroside treatment raised the threshold required for DA to implement reproductive program, implying a role of pheromone signaling pathways proximal or downstream of steroidal signaling. Critical tests of these models await accurate measurement of DA levels in various genotypes and tissues. 
FAVORABLE

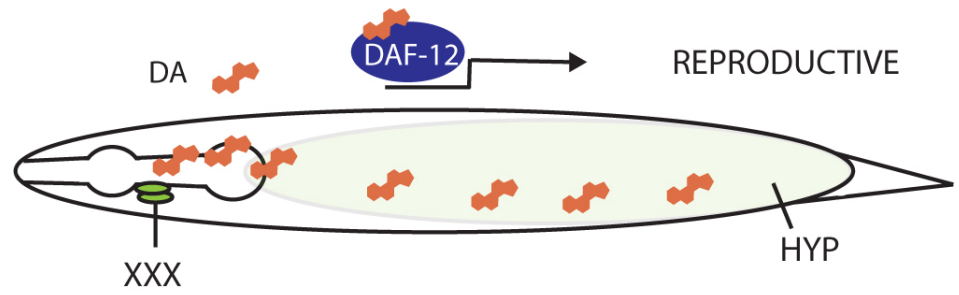

MILD STRESS

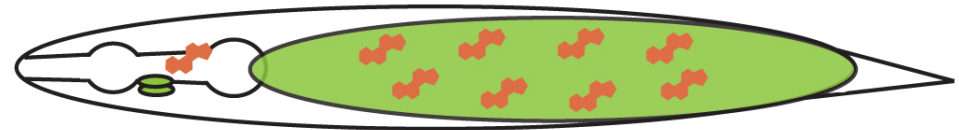

UNFAVORABLE DAUER DIAPAUSE

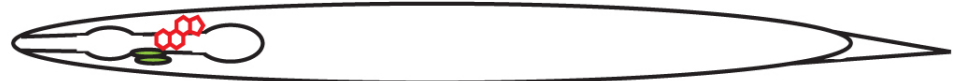

Figure 5. Feedback circuits for DA production. Under favorable conditions, ample DA made in the XXX cells and hypodermis causes dauer bypass and promotes reproductive development. Under mild stress conditions, diminished DA production in the XXX cells activates a positive feedback loop on daf-9/CYP27A1 in the hypodermis to increase DA levels sufficient to bypass dauer and promote reproductive development. Under unfavorable conditions, DA production is shut off and DAF-12 assembles a repression complex with DIN-1/SHARP, which leads to dauer formation.

\subsection{DAF-12 regulates L2/L3 transitions in developmental timing circuits}

An important aspect of larval development is the correct specification of temporal fates. As C. elegans develops through the four larval stages, tissues undergo stage-specific patterns of cell division, migration, fusion, and morphogenesis. Epidermal stem cells called seams undergo asymmetric divisions at each stage, with stage-specific variations in division (Sulston and Horvitz, 1977). At the larval-to-adult transition they cease dividing, fuse, and synthesize adult alae. Vulval cells undergo stereotyped induction and division in the L3 stage, and morphogenesis during the L4 stage. The gonad undergoes cell division, outgrowth, and differentiation from L2-L4 to form two U-shaped arms harboring the maturing germ cells, spermatheca, and uterus (Kimble and Hirsh, 1979). Intestinal nuclei undergo endoreplication at each stage, with a stage-specific nuclear division in L2 (Hedgecock and White, 1985). Motorneurons also undergo changes in synaptic connectivity (Zhou and Walthall, 1998).

The so-called heterochronic genes control developmental timing, and work as temporal selectors that specify these stage appropriate patterns. Their mutation results in precocious or retarded development within specific tissues (Ambros and Horvitz, 1984). Most of the identified heterochronic regulators are evolutionarily conserved, including the first discovered microRNAs lin-4 and let-7 (Lee et al., 1993; Wightman et al., 1993; Reinhart et al., 2000) and components that regulate their maturation such as LIN-28 (Moss et al., 1997; Viswanathan et al., 2008). Remarkably the human LIN28 has been linked to the timing of puberty (Ong et al., 2009). Several NRs also play various roles in the heterochronic circuit, including DAF-12/FXR, UNC-55/COUP, and NHR-25/SF1 (Antebi et al., 1998; Hada et al., 2010; Thompson-Peer et al., 2012). 
DAF-12 functions as a switch within the heterochronic circuits, promoting L2/L3 transitions. Mutants manifest retarded phenotypes in which they repeat L2 programs inappropriately at the L3 stage in seam, gonad, and intestine (Antebi et al., 1998). Such phenotypes were originally observed with high penetrance in specific LBD truncation mutants, and at low penetrance in null mutants (Antebi et al., 2000). The LBD truncation mutants, though recessive in nature, are thought to interfere with redundant or overlapping functions. Indeed, double mutant combination with other heterochronic loci affecting the L2/L3 transition strongly enhance the phenotypes of daf-12 null mutants, revealing multiple layers of regulation within the pathway (Abbott et al., 2005; Ding et al., 2005; Fielenbach et al., 2007; Hochbaum et al., 2011). Genetic epistasis experiments place DAF-12 downstream of the novel nuclear factor, LIN-14, but upstream or in parallel to LIN-28 (Antebi et al., 1998).

\subsection{DAF-12 works in a steroid-regulated microRNA switch}

An important clue to DAF-12's function within the heterochronic circuits came with the observation that a triple knockout of the let-7-related microRNAs, mir-48, mir-84, and mir-241 (collectively known as let-7s), results in phenotypes similar to daf-12 mutation, that is, a reiteration of L2 seam cell division programs at the L3 stage (Abbott et al., 2005). Moreover, daf-12 mutation reduced expression levels of the let-7 family microRNAs as measured by Northern blots or qPCR, revealing that it works upstream (Esquela-Kerscher et al., 2005; Bethke et al., 2009; Hammell et al., 2009). This led to the hypothesis that DAF-12 directly transcriptionally regulates these microRNAs. Indeed, DAF-12 together with the DAs, potently transactivates the promoters of mir-84 and mir-241 in mammalian cell culture, and expression of these two microRNAs shows daf-12 and DA dependence in specific tissues in the worm (Bethke et al., 2009). Interestingly, ecdysone and estrogen receptors also regulate let-7 microRNAs in flies and mammals, respectively, revealing a possible ancestral role for steroidal control of microRNA expression by nuclear receptors (Figure 3). For example 20-hydroxy ecdysone stimulates expression of the Drosophila let-7C complex, which regulates genes required for remodeling of neuromuscular architecture during the larval-to-adult transition (Bhat-Nakshatri et al., 2009; Chawla and Sokol, 2012) and promotes temporal transitions in mushroom body neuroblast progenitors (Kucherenko et al., 2012). In mammalian MCF7 cells, estradiol treatment upregulated 8 members of the let-7 family, and the related mir-98 (Bhat-Nakshatri et al., 2009; Chawla and Sokol, 2012).

In $C$. elegans, the data suggest a model in which liganded DAF-12 upregulates let- $7 s$, which in turn downregulate their target, the L2 regulatory factor HBL-1/hunchback Zn finger protein, allowing L3 reproductive programs to be expressed (Figure 6) (Bethke et al., 2009; Hammell et al., 2009). Conversely in the absence of hormone, the unliganded receptor potently represses microRNA expression during dauer formation. Thus DAF-12 works as a steroid-gated microRNA switch that functions to turn off earlier developmental programs to allow for later ones during reproductive growth, or to shut down the heterochronic timer altogether in the dauer stage. Interestingly, these same let-7-related microRNAs also feedback inhibit daf-12 through its 3'UTR, and curtail its activity for dauer formation and gonadal outgrowth (Bethke et al., 2009; Hammell et al., 2009). Similarly let-7 itself feedback inhibits DAF-12 late in larval development to facilitate the larval-to-adult transition (Figure 6) (Grosshans et al., 2005). Such feedback control may serve to temporally dampen DAF-12 activity, or help buffer developmental decisions in response to variable environmental and physiologic inputs.

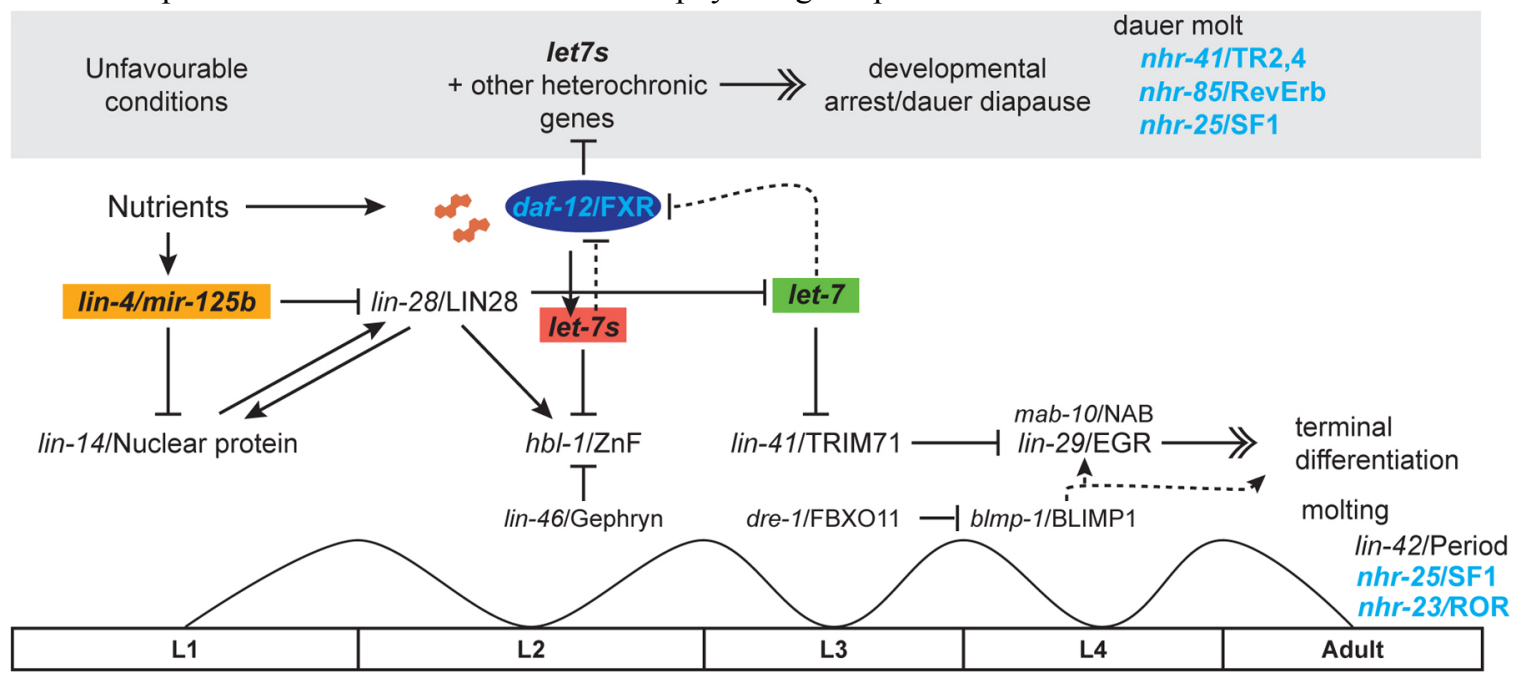


Figure 6. Developmental timing and life history regulation. In developmental timing circuits, shown here for the epidermis, transitions from one stage program to the next are catalyzed by distinct microRNAs. In nutrient rich environments, elevated expression of microRNA lin-4 downregulates LIN-14 nuclear protein and LIN-28/let-7 binding protein, leading to L1/L2 transitions. Liganded DAF-12 and presumably other transcription factors promote expression of let-7s (mir-84, mir-48, mir-241), which then downregulate HBL-1/hunchback Zn finger protein resulting in L2/L3 transitions. LIN-46/gephyrin and other factors also impinge on this transition. At the larval to adult transition, let-7 itself downregulates LIN-41/TRIM71 permitting expression of the terminal differentiation factor LIN-29/EGR1 and associated factor MAB10/NAB1. Other factors also working at the larval to adult switch, include DRE-1/FBXO11, which degrades BLMP-1 Zn finger by ubiquitin mediated proteolysis; alleviation of this inhibition promotes maturational events in the epidermis. It is unknown if BLMP-1 itself impinges on LIN-29 or works in parallel to regulate terminal seam cell fates. Additionally, let-7s and let-7 downregulate DAF-12 through negative feedback, resulting in normal progression. Molting regulators LIN-42, NHR-25, and NHR-23 drive the molt cycle and variously influence developmental timing events.

In unfavorable environments, animals arrest at the L1 diapause, where lin-4 remains low, and LIN-14 high, or arrest later at the L3 dauer diapause where unliganded DAF-12 represses microRNA expression and suppresses somatic growth. Several other nuclear receptors, including NHR-41, NHR-85, and NHR-25 are also implicated in the dauer molt.

In fact, mir-84 and mir-241 represent only a small fraction of DAF-12 target genes relevant to developmental progression. An analysis of DAF-12 binding sites and transcriptional activity reveals that it may regulate other heterochronic genes (lin-41, lin-42, lin-28, lit-1), other microRNAs, and genes involved in microRNA activity (ain-1, nhl-2), putative coregulators (din-1, cbp-1), as well as dauer transcription factors (daf-3, daf-16) (Shostak et al., 2004; Fisher and Lithgow, 2006; Hammell et al., 2009; Hochbaum et al., 2011), demonstrating that DAF-12 regulates key components in these circuits.

By lying at the confluence of dauer and heterochronic pathways, DAF-12 coordinates L2/L3 transitions, including the L3 dauer diapause, in response to environmental and physiologic inputs. In this capacity, it works intimately with LIN-42/Period, another heterochronic regulator that also affects dauer formation, developmental timing in epidermis, gonad, and other tissues, as well as molting (Jeon et al., 1999; Tennessen et al., 2006; Tennessen et al., 2010; Monsalve et al., 2011). LIN-42 is a homolog of Period, the circadian regulator, and is expressed in an oscillating pattern in concert with the molt cycle (Jeon et al., 1999; Monsalve et al., 2011), suggesting a clocklike function similar to its mammalian counterpart (Figure 6 and Figure 7). Notably, LIN-42 and DAF-12 appear to mutually antagonize one another's activity. For example, daf-12 retarded heterochronic phenotypes are suppressed by lin-42 mutation, and lin-42's precocious phenotypes are often suppressed by daf-12 mutation (Tennessen et al., 2006). lin-42(+) opposes dauer formation under mild stress and works at the same step as DAF-12 during the dauer decision. lin-42 mutants are Daf-c at elevated temperatures, and lin-42(+) overexpression prevents dauer formation even in daf-12 LBD Daf-c mutants, suggesting a close association with DAF-12 (Tennessen et al., 2010). These interactions could be direct, as the two proteins physically interact in yeast two-hybrid experiments, or indirect, reflect opposing regulatory activities on target processes. It is noteworthy that several mammalian NRs bind to and are inhibited by PER2, suggesting a conserved interaction between NRs and components of the circadian clock (Grimaldi et al., 2010; Schmutz et al., 2010). 

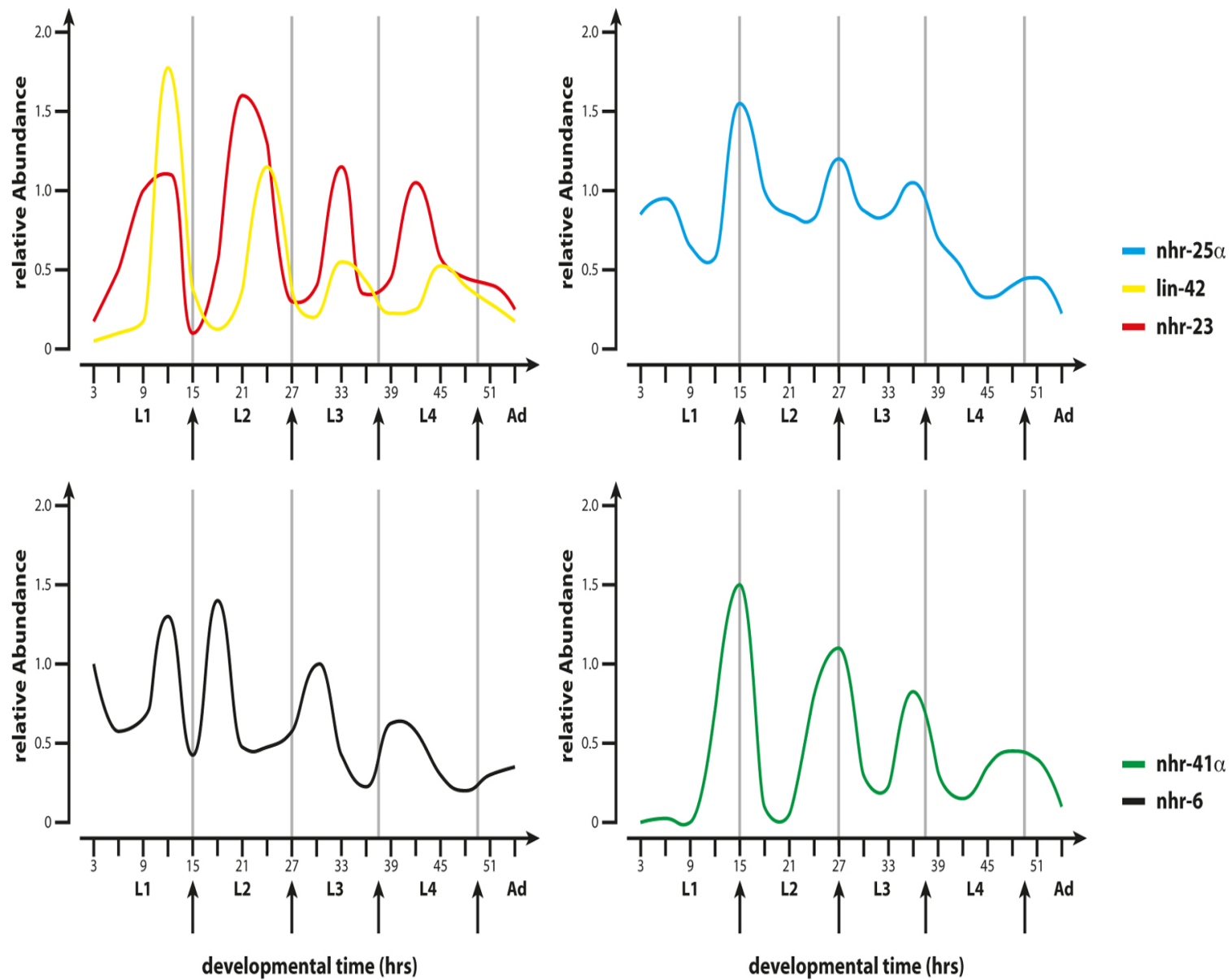

Figure 7. Molting NHRs. Schematic diagrams show the mRNA profiles of receptors and co-factors involved in molting during larval development. NHR-25 and LIN-42 mRNAs peak around the molt, while NHR-23 peaks with the intermolt. NHR-6 and NHR-41 also cycle with molt: NHR-41 affects the dauer molt, NHR-6 has no molting defect. Adapted from Jeon et al. 1999 ; Gissendammer et al. 2000 ; Monsalve et al. 2011 .

Many of the observed daf-12 heterochronic phenotypes are modulated by environmental conditions or dauer signaling (Bethke et al., 2009; Hochbaum et al., 2011; Huang and Zhang, 2011), revealing plastic and modulatory inputs into developmental timing pathways. Other processes influenced by daf-12 include the specification of chemoreceptors in sensory neurons (Nolan et al., 2002), male mate search behavior (Kleemann et al., 2008), foregut remodeling (Ao et al., 2004), and muscle arm extension (Dixon et al., 2008). These functions may be related to its roles in dauer or developmental timing. In particular extra muscle arms are induced by downregulation of DA, IIS, and TGF- $\beta$ signaling (Dixon et al., 2008). Interestingly this phenotype depends specifically on a DAF-12 isoform consisting of LBD only, revealing a novel previously unknown role for this protein. Altogether these processes imply substantial plasticity in remodeling of neural and neuromuscular architecture in response to environmental and hormonal cues.

\subsection{DAF-12 regulates life span in response to signals from the reproductive system}

C. elegans has served as a premier model for the study of aging, and at least four major pathways have been shown to extend life span across taxa including reduced insulin/IGF, mitochondrial function, dietary restriction, and signaling from the reproductive system (Kenyon, 2010). Notably, removal of germline stem cells by laser microsurgery or genetic ablation results in an extension of $C$. elegans adult life span by $60 \%$ (Hsin and Kenyon, 1999; Arantes-Oliveira et al., 2002). Further removal of the somatic gonad abolishes this life span extension, suggesting that the germline makes life-shortening signals that antagonize life-lengthening signals from the somatic gonad. Regulation of life span by the reproductive system is also seen in fruit flies (Flatt et al., 2008) and perhaps even in humans (Min et al., 2012). 
Regulation of longevity by the reproductive system requires the activity of at least five transcription factors, including DAF-12/FXR, DAF-16/FOXO, PHA-4/FOXA, NHR-80, and HLH-30/TFEB, which regulate lipid metabolism, fatty acid desaturation, lipolysis, autophagy, and proteasome activity to influence longevity (Figure 8) (Hsin and Kenyon, 1999; Wang et al., 2008; Goudeau et al., 2011; Lapierre et al., 2011; Vilchez et al., 2012; Lapierre et al., 2013; O'Rourke and Ruvkun, 2013). Communication between tissues suggests a hormonal mechanism is at work, and indeed, long life requires the activity of DA and DAF-12 signaling (Hsin and Kenyon, 1999; Gerisch et al., 2001; Rottiers et al., 2006; Gerisch et al., 2007; Wollam et al., 2012). In fact, life extending signals from the somatic gonad may be the DAs themselves since gonadless animals, which have normal life span, exhibit robust life span extension upon DAF-9 overexpression or DA supplementation (Yamawaki et al., 2010). Moreover, this extension is daf-12 dependent. Another key regulator in this pathway is the DAF-16/FOXO transcription factor, which mediates IIS (Hsin and Kenyon, 1999). Evidence indicates that DA/DAF-12 facilitates DAF-16/FOXO nuclear localization and activity (Berman and Kenyon, 2006 ; Gerisch et al., 2007), and that the two transcription factors cooperate to regulate longevity assurance genes in germlineless animals. DAF-12 may contribute to longevity by regulating expression of a fatty acid reductase, fard-1, as well as the lipase lips-17, which are required for longevity (McCormick et al., 2012). Surprisingly genetic manipulation of these molecules as well as the lipase lipl-4 (which is transactivated by DAF-16/FOXO) have little effect on bulk fat levels, and therefore may instead produce fatty acid signaling molecules that could work through additional nuclear receptors such as NHR-80 (see Section 4.8).

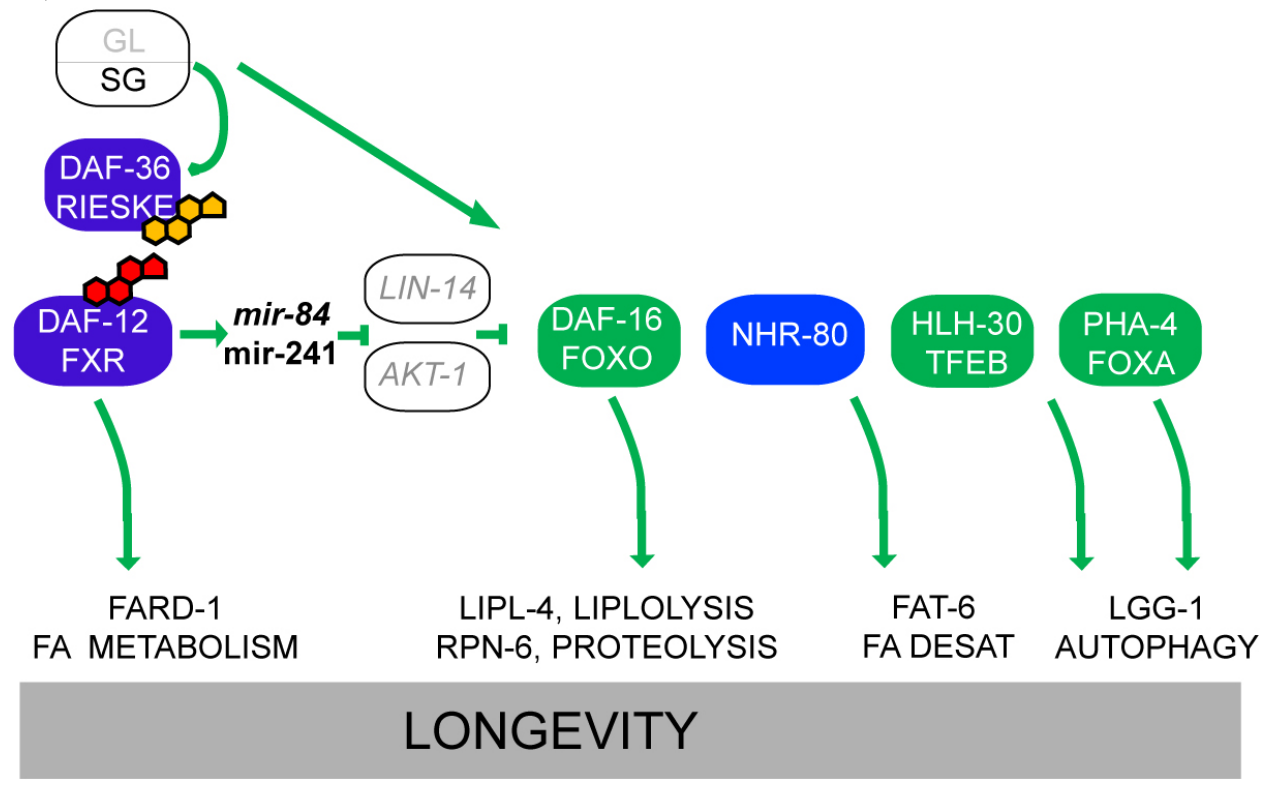

Figure 8. Gonadal longevity pathway. When germline stem cells are absent or quiescent, DA production is stimulated resulting in activation of DA/DAF-12 signaling. Upreguation of the let-7s microRNAs downregulates LIN-14 and AKT-1, leading to activation of DAF-16/FOXO. Together the transcription factors DAF-16/FOXO and DAF-12, as well as NHR-80, PHA-4, and HLH-30/TFEB turn on genes related to the processes of FA metabolism, desaturation, and lipolysis as well as autophagy and proteolysis to promote long life.

How might DAF-12 and DAF-16 cooperate to regulate longevity? Recent evidence suggests that DAF-12 regulation of let-7-related microRNAs mediates crosstalk between the two transcription factors (Shen et al., 2012). Studies by Shen and colleagues showed that germline removal results in upregulation of DA production, triggering DAF-12 dependent activation of mir-84 and mir-241, previously implicated in developmental timing circuits (Section 2.6) (Bethke et al., 2009). Importantly, these microRNAs, too, are required for the longevity of germlineless animals, as their deletion abolishes life span extension. Further molecular analysis reveals that mir-84 and mir-241 downregulate two inhibitors of DAF-16/FOXO, namely the AKT-1 kinase (Paradis and Ruvkun, 1998) and the LIN-14 heterochronic nuclear factor (Boehm and Slack, 2005), and thereby promote DAF-16/FOXO nuclear localization and activity (Figure 8) (Shen et al., 2012). Remarkably then, components of the developmental timing switch used during L2/L3 temporal transitions are co-opted to trigger a long lived adult mode. This discovery and others support the idea that components of developmental clocks are used to regulate animal life span (Gerisch et al., 2001; Boehm and Slack, 2005; Shen et al., 2012). Conceivably developmental timing components synchronize signaling between gonad and soma to ensure coordinate maturation under environmental or physiologic stress. 


\subsection{DAF-12 and longevity continued}

In ectotherms, longevity varies inversely with temperature, with animals living shorter at higher temperatures. Thermal effects on life span and other processes are ascribed to passive changes in metabolic rate, but recent evidence also suggests a regulated process that links thermotaxis and steroidal signaling (Lee and Kenyon, 2009). Thermotaxis genes $t t x-1$ and $t t x-3$ encode transcription factors that specify the fates of the temperature sensing neurons (Hobert et al., 1997; Lanjuin et al., 2003). Unexpectedly, loss of AFD thermosensory neurons through mutation or laser ablation, results in short life span at elevated temperatures $\left(25^{\circ} \mathrm{C}\right)$, which is restored by daf-12 loss of function (Lee and Kenyon, 2009). Similar observations are seen with daf-9 hypomorphs that reduce but do not abolish DA production; such mutants are short lived at $25^{\circ} \mathrm{C}$, and daf-12 mutation suppresses this phenotype, suggesting that the unliganded receptor is life shortening in this context. Overexpression of daf- 9 also restores normal life span to $t$ tx- 1 mutant animals. Altogether these observations suggest that a boost of DA production and DAF-12 activity at elevated temperatures is essential to maintain normal life. Conceivably this physiologic function is related to the activity of heat shock factor, $h s f-1$, which, similar to $t t x-1$ (Lee and Kenyon, 2009), regulates $d a f-9$ levels in response to temperature in feedback circuits described above (Barna et al., 2012), suggesting that thermal responses are coordinated hormonally.

daf-12 mutants also show complex interactions with IIS for life span regulation. So-called daf-2 class 1 mutants robustly extend life span in a manner that is partially abrogated upon daf-12 loss, while daf-2 class 2 mutants, which are more pleiotropic, show synergistic life span extension upon daf-12 depletion (Gems et al., 1998), an interaction that is hermaphrodite specific (McCulloch and Gems, 2007). Several other loci, such as let-60/Ras and hormone biosynthetic genes evoke a similar complex interaction, but the underlying molecular mechanism remains obscure (Nanji et al., 2005; Dumas et al., 2013). daf-12 also functions in hormesis-induced longevity. When animals are subjected to moderate brief pulses of heat stress, they acquire subsequent thermotolerance and longevity, which depends on the activity of daf-12, daf-16, daf-18, and other factors (Cypser et al., 2006). Lastly, DAF-12 has been shown to contribute to precocious aging and somatic collapse of hermaphrodites that have been mated by males (Shi and Murphy, 2013). Mated hermaphrodites shrink and die early due to signals from sperm and seminal fluid: the shrinkage phenotype is mediated by DA/DAF-12 pathways, while the short-lived phenotype largely arises from induction of INS-7 and inhibition of DAF-16/FOXO.

\subsection{DA/DAF-12 signaling in parasitic and other nematodes}

Remarkably, DA/DAF-12 signaling has been conserved in nematodes that are diverged from C. elegans by over 150 million years, and functions similarly as an important regulator of life history traits and phenotypic plasticity. The free-living nematode Pristionchus pacificus has co-opted the DA/DAF-12 module, not only to regulate dauer formation, but also to select alternative mouth dimorphisms involved in predatory feeding (Ogawa et al., 2009; Bento et al., 2010). As with C. elegans, germline elimination extends P. pacificus life span, and in addition enhances innate immunity in a manner dependent upon daf-12 and daf-16 (Rae et al., 2012). The DA/DAF-12 module has also been deployed to regulate the infective stage of parasitic nematodes, which is comparable to dauer. Treatment of the parasites Strongyloides stercoralis, Acylostoma spp, and Strongyloides papillosus with $\Delta^{7}$-DA variously prevents formation of the L3 infective stage or promotes exit from the infective stage, much like DA prevents dauer formation or promotes dauer exit (Ogawa et al., 2009; Wang et al., 2009). Several nematode DAF-12s are transactivated by DA and cholestenoic acid in cell culture. Such activity is confirmed in the crystal structure of $\Delta^{7}$-DA bound to the LBD of DAF-12 from S. stercoralis, which reveals that the receptor forms a canonical three layered sandwich comprised of 13 alpha helical regions and three beta strands typical of NRs (Wang et al., 2009). The orientation of ligand and contact residues within the LBD pocket most resembles the way in which bile acids bind to FXR, implying that DAF-12 and FXR are biochemical orthologs (Zhi et al., 2012). Significantly, many of the parasitic nematodes lack endogenous DAs as well as a daf-9/CYP27A1, suggesting they rely on host-produced bile acid-like steroids to stimulate exit from the infective stage.

Altogether these studies indicate the vast potential for exploiting the DA/DAF-12 axis to combat parasitic disease. For example, DA-like molecules could be used to trigger precocious exit from the infective stage in the wrong environment, or DA-inhibitors could be used to prevent exit in compatible hosts.

\subsection{NHR-8/LXR regulates cholesterol, bile acid, and fatty acid metabolism}

NHR-8 is the closest relative to DAF-12 in C. elegans, and homologous to vertebrate LXR, FXR, PXR, and VITD receptors. Expressed primarily in the gut, NHR-8 controls production of the bile-acid like DAs and thereby DAF-12 activity through regulation of DAF-36/Rieske oxygenase and cholesterol disposition (Magner et al., 2013). 
Mutants display lower levels of daf-36 mRNA and protein, and make less of the DAF-36 metabolic product, 7-dehydrocholesterol, as well as DA itself. Consistent with a role in DA metabolism, mutants enter the dauer diapause constitutively on low cholesterol or at elevated temperature $\left(27^{\circ} \mathrm{C}\right)$, and have reduced expression of the DAF-12 target gene mir-241. By controlling the first step in DA production, NHR-8 may thereby regulate cholesterol, bile acid flux, and DAF-12 activity. These functions are analogous to its vertebrate relative, LXR, which regulates the first step of bile acid synthesis and affects activity of FXR (Calkin and Tontonoz, 2012), the homolog of DAF-12 (Figure 4). Steady state levels of cholesterol are lower in $n h r-8$ mutant embryos as measured by uptake of NBD-cholesterol, suggesting a deficiency in transport or metabolism in the germline. Indeed, several phenotypes manifest under low cholesterol (e.g., shortened life span, FA desaturation defects) or no cholesterol conditions (larval arrest). Transcriptome analysis of $n h r-8$ mutants under low cholesterol conditions reveals altered expression of genes involved in fatty acid desaturation, lipolysis, transport and vitellogenesis, as well as those functioning in host defense and life span regulation (Magner et al., 2013). $n h r-8$ mutants have reduced mRNA expression of the fatty acid desaturases, fat-5 and fat-7, and correspondingly higher levels of saturated and lower levels of mono- and polyunsaturated FA. Regulation of FA desaturation and apolipoprotein production are also features of the vertebrate LXR (Calkin and Tontonoz, 2012). Interestingly, the Drosophila DHR96, a close relative of NHR-8 and DAF-12, also regulates fatty acid and cholesterol metabolism (Horner et al., 2009; Sieber and Thummel, 2012). Mutants are sensitive to cholesterol deprivation, and have dysregulated cholesterol balance. DHR96 has been shown to bind to cholesterol, although it is not known if this serves as an activating ligand, inverse agonist, or competency factor (Horner et al., 2009). Although the NHR-8 ligand is unknown, it is surmised to be a sterol derivative based on its sterol dependent phenotypes.

\subsection{UNC-55/COUP, a switch in neuronal developmental timing circuits}

The NR COUP is highly conserved in evolution and functions in neural and cardiovascular development, pituitary and reproductive function, and metabolism (Lin et al., 2011). The C. elegans homolog unc-55 regulates synaptic remodeling of GABAergic motoneurons during the L1 stage, through conserved developmental timing pathways (Zhou and Walthall, 1998; Thompson-Peer et al., 2012). Specifically, embryonically born DD motoneurons switch their synaptic outputs from ventral onto dorsal muscles during the L1 stage, while larval-born VD neurons do not. Normally, unc-55(+) prevents VD neurons from undergoing synaptic remodeling; in null mutants larval VD neurons remodel inappropriately, similar to the embryonic DDs. Consistent with a cell autonomous role, unc-55 is expressed in the VDs during larval development. Additionally, it resides in AS and other motor neurons (Zhou and Walthall, 1998), suggesting that other roles remain to be discovered.

How might unc-55 regulate synaptic switching? Apparently DD switching is driven by the heterochronic regulator $h b l-1 /$ hunchback, which is repressed by unc-55 in the VDs (Thompson-Peer et al., 2012). In C. elegans $h b l-1$ loss-of-function mutants, DD remodeling is delayed, whereas in microRNA mir-84 mutants, which conversely cause $h b l-1$ overexpression, DD remodeling is precocious. Given the regulatory relationships of daf-12, mir-84, and $h b l-1$ in seam cells described above, it seems plausible that steroid signaling too might function in synaptic remodeling. Transcriptional profiling of unc-55 reveals differential expression in a large number of genes compared to wild type, including the Iroquois homeodomain protein IRX-1, which also regulates DD remodeling (Petersen et al., 2011). The UNC-55/HBL-1 regulatory interaction strikingly resembles those seen in Drosophila where seven-up/COUP temporally regulates $h b /$ hunchback during neurogenesis (Kanai et al., 2005; Benito-Sipos et al., 2011).

\subsection{NHR-25/SF-1 and the molting clock}

We now turn our attention to NHR-25, NHR-23, and other receptors that function in another type of timing device, the molting clock. NHR-25 is a highly conserved NR that plays critical roles in development and metabolism. Its closest relative in Drosophila, Ftz-F1, is involved in early embryonic patterning, larval molting, and metamorphosis (Ou and King-Jones, 2013). The mammalian homolog, SF-1, is implicated in steroidogenesis, hypothalamic, adrenal and gonadal development, and sex determination (Ferraz-de-Souza et al., 2011). Another homolog, LRH, functions in cholesterol, bile acid, glucose, and fatty acid metabolism. It also modulates pluripotentency of embryonic stem cells, and has a role in inflammation and stem cell renewal in the gut (Fernandez-Marcos et al., 2011)

Like its fly counterpart, C. elegans NHR-25/SF-1 coordinates epidermal morphogenesis, differentiation, and molting. $n h r-25$ is expressed early in embryogenesis first within the E lineage, which gives rise to the gut, and thereafter in hypodermal cells, pharyngeal and rectal epithelial cells, somatic gonad, and germline. During embryogenesis, mutation of $n h r-25$ or knockdown by RNAi results in lethality at the two-fold stage at the initiation 
of elongation (Asahina et al., 2000; Gissendanner and Sluder, 2000). Although epidermal cells are specified and divide normally, they fail to fuse properly during epidermal morphogenesis resulting in ventral closure defects. During larval development, the epidermal seam cells fail to reestablish contacts at the lateral midline and lose their spindle shape, possibly leading to ectopic cell division in the adult and poor alae formation (Chen et al., 2004; Silhankova et al., 2005). Knockdown of $n h r-25$ within the seam cells is sufficient to recapitulate these defects, suggesting a cell autonomous role (Hajduskova et al., 2009; Hada et al., 2010). Mutants also have additional defects in vulva division, fusion, and morphogenesis (Chen et al., 2004). In this context, correct vulval specification depends on dampening of NHR-25 transcriptional activity by sumoylation (Ward et al., 2013).

NHR-25 functions most prominently within the C. elegans molt cycle (Figure 6 and Figure 7). Each of the four successive larval stages (L1-L4) is punctuated by molts. The molt cycle begins with synthesis of the new cuticle, an intermolt period characterized by feeding, activity, and growth, followed by a brief hiatus of sleep-like inactivity, termed lethargus, during which the new cuticle is deposited and the old one shed, and then emergence into the new intermolt. This process takes approximately 8-10 hours for each stage (Monsalve and Frand, 2012). During the larval molts, $n h r-25$ mutants are unable to shed the old cuticle and often bear residual cuticle stuck to mouth, vulva, and rectal areas (Asahina et al., 2000; Gissendanner and Sluder, 2000). nhr-25 mRNA and protein levels oscillate, with peak mRNA levels at the molt (Figure 7) (Gissendanner et al., 2004; M. Horn and A. Antebi, unpublished). Several key genes implicated in ecdysis and epidermal differentiation are regulated by $n h r-25$, including the angiotensin converting enzyme homolog acn-1, the nematode-specific gene mlt-10, the collagenase nas-37, and the amyloid precursor protein homolog apl-1 (Brooks et al., 2003; Davis et al., 2004; Frand et al., 2005; Hornsten et al., 2007; Hada et al., 2010; Meli et al., 2010; Wiese et al., 2010).

Recently, it has been suggested that $n h r-25$ also acts in the heterochronic circuit. $n h r-25$ mutants display defects reminiscent of retarded heterochrony, including shallow adult alae formation and delayed male tail retraction (Hada et al., 2010; Nelson et al., 2011). Moreover, nhr-25 depletion suppresses the precocious heterochronic phenotypes of $h b l-1$, lin-41, and lin-42 mutants, although its interactions with other heterochronic mutants suggest a more complex network (Hada et al., 2010). $n h r-25$ RNAi also suppresses the supernumerary molt phenotype of let-7 mir-84 double mutants, suggesting that let- $7 \mathrm{~s}$ downregulate $n h r-25$ at the L4/adult transition, leading to a cessation of molting (Hayes et al., 2006; Hada et al., 2010). In accord with this idea, the $n h r-253$ 'UTR contains predicted let-7 binding sites, but it remains to be seen whether regulation is direct. The observation that $n h r-25$ works at the convergence of the molt cycle and the developmental timer strongly suggests intimate interactions with lin-42/period, a gene that also affects both processes (see Section 2.14) (Jeon et al., 1999; Monsalve et al., 2011).

\subsection{NHR-23/ROR regulates the molt cycle}

Molting is also controlled by another key nuclear hormone receptor, NHR-23, a homolog of Drosophila DHR3 and the mammalian ROR (Figure 7), which are all components of biological clocks. During the Drosophila larval molt cycle and prepupal to pupal transition, the ecdysone receptor stimulates Ftz-F1 $\beta$, which in turn regulate DHR3 within ecdysone signaling cascades (Ou and King-Jones, 2013). The mammalian ROR $\alpha$ is a central component of the circadian clock, positively regulating BMAL and the NR REV-ERB (Ranhotra, 2012). In turn, REV-ERB feedback inhibits ROR, contributing to the periodicity of circadian rhythms. ROR also functions in cerebellum development, immunity, and lipid, cholesterol, and glucose metabolism. 
Similar to $n h r-25, n h r-23$ null mutants arrest at the comma or three-fold stage of embryogenesis (Kostrouchova et al., 1998; Kostrouchova et al., 2001). Hatched L1 larvae are dumpy, indicating morphologic or elongation defects. Also similar to $n h r-25, n h r-23$ RNAi knockdown in larvae results in defects in molting and alae formation (Kostrouchova et al., 2001). $n h r-23$ is expressed predominately in epidermal tissues, including seam cells, P-ectoblasts, and hypodermal cells. Expression of $n h r-23$ mRNA oscillates with the molt cycle, but with opposite phase to $n h r-25$, peaking during the intermolt (Figure 7) (Gissendanner et al., 2004), though whether protein expression also oscillates has yet to be determined. The reciprocal relationship between $n h r-23$ and $n h r-25$ expression suggests that they could regulate one another in a feedback loop, but this has not been directly tested. Surprisingly, the reciprocal regulatory relationship of ROR and REV-ERB seen in the mammalian circadian clock is not seen in the $C$. elegans counterparts, NHR-23 and NHR-85. Although $n h r-85$ expression varies with the molt cycle, $n h r-85$ depletion does not result in molting defects except at the dauer molt. $n h r-85$ also affects egg laying (Gissendanner et al., 2004). Another REV-ERB homolog, sex-1, specifies the hermaphrodite sexual fate. It serves as a dose dependent $\mathrm{X}$ chromosome signaling element that antagonizes autosomal signaling elements in the promoter of xol-1, a key sex determination gene (Carmi et al., 1998; Farboud et al., 2013).

Transcriptome profiling reveals that NHR-23 regulates expression of various genes implicated in molting including, cuticle collagens ( $d p y-2,-3,-5,-7,-8,-10)$, hedgehog-related genes (wrt-1,-2,-3, grd genes), patch-related genes (ptc-3), and molting genes (mlt-8,-9,-10,-11) (Kouns et al., 2011). Similar to nhr-25, nhr-23 also affects expression of a number of genes functionally implicated in molting, including acn-1 and mlt-10 (Frand et al., 2005; Kouns et al., 2011). Curiously, several genes involved in DA biosynthesis, including dhs-16 and daf-9, also appear to be $n h r-23$ regulated, perhaps relevant to a role in the dauer molt (Gissendanner et al., 2004; Kouns et al., 2011).

Other NRs may also be tied to the molt cycle. The HNF4-like family member, $n h r-60$, is regulated by NHR-23 within seam cells (Simeckova et al., 2007). RNAi knockdown of $n h r-60$ results in embryonic lethality, poor ventral closure, and seam cell defects similar to $n h r-23$ and $n h r-25$ mutants, suggesting $n h r-60$ could work in transcriptional cascades driving early morphogenetic events. The $D H R 78 / T R 2$ homolog, $n h r-41$, and possibly daf-12, are expressed in a cyclical pattern along with the molt cycle, as measured by mRNA (Figure 7) (Gissendanner et al., 2004; Merris et al., 2007). However, DAF-12::GFP does not overtly oscillate at the protein level, and mutation of these receptors does not explicitly affect molting per se, though both affect the dauer molt and fat accumulation (Gerisch et al., 2001; Gissendanner et al., 2004; Arda et al., 2010).

NHR-40 is another receptor required for late embryonic morphogenesis, elongation, and proper muscle formation and motility. Accordingly, it is expressed primarily in the pharyngeal, body wall, and sex muscles, but also in a handful of neurons (Brozova et al., 2006). Proteomic analysis of $n h r-40$ mutants reveals changes in the level of proteins enriched in muscle function and metabolism (Pohludka et al., 2008). Given its phenotypes and expression pattern, $n h r-40$ will likely strongly interact with genes involved in muscle biogenesis, morphogenesis, and attachment, such as the paralyzed at two-fold (Pat) mutants (Williamsa and Waterston, 1994).

\subsection{Molting and beyond}

Although the molt cycle is apparently an adaptation of the Ecdysoa clade of animals, the study of its circuitry could very well shed light on mammalian circadian rhythms and sleep. As mentioned earlier, components of the molt cycle include those implicated in circadian rhythms in mammals, NHR-23/ROR and LIN-42/Period, suggesting an ancient origin for these clocks (Figure 6 and Figure 7). The short C-terminal lin-42a isoform is specifically implicated in molting. It affects the length of lethargus and the molt cycle, the execution of the molt, the expression of molting genes, and seam cell morphology, functionally resembling $n h r-23 / 25$. Accordingly, lin- $42 a$ is expressed cyclically with peaks at the molt, while the longer lin-42bc isoforms, which specifically affect developmental timing, peak during the intermolt (Jeon et al., 1999; Tennessen et al., 2006; Monsalve et al., 2011). Thus regulatory cascades used in mammalian circadian timers may have been co-opted by the molt cycle, and components identified in either pathway may inform the other. Another interesting aspect of the molt cycle that resembles sleep of mammalian circadian rhythms is lethargus, a quiescent sleep-like state, during which the animal lays down the new cuticle and sheds the old (Raizen et al., 2008). A molecular genetic dissection of genes that affect lethargus in $C$. elegans so far include lin-42a/period, cGMP (egl-4/protein kinase G), EGF, Notch signaling, and others (Van Buskirk and Sternberg, 2007; Raizen et al., 2008; Monsalve et al., 2011; Schwarz et al., 2011). Study of such molecules may help illuminate related conserved pathways involved in metazoan sleep.

A major unresolved question is whether the $C$. elegans molt cycle is hormonally regulated. The broad synchronization of events across tissues suggests so, but no hormone has yet been found. Although homologs of DA 
hormone biosynthetic genes have been implicated in insect ecdysteroid metabolism (Yoshiyama et al., 2006; Guittard et al., 2011), the worm genes do not obviously affect molting. Moreover, C. elegans lacks ecdysteroids and the ecdysteroid receptor. Nor have high throughput RNAi screens for molting defects identified obvious steroidogenic enzymes (Frand et al., 2005). Nevertheless, C. elegans molting is contingent upon dietary cholesterol, and several genes inferred to be involved in cholesterol transport, including the megalin homolog lrp-1, hedgehog-related and patch-related receptors, and the APP homolog apl-1, affect molting (Yochem et al., 1999; Zugasti et al., 2005; Hornsten et al., 2007; Wiese et al., 2010). Intriguingly, various 7-oxysterols reportedly bind mammalian ROR as inverse agonists (Wang et al., 2010); conceivably similar molecules could regulate NHR-23. Alternately $C$. elegans molting may be regulated by other lipids, since mammalian SF-1 binds phospho- and sphingolipids (Krylova et al., 2005; Urs et al., 2007; Lee et al., 2011), and C. elegans NHR-25 reportedly binds to fatty acid-phosphoinositides (Mullaney et al., 2010). These could also serve as molting hormones that link fatty acid availability to developmental advance. Clearly identifying molting hormones will remain a major important challenge for the future.

\section{Nuclear receptors as regulators of cell fate and organogenesis}

During development, multipotent cells progress through a succession of states to build cell types, organs, tissues, and integrated systems. Cells choose between alternate fates of more restricted potential in response to intrinsic and extrinsic cues. These fate choices often entail integrating inputs from growth and signal transduction pathways that impart positional and temporal information. Signaling inputs also serve to detect, quantify, and relay information about the state of the system, and often work combinatorially to specify fate choice. Ultimately, these converge on a coterie of transcription factors whose transcriptional output determines cell type. As key transcriptional regulators responding to physiologic and environmental input, NRs also function as important modulators of cell fate and organogenesis. Below, we highlight the interactions of $n h r-25$, nhr-67, and nhr-6 with various signaling pathways during morphogenesis.

\subsection{NHR-25/SF-1 and wingless signaling}

The wingless signaling pathway $(W n t)$ is used at various points in development to specify asymmetric patterns of division and differentiation. In C. elegans, $n h r-25$ both antagonizes and enhances non-canonical Wnt signaling in the somatic gonad and epidermis, respectively (Asahina et al., 2006; Hajduskova et al., 2009). During C. elegans gonadogenesis, two primordial somatic gonadoblasts each give rise to distal and proximal blast cells that organize the bilobed arms of the gonad along the distal-proximal axis. Migratory distal tip cells coordinate outgrowth of the gonad, while proximal gonadal cells give rise to spermatheca and uterine tissues (Kimble and Hirsh, 1979). Wnt signaling components primarily help specify the gonadal distal fate. Reduction of function mutations in pop-1/TCF, the $\beta$-catenin homologs sys-1 and wrm-1, and the map kinase homolog lit-1 result in loss of the distal tip cells, resulting in a stunted gonad and sterility (Miskowski et al., 2001; Siegfried and Kimble, 2002; Siegfried et al., 2004). Conversely, $n h r-25$ loss results in a defect in the specification of proximal fate and inappropriate promotion of the distal fate, resulting in improperly formed spermatheca and uterine tissues, excess distal tip cells, and a tumorous germline (Asahina et al., 2006). Consistent with antagonistic behavior between $n h r-25$ and wnt signaling, double mutant combinations result in mutual suppression and more normal gonadal development.

This genetic interaction corresponds to physical and functional interactions of NHR-25 with the $\beta$-catenin homologs controlling transcriptional events. WRM-1 protein inhibits the transcriptional activity of NHR-25 in cell culture, while SYS-1 enhances it (Asahina et al., 2006). Moreover, NHR-25 inhibits the transcriptional activity of the POP-1/SYS-1 complex. This has led to a model in which NHR-25 in presumptive proximal cells inhibits the activity of the POP-1/SYS-1 complex to suppress distal fates, and works together with SYS-1 to promote proximal fates (Figure 9) (Asahina et al., 2006). Conversely, NHR-25 in presumptive distal cells is inhibited by WRM-1, where the POP-1/SYS-1 complex can then specify distal fates. The antagonistic interaction with Wnt signaling appears to be tissue specific, since $n h r-25$ works synergistically with $W n t$ signaling to specify asymmetric cell fates in the epidermal T cells (Hajduskova et al., 2009). This behavior fits with observations in mammals where SF-1 works in concert with Wnt signaling to regulate target gene expression (Salisbury et al., 2007). 


\section{Proximal Cell}

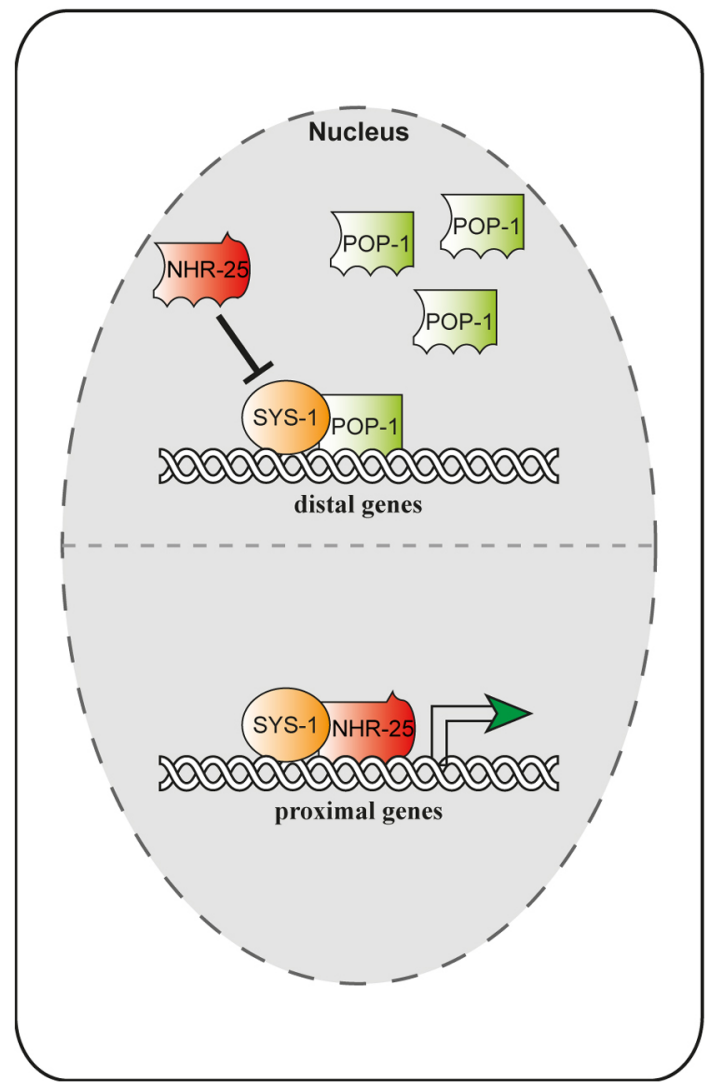

\section{Distal Cell}

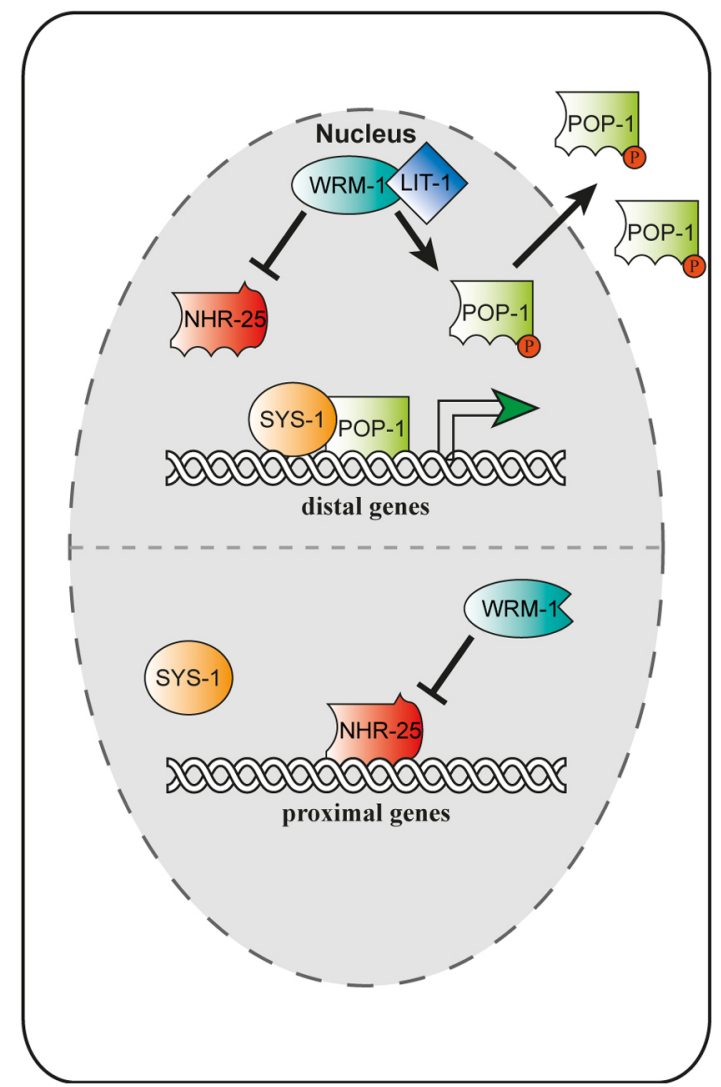

Figure 9. Organogenesis of the somatic gonad. Somatic gonad and specification of cell fates. In proximal cells, NHR-25 prevents distal fates by inhibiting SYS-1/POP-1 complexes, while NHR-25/SYS-1 complexes promote proximal fates. In distal cells, NHR-25 is inhibited by WRM-1/ $\beta$-catenin, thereby allowing distal fates, and preventing proximal fates.

Evidence suggests that NHR-25 also physically and functionally interacts with other transcription factors for epidermal phenotypes. These include the homeobox proteins, CEH-39, involved in regulating Pn.p fusion events, NOB-1, involved in specification of posterior regions of the animal (Chen et al., 2004), as well as the NR NHR-91/GCNF (Ward et al., 2013). These observations suggest that NHR-25 may serve as a competency factor for other transcription factors in a number of contexts.

\subsection{NHR-67/TLL controls cell fate through EGF, FGF, and Notch signaling}

NHR-67 is an ortholog of the highly conserved TLL/TLX tailess NR. During Drosophila embryogenesis tailless inhibits segmentation, and promotes terminal fates in the posterior of the embryo (Gui et al., 2011). Later in development it regulates neurogenesis and neural stem cell renewal. Similarly, mammalian TLX affects nervous system and visual development, embryonic and adult neural stem maintenance, and prevents glial differentiation. It is thought that TLX/TLL are orphan receptors working principally as transcriptional repressors (Gui et al., 2011). $C$. elegans $n h r-67$ is expressed in late stage embryos, in epidermal cells including hyp7 and vulval cells, the excretory cell, somatic gonadal cells including the hermaphrodite anchor cell, uterine cells, and the male linker cell, as well as the male tail, and a handful of head neurons. Null mutations result in L1 arrest and lethality along with cuticle malformations and bulges, suggesting a role in embryonic morphogenesis (Gissendanner et al., 2004; Verghese et al., 2011). Additionally, animals exhibit cystic canal defects, which may be another cause of lethality (Sarin et al., 2009). RNAi knockdown or partial loss of function in larvae results in egg laying and protruding vulva phenotypes at the gross level (Gissendanner et al., 2004; Verghese et al., 2011). Detailed examination of egg-laying (Egl) and protruding vulval (Pvul) defects reveals that they arise from altered fate specification in vulva and somatic gonad, suggesting a coordinate role in late stage aspects of reproductive maturation (Fernandes and Sternberg, 2007; Verghese et al., 2011). 
Specific $n h r-67$ regulatory interactions and phenotypes suggest a complex late larval role in vulval morphogenesis in which the receptor regulates key growth factor signaling pathways. Although vulval cell lineages are grossly normal in $n h r-67$ RNAi treated animals, specific fusion events in primary derived (P6.p) vulE and vulF cells are aberrant (Fernandes and Sternberg, 2007). In vulF cells, $n h r-67$ positively regulates the primary fate marker lin-3/EGF and simultaneously inhibits secondary fate markers, egl-17/FGF and egl-26/LRAT. In secondary vulval cell derivatives, $n h r-67$ positively regulates zmp-1/zinc matrix metalloproteinase in vulA and pax-2 and egl-17/FGF in vulD cells. Thus $n h r-67$ can activate or repress the same gene (e.g., egl-17/FGF) depending on cell type. $n h r-67$ is expressed in a dynamic pattern during vulval morphogenesis and exhibits complex genetic and regulatory interactions with a number of other transcription factors in these tissues, namely lin-11/LIM, cog-1/NKX6.1/6.2, and egl-38/PAX2. In particular, $n h r-67$ and cog-1 appear to have mutually antagonistic inhibitory interactions in this context (Fernandes and Sternberg, 2007). Further understanding of such interrelationships may give insight into the complex regulatory networks governing organ morphogenesis.

nhr-67 also functions in uterine morphogenesis, which is closely coordinated with vulval morphogenesis. Again $n h r-67$ is expressed in a highly dynamic pattern within various cells of somatic gonad and uterus (Verghese et al., 2011). An important insight into $n h r-67$ function came from the realization that it affects several binary fate decisions governed by lin-12/Notch and its ligand lag-2/delta, including the anchor cell (AC)/ventral uterine (VU) blast cell decision, and the fates of uterine pi and uterine seam junction cell fusions (Verghese et al., 2011). Consistent with a role in regulating Notch, expression of both LIN-12/Notch and its ligand are down in various uterine cell types in nhr-67 mutants. Consequently, mutant animals have two AC cells, that is, VU cells are transformed to AC, a phenotype similar to Notch loss of function (Seydoux and Greenwald, 1989). The AC fate is nevertheless weakly determined, since several AC markers such as $z m p-1$ are not expressed. Because the AC further induces fates amongst vulva precursor cells, it seems likely that some of the observed vulval defects are a secondary consequence of the AC/VU decision. Interestingly, mammalian tailless regulates neural stem cell cycling, which also is influenced by Notch (Gui et al., 2011). Conceivably this regulatory circuitry is conserved throughout evolution.

A related gonadal function of $n h r-67$ lies in the developmental timing of male gonadal morphogenesis (Kato and Sternberg, 2009). During larval development the male somatic gonadal linker cell (LC) leads a column of proliferating germ cells through stereotyped outgrowth. Shortly after its birth, the LC migrates anteriorly during the L2 stage, dorsally by the L2 molt, posteriorly and then ventrally during the L3, and back to the tail tip during L4 (Kimble and Hirsh, 1979). These migrations are subject to both positional guidance cues as well as temporal control. Several transcription factors regulate various segments of the migratory path. In particular, $n h r-67$ is expressed in the LC and responsible for promoting ventral and posterior migrations during the L4 stage (Kato and Sternberg, 2009). In nhr-67 RNAi treated animals, these migrations fail, and the LC often remains dorsal. Ventral migration depends on expression of the $u n c-40$ and repression of the $u n c-5$ guidance receptors, which are respectively attracted to or repelled by ventral netrin cues (Hedgecock et al., 1990). nhr-67 functions to repress unc-5 expression in the LC, and activate $z m p-1$ at the same time. The general role of $n h r-67$ seems primarily to affect the temporal aspects of the LC migration program, including the timed polarization of the LC in the L4 stage. Surprisingly, the corresponding migratory cell in hermaphrodites, the distal tip cell, does not express $n h r-67$, nor does it show a phenotype in the $n h r-67$ knockdown, suggesting a male specific role. Null mutations in daf-12 also affect late stage migrations of the LC (Antebi et al., 1998). It would be of interest to understand the regulatory relationship between $n h r-67$ and $d a f-12$ in this context.

Expression profiling of microdissected male LCs, comparing $n h r-67$ mutants to wild type, reveals that a remarkable number of genes are expressed within the migrating cell, including a multiplicity of transcription factors, cytoskeletal elements, and ion channels (Schwarz et al., 2012). Upon knockdown, several of these genes perturb migration, including $h l h-8 /$ Twist homolog, $c r h-2 /$ CREB homolog, sphk-1/sphingosine kinase, the conserved transmembrane mechano- and cold sensor trpa-1, and tandem pore potassium ion channels. Future exploration of the mechanism underlying the activity of these various genes in the migration program should prove interesting.

Like its vertebrate relatives, $n h r-67$ has a prominent role in the specification of neuronal cell fates. The best-studied case involves the specification of the bilateral ASER/L neurons, a pair of head chemosensory neurons responsive to soluble attractants. Their fates are first specified by the zinc finger transcription factor che-1, which turns on genes specific for ASE function (Uchida et al., 2003). Thereafter ASEL and ASER become asymmetric and functionally distinct, by virtue of an elaborate bi-stable feedback loop that restricts expression of left/right markers (Johnston and Hobert, 2003; Sarin et al., 2007). Among the many players, the $n k x 6.1 / 6.2$ transcription factor cog-1 specifies the ASER fate, while its downregulation by the $l s y-6$ microRNA species the ASEL fate. 
Notably $n h r-67$ functions at both steps to specify ASEL/R fate. First, it regulates expression of $c h e-1$, thereby functioning in the initial specification of the ASE cell. Second, it regulates asymmetry by promoting the ASER fate and repressing the ASEL fate (Sarin et al., 2009). $n h r-67$ facilitates ASER by direct transcriptional activation of $\operatorname{cog}-1$. Consequently, mutations in $n h r-67$ often result in the expression of ASEL markers in the ASER cell, and loss of ASER markers in ASER (Sarin et al., 2009). nhr-67 also regulates the fate of a number of other amphid neurons, including ASK and ASJ but its role in these cells is less well defined. Interestingly, L/R symmetry breaking events in the nervous system deploy Notch signaling at distinct points earlier in embryogenesis (Cochella and Hobert, 2012). It remains to be seen whether $n h r-67$ regulates Notch signaling in this context.

A close relative of NHR-67, FAX-1 is a conserved homolog of the vertebrate PNR implicated in the specification of photoreceptor rods and cones of the retina. Mutations in this receptor lead to night blindness and eye degeneration (Schorderet and Escher, 2009). In C. elegans, fax-1 is responsible for axon pathfinding and neurotransmitter expression in the AVK interneurons, and helps specify various terminal interneuron identities in conjunction with the UNC-42 homeodomain protein (Much et al., 2000; Wightman et al., 2005).

\subsection{NHR-6/NGF-1 regulates spermatheca organogenesis}

NHR-6 is a homolog of the highly conserved NOR1/Nurr77/Nurr1 subgroup of receptors. In mammals the three paralogs function in diverse processes including immediate early response, neural development, specification of midbrain dopaminergic neurons, immunity and inflammation, atherogenesis, adrenal steroidogenesis, and glucose and mitochondrial metabolism (Zhao and Bruemmer, 2010). DHR38 is the Drosophila homolog and functions in molting and metamorphosis, as well as glycogen storage and carbohydrate metabolism (Ruaud et al., 2011). These receptors are thought to work in a ligand independent fashion.

$n h r-6$ is expressed in a single pair of neurons in the head, possibly the ASI, as well as within dorsal somatic gonadal cells that later give rise to the hermaphrodite spermatheca (Gissendanner et al., 2004; Gissendanner et al., 2008). Consistent with a role in this organ, mutants have abnormal spermathecal morphogenesis, resulting in an Egl phenotype and ovulation defects. Spermathecae lack about half their cells, and are missing the uterine/spermathecal valve, suggesting cell lineage defects arising from various gonadoblasts (Gissendanner et al., 2008). Accordingly, various spermathecal markers are misexpressed or down, including cog-1/nkx6.1 and let-502/rho associated kinase. The neuronal function of $n h r-6$ remains unknown, but possible localization in ASI may suggest a role in dauer formation, sensory signal transduction, or endocrine control. Recently NHR-6 has been shown to physically and functionally interact with c-jun during spermathecal development. (Gissendanner et al., 2013). Moreover, two-hybrid data suggest physical interaction with several components of wingless signaling (Li et al., 2004). It would be of interest to investigate the in vivo relevance of such interactions in the future, as well as possible interaction with NHR-25 and NHR-67. nhr-6 also varies with the molt cycle, but the significance of this is not clear (Figure 7) (Asahina et al., 2000; Gissendanner and Sluder, 2000).

\section{Nuclear receptors in nutrient sensing, metabolism, and energy homeostasis}

From juvenile stages to adult, animals must sense nutrient levels and modulate growth rates, maturation, and reproductive output accordingly. Nutrient levels must be closely monitored, balanced, and coordinated with biosynthetic and energy demands of the organism. NRs are crucial nutrient sensors involved in detecting key metabolites and coupling their flux to metabolism, energy homeostasis, growth, and reproduction. They play a particularly important role in lipid and carbohydrate metabolism, and function in circuits governing their synthesis, transport, storage, and breakdown. Several C. elegans receptors are implicated in coupling nutrient levels to growth, and metabolism, including $n h r-91, n h r-62, n h r-23$, and $n h r-25$. Other NRs may more specifically regulate fat and glucose metabolism, including $n h r-49, n h r-80, n h r-64, n h r-69, n h r-76$, and others. Finally, some NRs, such as $n h r-49$ and $n h r-114$, are also involved in maintaining metabolic balance, and detoxifying endo- and xenobiotics to preserve organismal homeostasis. Below we discuss the role of the various NRs in these circuits.

\subsection{NHR-91 regulates blast cell progression in response to nutrients}

NHR-91 is a homolog of the mammalian GCNF (germ cell nuclear factor), a transcriptional repressor that restricts pluripotency gene expression during stem cell differentiation in embyrogenesis (Wang and Cooney, 2013). Although little is known about $n h r-91$ function in the worm, recent studies suggest a connection between nutrient sensing and stem cell quiescence and progression during the L1 diapause (Kasuga et al., 2013). When L1 larvae are starved, they arrest development and shut down blast cell division, entering a stress and starvation resistant L1 
diapause (Johnson et al., 1984). A number of loci have been found that inappropriately stimulate L1 progression of blast cells (M mesoblast, P ectoblasts) under nutrient deprivation (Baugh and Sternberg, 2006; Fukuyama et al., 2006), including loss of function of microRNA mir-235 (Kasuga et al., 2013). Evidently, one of the targets of mir-235 downregulation during starvation is $n h r-91$, which harbors mir-235 binding sites in its 3'UTR. Consistent with a role in this pathway, $n h r-91$ expression is downregulated in the L1 diapause, and nhr-91 loss alleviates mir-235 mutant defects, thereby preventing $\mathrm{P}$ ectoblast migration, and halting the onset of markers of molting and developmental progression under starvation (Kasuga et al., 2013). These studies suggest that $n h r-91$ downregulation is important for blast cell quiescence under nutrient limitation, and conversely, that its upregulation is associated with stem cell progression. Knockdown of $n h r-91$ by RNAi also reportedly gives rise to molting and vulval defects, although it is unclear if these phenotypes are seen in the deletion mutant (Zhao et al., 2004).

\subsection{NHR-62 regulates dietary restriction mediated longevity}

Dietary restriction (DR), a modest reduction of food intake without malnutrition, leads to health benefits and extends the life span of yeast, worms, flies, rodents, and perhaps primates (Mair and Dillin, 2008; Mattison et al., 2012; Colman et al., 2014). Several paradigms of DR in the worm extend life span, including bacterial dilution (Klass, 1977) and mutation of eat-2 (Lakowski and Hekimi, 1998), which affects a nicotinic acetylcholine receptor subunit causing worms to ingest less food (McKay et al., 2004). Recently, the C. elegans HNF4 $\alpha$ related receptor, NHR-62, has been shown to extend lifespan under DR, providing the first causal evidence of NR control of DR-induced longevity (Heestand et al., 2013). Deletion of $n h r-62$ largely abolished the longevity of eat-2 mutants, and dampened life extension by bacterial dilution at lower nutrient ranges. nhr-62 mutants also perturbed DR-induced changes in triglyceride accumulation, fat metabolism, and autophagy. In particular, autophagy-the turnover of cytosolic and organellar components through engulfment and lysosomal degradation-is induced under nutrient limitation and has been shown to be required for DR induced longevity (Hansen et al., 2008). NHR-62 affects autophagy, since mRNA levels of the LC3 homolog, $\operatorname{lgg}-1$, as well as LGG-1::GFP puncta are down in $n h r-62$ mutants under DR. Transcriptome analysis reveals approximately 600 genes regulated by NHR-62 under $\mathrm{DR}$, including various kinases, phosphatases, genes involved in lipid transport and metabolism, amine metabolism, and chromatin structure (Heestand et al., 2013). These findings raise the possibility that DR mediated longevity could be modulated by a NHR-62-dependent metabolite or ligand, and suggest various biological processes that could contribute to the health and longevity benefits of DR. Notably HNF4 $\alpha$ itself constitutively binds fatty acids and is known to regulate lipid and glucose metabolism (Gonzalez, 2008), raising the prospect that this NR could influence DR in mammals.

\subsection{NHR-23 regulates nutrient dependent maturational time}

Recently, the molting NR, NHR-23/ROR, has been tied to nutrient-dependent regulation of life history. Walhout and co-workers found that propagation of C. elegans on an alternative bacterial food source, Comomonas, results in developmental acceleration, reduced brood size, and shortened life span (MacNeil et al., 2013). Remarkably, this physiological response is observed even if trace amounts of Comomonas are mixed in with the normal food source, OP50, suggesting a nutrient sensing mechanism. However, these physiologic phenotypes appear independent of major nutrient sensing pathways such as TOR and IIS, and were instead associated with a dampening of gene expression of molt-cycle oscillatory as well as critical nutrient responsive genes such as acdh-l (MacNeil et al., 2013). Transcriptome analysis further suggests that major expression changes could be mediated by $n h r-23$, although a definitive functional role for $n h r-23$ in regulating these life history traits remains to be seen (MacNeil et al., 2013). Additionally, the HNF-4 related NRs, $n h r-10$ and $n h r-68$, also mediate major changes in metabolic gene expression in response to Comomonas (Watson et al., 2013). These studies suggest that diet and metabolism are intimately linked with temporal regulation of development and that food quality as well as quantity can affect life history traits.

\subsection{NHR-25/SF1 and fat metabolism}

Interestingly, the molting NR, NHR-25/SF-1, also plays a role in fat metabolism. It was identified in a genetic screen for suppressors of the acyl-coA synthase gene acs-3 (Mullaney et al., 2010). Acyl-CoA synthases condense fatty acids of various lengths with acyl-CoA, and function in $\beta$-oxidation and other fat metabolic processes. acs- 3 in particular has a preference for working on C18 fatty acids. Loss of function mutations in acs-3 result in increased fatty acid uptake, greater rates of de novo fatty acid synthesis, and accumulation of Nile red and bodipy-labeled fatty acids in large neutral lipid compartments in the C. elegans intestine (Mullaney et al., 2010). Surprisingly, acs-3 expression in epidermal seam cells triggers these metabolic effects in the gut, suggesting action at a distance. Suppressors of the acs-3 mutant include several other fatty acid metabolic genes, as well as hypomorphic mutations 
in $n h r-25$ (Mullaney et al., 2010). Conversely, acs-3 loss partially suppressed egg-laying and sterility phenotypes of $n h r-25$ hypomorphs, suggesting an antagonistic interaction. NHR-25 and its mammalian homologs SF-1 and LRH can accommodate fatty acyl-phosphoinositides in the LBD (Krylova et al., 2005; Urs et al., 2007; Mullaney et al., 2010; Lee et al., 2011). It is therefore surmised that acs-3 loss results in a depletion of long chain fatty acid-CoA inhibitory ligands for NHR-25, with the result that overactive NHR-25 provokes the observed changes in fat metabolism (Figure 10) (Mullaney et al., 2010). Because of mutual suppression, however, it is unclear whether $n h r-25$ acts upstream or downstream in these pathways. Curiously acs-3 mutants do not have a reported molting defect, presumably because NHR-25 still retains activity. Other genes implicated in fatty acid synthesis, however, do impact cuticle formation and expression of molting genes, namely pod-2, encoding acetyl-CoA carboxylase, and fasn-1, encoding fatty acid synthase ( $\mathrm{Li}$ and Paik, 2011). Conceivably, fatty acid molecules could affect molting by modulating NR activity, or could provide mechanical integrity to the cuticle.

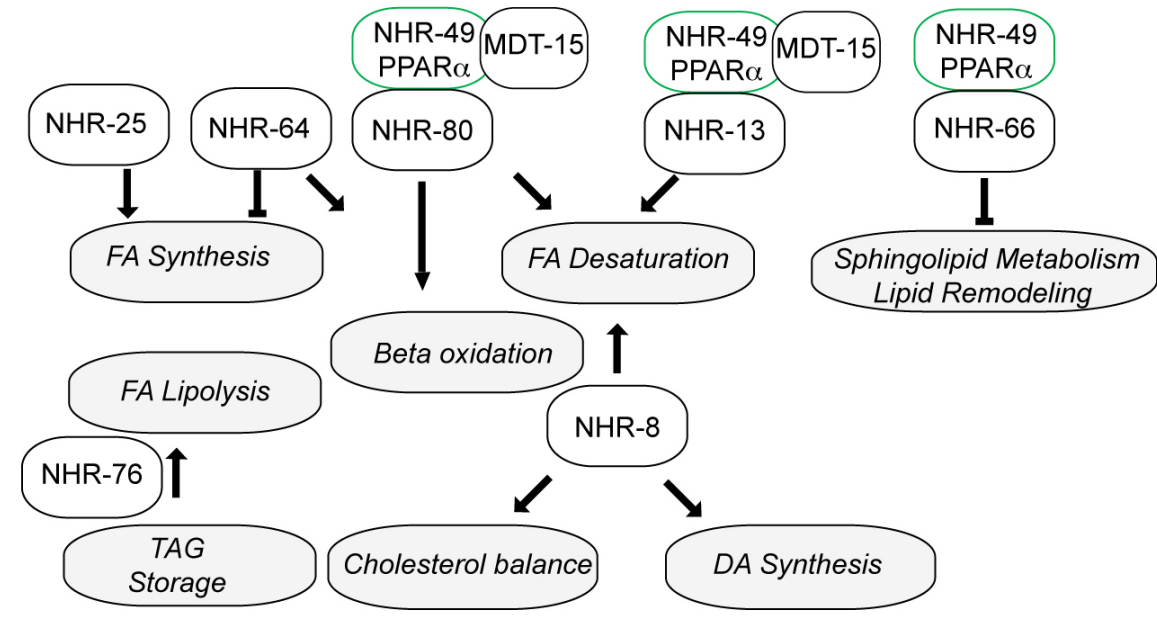

Figure 10. NRs control fat metabolism. NHR-25 promotes fat synthesis while NHR-64 represses it. NHR-49 interacts with NHR-80, NHR-13, and NHR-66 to promote fatty acid desaturation, beta-oxidation, and inhibit lipid remodeling and sphingolipid metabolism. MDT-15 is a co-activator of NHR-49 that likely interacts with NHR-49 for at least the positive transcriptional functions. NHR-76 promotes lipolysis in response to serotonin signaling. NHR-8 promotes FA desaturation and regulates cholesterol and DA flux.

\subsection{NHR-49/PPAR regulates fat metabolism and the nutrient response}

NHR-49 has emerged as one of the most important HNF4-like NRs, which coordinates fat metabolism in response to nutrient conditions, and whose responsibilities resemble that of mammalian lipid-sensing NRs, PPAR $\alpha$ or PPAR $\delta$. Among other things, PPAR $\alpha$ regulates expression of $\beta$-oxidation and fatty acid desaturase genes, and manages energy balance in response to starvation (Van Gilst et al., 2005a; Van Gilst et al., 2005b).

Consistent with a broad role in coordinating metabolism, NHR-49 resides in multiple tissues including intestine, hypodermis, body wall muscle, and pharynx (Van Gilst et al., 2005a). Among genes activated by $n h r-49$ in the fed state are those involved in mitochondrial $\beta$-oxidation of fatty acids (Table 2, Figure 10) (ech-1 enoyl-CoA-hydratase, acs-2 acyl-CoA synthase, cpt-5 carnitine palmitoyl transferase) the monodesaturation of fatty acids by $\Delta-9$ fatty acid-CoA desaturases (fat-5, fat-6, fat-7), and lipid transport (lbp-8) (Van Gilst et al., 2005a; Van Gilst et al., 2005b). Additionally, nhr-49 promotes expression of genes in the glyoxylate cycle (gei-7, malate synthase; sdha-1, succinate dehydrogenase), which are involved in the conversion of fat to glucose. By contrast $n h r-49$ represses genes involved in peroxisomal $\beta$-oxidation (two acyl-CoA oxidases, ech-9) and lipid binding $(l b p-7)$. It also inhibits expression of genes involved in sphingolipid processing, (acid ceramidase, glycosyl hydrolase, and sphingosine phosphate lyase) and lipid remodeling (a triacylglycerol lipase, an o-acyl transferase, two phospholipases) (Pathare et al., 2012). Ligands for $n h r-49$ remain unidentified but are hypothesized to be fatty acids or derivatives.

In support of the notion that $n h r-49$ coordinates fat usage, mutants exhibit lower levels of $\beta$-oxidation and oxygen consumption, and accumulate the vital dye Nile red, which stains a lysosomal-like acidic fat compartment (Pathare et al., 2012; Van Gilst et al., 2005a). As a result of a deficiency in $\Delta-9$ fatty acid-CoA desaturase activity, they accumulate the saturated fatty acids C16:0 palmitic acid and C18:0 stearic acid (Van Gilst et al., 2005a). Accordingly, they have reduced C16:1n7 palmitoleic and C18:1n9 oleic monounsaturated fatty acids (MUFAs). Little change is seen in measured polyunsaturated fatty acid (PUFA) levels, although enzymes involved in their production (e.g., fat-1, fat-2) are also changed in quantitative proteomic experiments (Fredens et al., 2011). 
The transcriptional response of $n h r-49$ very much depends on nutrient status. Notably, starvation induces a number of genes, some of which show $n h r-49$ dependence. These include acyl Co-A synthase genes, acs-2, acs-11, hacd-1, and gei-7 (Van Gilst et al., 2005b). Surprisingly, starvation also results in $n h r-49(+)$ dependent suppression of $c p t-4$, revealing a complex regulation of genes involved in $\beta$-oxidation. Proteomic analysis confirms that $n h r-49$ plays a major role in fat metabolism, although its role in peroxisomal $\beta$-oxidation may be more important than that in mitochondrial $\beta$-oxidation, since many proteins reduced in $n h r-49$ mutants contain a peroxisomal localization signal (Fredens et al., 2011). $n h r-49(+)$ may more broadly coordinate nutrient sensing systems since analyses of transcriptome, proteome, and metabolome data also reveals changes in amino acid, protein and xenobiotic metabolism (Atherton et al., 2008; Fredens et al., 2011; Pathare et al., 2012).

\subsection{NHR-49/PPAR affects life span and the adult reproductive diapause}

One of the most striking phenotypes of $n h r-49$ is its effect on life span. $n h r-49$ mutants are dramatically short lived compared to wild type (mean life span 9 days vs. 17 days) (Van Gilst et al., 2005a). Short life span is ascribed to lower expression of the fatty acid desaturases, and the higher ratios of saturated to unsaturated fatty acids, which can be lipotoxic in higher animals. In fact, several studies suggest an inverse correlation between the accumulation of saturated fat and longevity (Goudeau et al., 2011; Shmookler Reis et al., 2011), but the molecular basis of this correlation is unknown.

Although $n h r-49$ has no known role in dauer formation, it plays a critical role in a similar long-lived quiescent state termed the adult reproductive diapause (ARD), in which animals cease reproductive activities under starvation (Angelo and Van Gilst, 2009). Worms shifted to no food during the L4 stage stop embryo production and trim back germline stem cells through apoptosis or necrosis. A subset of animals retains arrested embryos for a week or so. Even after several weeks of starvation, animals sustain expression of the lag-2 Notch ligand, whose expression in the niche (gonadal distal tip cells) prevents meiotic progression and maintains the germline stem cells. When returned to ample food, animals will reconstitute their germline and other tissues, produce viable progeny, and live a normal life span, revealing protective mechanisms for soma and germline in response to nutrient deprivation, and robust rejuvenation in response to a return to food. Evidently $n h r-49$ is important for ARD, since fewer mutant animals enter the adult reproductive diapause (Angelo and Van Gilst, 2009). For those animals that successfully enter ARD, however, $n h r-49$ did not play an obvious role in the recovery of germline stem cells. Presumably $n h r-49$ promotes ARD by mobilizing metabolic genes important for energy homeostasis, stress, and turnover.

Interestingly, mammalian PPAR $\alpha$ is also implicated in the response to fasting. PPAR $\alpha$ transgenic mice massively upregulate expression of the fasting hormone FGF21, which turns on genes involved in hepatic $\beta$-oxidation, ketogenesis, and gluconeogenesis (Potthoff et al., 2012). Remarkably, FGF21 overexpression has been recently shown to be sufficient to improve insulin sensitivity and extend murine life span (Zhang et al., 2012). It does so by suppressing production of hepatic IGF-1, mimicking a state of growth hormone deficiency. Whether similar downstream pathways operate to regulate starvation induced longevity in C. elegans remains to be seen.

\subsection{NHR-49/PPAR transcriptional complexes}

NHR-49 works in a number of transcriptional complexes to regulate metabolism. $n h r-49$ acts in conjunction with the co-activator $m d t-15$ to impact fatty acid metabolism (Figure 10). $m d t-15$ was found in yeast two-hybrid screens with $n h r-49$ as bait, and encodes a homolog of the mediator subunit 15, a multisubunit complex that functions as a transcriptional coregulator (Taubert et al., 2006). Consistent with the idea that $m d t-15$ and $n h r-49$ act together, both gene products are found in the intestine, the major metabolic and endocrine organ in the worm. $m d t-15$ loss of function results in a failure to accumulate $n h r-49$-dependent fasting induced genes, including gei-7, $a c s-2$, acs-11, and hacd-1, as well as reduced expression of genes fat-5, fat-7, lbp-8, and cpt-5 in the fed state. mdt-15 mutants have perturbed fatty acid composition, increased saturated FA, reduced MUFAs and PUFAs, and are short lived. In fact, $m d t-15$ plays a broad role in the fatty acid/fasting response since it is required for regulation of additional genes, such as fat-2, acdh-1, acdh-2, ech-9, F08A8.2-4 acyl-CoA-oxidase and others, which are relatively unaffected by $n h r-49$. Accordingly $m d t-15$ physically interacts with a number of other NRs as well as the SREBP homolog sbp-1 (Yang et al., 2006; Arda et al., 2010). mdt-15 also has other $n h r-49$ independent roles including in PUFA production, as well as oxidative, xenobiotic and heavy metal metabolism (Taubert et al., 2008; Goh et al., 2013), and affects longevity in a number of contexts (Taubert et al., 2006; Schleit et al., 2011; McCormick et al., 2012). 
In analogy to the mammalian heterodimeric partner RXR, NHR-49 also complexes directly with various other NRs (Figure 10). Namely $n h r-49$ interacts with $n h r-66, n h r-80, n h r-13, n h r-22$, and $n h r-105$, as measured through yeast two-hybrid interactions and/or GST-pulldowns (Pathare et al., 2012). Genetic and biochemical analysis reveals that these NRs execute separable aspects of $n h r-49$ function. For example, $n h r-80$ and $n h r-13$ specifically affect expression of fatty acid desaturase genes fat-5, fat-6, and fat-7. Similar to $n h r-49$, nhr-80 mutants accumulate saturated fats, have reduced monounsaturated fats, and are somewhat short lived. Although nhr-13 has no discernible change in fatty acid composition, mutants are also short lived. By contrast, $n h r-66$ functions specifically in the repression of genes involved in sphingolipid processing and lipid remodeling, and displays normal lifespan, suggesting that $n h r-66$ may carry out repressive aspects of $n h r-49$ function. $n h r-49, n h r-80$, and $n h r-66$ mutants have reduced $\beta$-oxidation, oxygen consumption, and altered mitochondrial morphology (Pathare et al., 2012). Altogether, these studies reveal that $n h r-49$ works in a combinatorial fashion in distinct complexes to carry out its diverse functions. It seems plausible that $n h r-49$ may interact with additional NRs.

\subsection{NHR-80/HNF4 regulates fatty acid desaturation and longevity}

Levels of saturated and desaturated fatty acids must be precisely controlled, and importantly, $n h r-80$ functions in homeostatic circuits that serve to regulate fatty acid desaturation gene expression and balance (Brock et al., 2006). As mentioned above, $n h r-80$ promotes expression of the $\Delta-9$ fatty acid desaturases, particularly fat -7 , fat-5, and to a lesser extent fat-6, under well-fed conditions (Figure 10). Correlatively, mutants accumulate C18:0 stearic acid and have reduced levels of C18:1n9 monounsaturated oleic acid (Brock et al., 2006; Pathare et al., 2012). Whereas the fat-7 fat-5; fat-6 triple mutant is lethal, single and double mutants are viable due to compensatory upregulation of the remaining intact genes by $n h r-80$. For example, when the fat- 6 gene is mutated, the fat-5 and fat-7 genes are substantially upregulated. This upregulation depends largely on $n h r-80(+)$ : in the absence of the receptor, fat-7 induction is abrogated. As might be predicted, $n h r-80$ RNAi combined with fat- 6 mutation exacerbates the imbalance in fatty acid composition. Moreover, $n h r-80$; fat-6 double mutants are synthetically lethal and only survive if provided with exogenous desaturated fatty acids (Brock et al., 2006).

NHR-80 is also required for longevity in response to signals from the reproductive system (Goudeau et al., 2011) (Figure 8). As mentioned above, C. elegans life span is extended considerably by removal of germline stem cells. Germline loss results in induction of $n h r-80:: g f p$ expression in the intestine, and deletion of $n h r-80$ suppresses

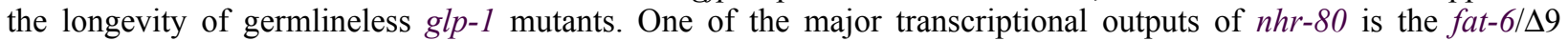
desaturase, which is strongly induced in germlineless animals in an $n h r$ - 80 -dependent manner. Accordingly, germlineless animals exhibit elevated levels of C18:1n9 oleic acid, the metabolic product of FAT-6 activity. Consistent with an important physiological role, a double knockout of the fat- 6 and fat-7 desaturases abrogates gonadal longevity, yet long life is restored by supplementation with oleic acid (Goudeau et al., 2011). These studies point to the importance of $n h r-80$ and fatty acid desaturation in extending life in response to germline signals. Germline removal also results in an upregulation of the lipase lipl-4 via DAF-16/FOXO (Wang et al., 2008) (Figure 8). lipl-4 overexpression is sufficient to extend life span in gonad-intact animals, while lipl-4 loss abrogates life span extension in germlineless $g l p-1$ mutants, presumably due to FA released upon lipolysis. Interestingly lipl-4 overexpression has been shown to induce autophagy, and knockdown of autophagy gene function abrogates longevity (Lapierre et al., 2011). Omega-6 polyunsaturated fatty acids stimulate autophagy and longevity, revealing an important connection between fatty acid desaturation, autophagy, and longevity (O'Rourke et al., 2013). Conceivably oleic acid, omega-6 PUFAs, or their derivatives could stimulate longevity by altering fatty acid metabolism, directly stimulating autophagy, or working through nuclear receptor signal transduction.

\subsection{NHR-64/HNF4 and fat metabolism}

Another HNF4-like receptor implicated in fat metabolism is NHR-64 (Liang et al., 2010). $n h r-64$ was identified in RNAi screens as a suppressor of the reduced Nile red staining and decreased fat storage phenotype of fat-6; fat-7 double mutants. Additionally, nhr-64 RNAi partially restores the low triacylglyceride levels, brood size and slow growth rates seen in fat-6; fat-7 mutants. As in mammals, the sterol regulatory element binding protein homolog, $s b p-1$ regulates $\Delta-9$ desaturase expression, and levels of fatty acid desaturation (Yang et al., 2006). Like fat-6; fat-7 mutants, sbp-1 mutant animals fail to accumulate TAGs and exhibit slow growth phenotypes; $n h r-64$ RNAi also suppresses these phenotypes (Liang et al., 2010). An analysis of FA composition reveals that $n h r-64$ knockdown results in a reduction of saturated fatty acids, and an increase in monomethyl branched-chain fatty acids, which are important signals for cellular growth (Kniazeva et al., 2004; Zhu et al., 2013). In addition, several fatty acid metabolic genes show dysregulation upon $n h r-64$ knockdown. The pod-2 fatty acetyl-CoA carboxylase gene is substantially upregulated, revealing that fatty acid synthesis is increased. At the same time, the acyl-CoA-oxidase, 
F08A8.4, is decreased, suggesting that peroxisomal $\beta$-oxidation may be down (Figure 10). Accordingly, RNAi of F08A8.4 itself suppresses the slow growth phenotype of fat-6; fat-7 double mutants. Taken altogether, these results suggest that $n h r-64(+)$ normally functions to remove fatty acids through oxidation and suppression of synthesis, and to thwart growth signaling. In this view, $n h r-64$ knockdown tempers fatty acid catabolism, and permits a more balanced metabolism in fat-6; fat-7 double mutants. Alternately, high levels of C18:0 stearic acid seen in fat-6; fat-7 mutants could overstimulate $n h r-64$ towards fatty acid catabolism and away from storage. In this view $n h r-64$ knockdown would decrease these activities. In the future it will be important to actually measure $\beta$-oxidation and other metabolic processes directly to interpret these observations.

\subsection{NHR-76 integrates biogenic amine signaling to mediate lipolysis}

The neurally produced biogenic amines, serotonin (5-HT) and octopamine, play an important role in regulating metabolism, feeding and behavior. In C. elegans they have been shown to synergistically induce fat loss in the intestine analogous to mammals where serotonin and beta-adrenergic signaling also cooperate (Noble et al., 2013). One of the prominent outputs of 5-HT treatment is the induction the major triacylglycerol lipase 1, atgl-1, expressed in the intestine. Interestingly, atgl-1 expression in this context is dependent on the NR NHR-76 (Figure 10) (Noble et al., 2013). Mutation of atgl-1 or $n h r-76$ prevents 5-HT-induced fat loss. Evidently this relay is indirect. Serotonin appears to first impinge upon the mod-1 serotonin-gated Cl-channel within URXR/L neurons, which are exposed to the body cavity and pseudocoelem. Presumably thereafter, unidentified molecules secreted from URX impinge on NHR-76 in the intestine, which promotes atgl-1 transcription, thus catalyzing FA lipolysis and breakdown. Interestingly, NHR-76 bears significant homology to RXR, which works as a heterodimeric partner with multiple nuclear receptors, and binds to retinoic acid derivatives. It will be especially interesting to see whether NHR-76 is ligand gated and whether it functions similar to RXR.

\subsection{NHR-69/HNF4 regulates insulin secretion and dauer formation}

NHR-69 is one among the HNF4-like receptors that has been recently shown to function in glucose sensing, insulin signaling, dauer formation, and longevity (Park et al., 2012). NHR-69 protein was found associated in pulldown experiments with the R-smad homolog DAF-8, a component of TGF- $\beta$ signaling that functions in dauer formation. Consistent with a role in dauer formation, mutation of $n h r-69$ mildly enhances the Daf-c phenotypes of mutants in TGF- $\beta$ signaling. $n h r-69$ is expressed in the ASI, an important sensory neuron governing dauer formation and longevity. daf-8; $n h r-69$ double mutants synergize for a number of phenotypes indicative of reduced IIS, including increased life span and upregulated DAF-16/FOXO target gene expression. Most interestingly, double mutants exhibit decreased neuropeptide secretion, resulting from derepression of exp-2, an NHR-69 target gene encoding a conserved potassium channel (Park et al., 2012). This ion channel inhibits secretion of DAF-28, an insulin-like peptide expressed in ASI. Conversely, exp-2 loss of function results in insulin hypersecretion, and short life span. Genetic epistasis experiments suggest that exp-2 works downstream of $n h r-69$, but upstream of the daf-2/insulin receptor with respect to longevity. Additionally, $n h r-69$ expression in ASI is upregulated by IIS, presumably through positive feedback. Altogether these data suggest a model whereby an NHR-69-DAF-8 complex inhibits exp-2 expression, which results in insulin secretion and normal life (Figure 11). Upon downregulation of these transcription factors, exp-2 expression is elevated, thereby inhibiting insulin secretion, and leading to dauer formation and long life. Finally nhr-69 overexpression in the ASI neuron leads to a lethargic phenotype that is rescued by exogenous glucose. Thus NHR-69 behaves much like HNF4 $\alpha$ in regulating glucose metabolism, insulin signaling, and metabolic homeostasis. Mammalian HNF4 and SMAD3 physically interact and evidence suggests conserved crosstalk between the pathways (Mizutani et al., 2011). 


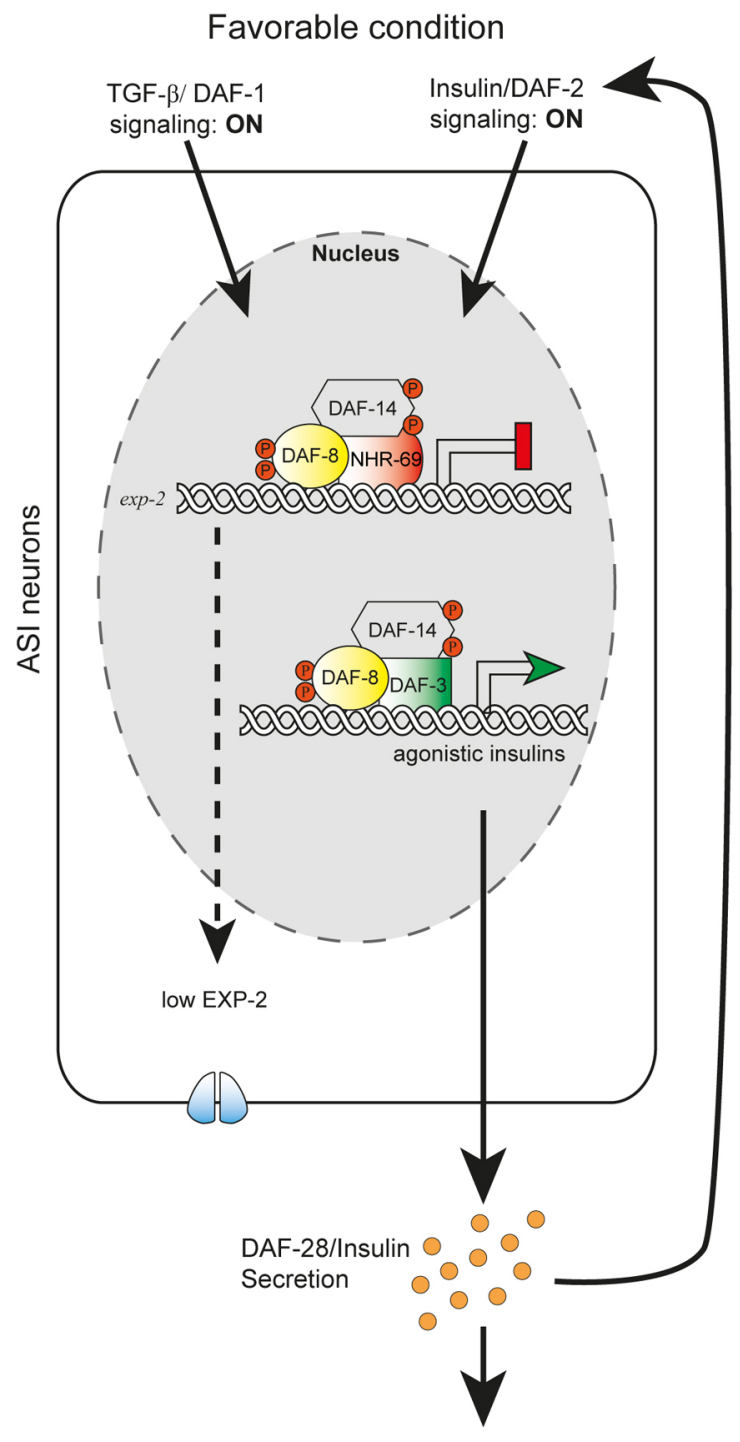

Reproductive Growth

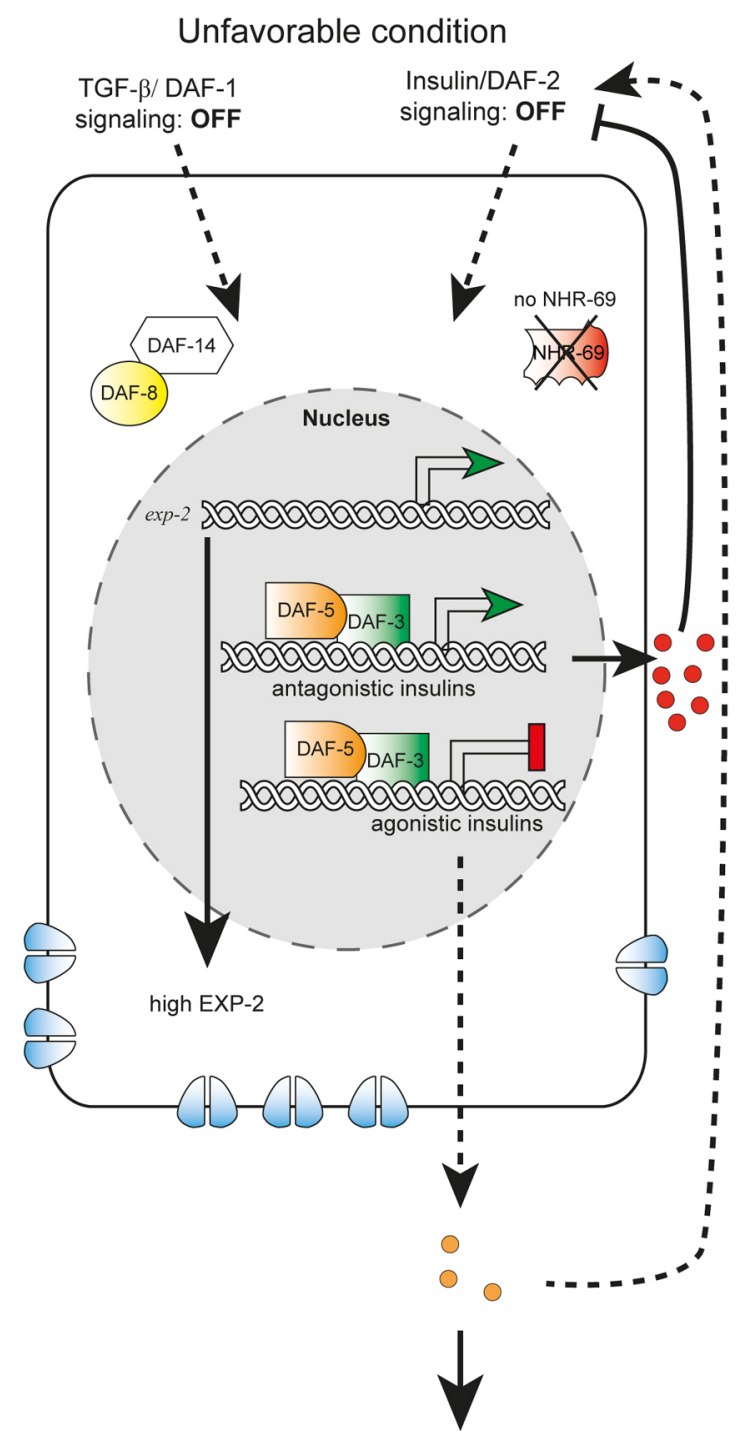

Dauer

Figure 11. Model of NHR-69/DAF-8 interaction and regulation of insulin release from the ASI neuron. High IIS and TGF- $\beta$ levels stimulate the activity of DAF-8-DAF-14 complexes which assemble with NHR-69 to inhibit expression of the $\mathrm{K}^{+}$channel, exp-2, while DAF-8-DAF-14-DAF-3 SMAD complexes promote agonist insulin expression in the ASI neurons. This results in increased DAF-28/insulin-like peptide release, and reproductive growth through IIS. Positive feedback regulation maintains this state. Conversely, under low IIS and TGF- $\beta$ signaling, DAF-14/DAF-8/NHR-69 complexes are inactive, resulting in high EXP-2 expression. DAF-3/DAF-5 complexes activate antagonistic insulins and inhibit agonist insulins, leading to inhibition of DAF-28 release, dauer formation, and longevity.

\subsection{NHR-31/HNF4 controls fluid balance}

The HNF4 $\alpha$-like NR, NHR-31, has an extraordinarily specific role in tubulogenesis of the worm excretory cell (Hahn-Windgassen and Van Gilst, 2009), which functions analogously to the kidney tubule mediating ion and water balance in mammals. During larval development a single excretory cell in the head sends out paired tubular processes anteriorly and posteriorly which extend the length of the animal. nhr-31 is expressed within the excretory cell, as well as in the intestine and in unidentified tail cells. Deletion of the gene results in early embryonic lethality, presumably due to excretory cell dysfunction. RNAi knockdown of $n h r-31$ late in larval development results in sensitivity to high salt challenge (Hahn-Windgassen and Van Gilst, 2009). The excretory cell tubules in $n h r-31$ depleted animals harbor large varicosities, which contain a surplus of endoplasmic reticulum, mitochondria, and vacuole-like vesicles, as visualized by electron microscopy, which could be interpreted as regions of unregulated membrane growth or failure to turnover such organelles. Analysis of the transcriptional profile comparing $n h r-31$ RNAi to wild-type reveals a striking reduction in the expression of 16 subunits of the vacuolar ATPase, a proton 
pumping ATPase involved in lysosomal function and vesicle trafficking. Notably knockdown of these subunits induces a swelling of tubule varicosities similar to $n h r-31$ knockdown. The promoters of these V-ATPase genes are enriched in a putative binding site for NHR-31. Similarly, the mammalian HNF4 $\alpha$ binding site is also enriched in the promoters of genes for the V-ATPase subunits, suggesting a possible related role for this receptor in kidney function.

\subsection{NHR-114 affects germ cell integrity in response to diet}

Organisms in the wild encounter unpredictable food sources with differing levels of nutrients. The somatically expressed HNF4 $\gamma$-like NR, NHR-114, affects the survival of germ cells in response to nutrient imbalance (Gracida and Eckmann, 2013). In nhr-114 deletion mutants, germ cells fail to proliferate normally, rendering the animal sterile. Curiously, this phenotype is observed on an E. coli B food source (e.g., OP50), but not with an E. coli K12 food source (e.g., HT115). This phenotype could in part be attributed to levels of dietary tryptophan, as supplementation of OP50 with tryptophan restored fertility. Moreover, rescue depended on live E. coli suggesting that tryptophan metabolites produced by the microbiome contribute to the response. An analysis of the NHR-114 transcriptome in response to tryptophan revealed changes in various xenobiotic and detoxifying genes. This suggests a role for HNF4 $\gamma$ in buffering tissue damage against dietary or metabolic insults, and a protective role of chemical defense in this response.

\subsection{Other NR regulators of metabolism}

Several other less well-characterized NRs that affect various aspects of metabolism have emerged from genetic screens. Some have been identified through altered Nile red accumulation (Ashrafi et al., 2003), which marks a lysosomal-like organelle (O'Rourke et al., 2009). Others have been identified through stimulated Raman microscopy to visualize fat levels in vivo (Wang et al., 2011). The yeast one hybrid approach was used to systematically identify transcriptional regulators of defined sets of metabolic genes (Arda et al., 2010), and NRs emerged as an overrepresented transcription factor class, strongly implicating them in metabolic control. A network model of the interactions further revealed that multiple NRs converge on specific target genes, or regulate other NRs. Moreover, the MDT-15 co-activator was shown to interact with at least 12 such receptors. NHR-86 in particular emerged as a hub with 12 NRs converging on its promoter, and NHR-86 itself regulating several downstream NRs in this network. Consistent with a role in metabolism RNAi knockdown of these receptors resulted in alterations in Nile red accumulation, and some (e.g., $n h r-178, n h r-45$ ) showed nutrient dependent regulation, as well as predicted regulatory interactions in vivo (Arda et al., 2010). Clearly this powerful approach should be further exploited to expand the links in such networks, and used to elucidate the underlying physiology.

\section{Future perspectives}

Studies in the worm demonstrate that NRs are key regulators of cellular fate, stage structure, metabolism, and longevity that can illuminate fundamental aspect of metazoan biology. Several challenges lie ahead for the future and many questions remains. What is the molecular architecture of the molt cycle and how does this integrate with sleep, metabolism, and developmental timing? What is the interrelationship between developmental timing components and longevity? How are the various NRs integrated into signal transduction pathways controlling cell fate and morphogenesis? What is the nature of metabolic networks and function of NRs in these circuits? What are the transcriptional regulatory networks in which NRs are embedded? What roles might NRs play in other physiologic functions, such as innate immunity, xenobiotic metabolism, behavior, and stress response? Beyond these physiologic questions are nuts and bolts issues of identifying the ligands, direct target genes, and coregulatory molecules that interface with the various NRs. Finally, what are the functional homologs of the diversified $C$. elegans NRs? The answers to these questions and many more are bound to yield important insights into evolutionarily conserved facets of metazoan NRs. 


\section{Tables 1 and 2}

Table 1. C. elegans NRs

\begin{tabular}{|c|c|c|c|c|c|c|c|}
\hline $\begin{array}{c}\mathrm{Ce} \\
\text { receptor }\end{array}$ & Expression & Function & $\begin{array}{l}\text { Regulated } \\
\text { Genes }\end{array}$ & $\begin{array}{c}\mathrm{Dm} \\
\text { receptor }\end{array}$ & Function & $\begin{array}{l}\mathrm{Hs} / \mathrm{Mm} \\
\text { receptor }\end{array}$ & Function \\
\hline DAF-12 & $\begin{array}{c}\text { neurons, } \\
\text { intestine, } \\
\text { hypodermis, } \\
\text { vulva, } \\
\text { pharynx, } \\
\text { muscle, } \\
\text { somatic } \\
\text { gonad }\end{array}$ & $\begin{array}{c}\text { dauer } \\
\text { formation, } \\
\text { developmental } \\
\text { timing, fat } \\
\text { metabolism, } \\
\text { longevity } \\
\text { regulated by } \\
\text { dafachronic } \\
\text { acid ligands }\end{array}$ & $\begin{array}{c}\text { mir-241, } \\
\text { mir-84, lit-1, } \\
\text { lin-41, lin-42, } \\
\text { lin-28, ain-1, } \\
\text { nhl-2, din-1, } \\
\text { cbp-1, daf-3, } \\
\text { daf-16, fard-1, } \\
\text { cdr-6 }\end{array}$ & DHR96 & $\begin{array}{l}\text { cholesterol, } \\
\text { TAG, } \\
\text { xenobiotic } \\
\text { metabolism, } \\
\text { binds } \\
\text { cholesterol }\end{array}$ & FXR/ NR1H3 & $\begin{array}{l}\text { cholesterol, } \\
\text { fat, bile acid } \\
\text { metabolism }\end{array}$ \\
\hline \multirow[t]{3}{*}{ NHR-8 } & intestine & $\begin{array}{c}\text { dauer } \\
\text { formation, fat } \\
\text { metabolism, } \\
\text { cholesterol } \\
\text { metabolism, } \\
\text { xenobiotic } \\
\text { metabolism }\end{array}$ & $\begin{array}{l}\text { daf-36, fat-5, } \\
\text { fat-7, vit-1, } \\
\text { vit-2, lipases, } \\
\text { elo-1, fat-2 }\end{array}$ & & & $\begin{array}{c}\mathrm{LXR} \alpha / \\
\text { NR1H2, LXR } \beta / \\
\text { NR1H1 }\end{array}$ & $\begin{array}{c}\text { glucose, } \\
\text { cholesterol, } \\
\text { fat, bile acid } \\
\text { metabolism, } \\
\text { neural } \\
\text { development, } \\
\text { immune } \\
\text { function, skin } \\
\text { barrier } \\
\text { function and } \\
\text { protection }\end{array}$ \\
\hline & & & & & & $\begin{array}{l}\text { PXR/ NR1I2, } \\
\text { CAR/ NR1I3 }\end{array}$ & $\begin{array}{c}\text { xenobiotic and } \\
\text { bile acid } \\
\text { metabolism }\end{array}$ \\
\hline & & & & & & VDR/NR11 & $\begin{array}{c}\text { bone } \\
\text { development } \\
\text { and } \\
\text { homeostasis, } \\
\text { phosphate and } \\
\text { calcium } \\
\text { homeostasis, } \\
\text { cellular } \\
\text { differentiation }\end{array}$ \\
\hline UNC-55 & $\begin{array}{l}\text { motor- } \\
\text { neurons }\end{array}$ & $\begin{array}{l}\text { regulates } \\
\text { remodeling of } \\
\text { VD } \\
\text { motoneuron } \\
\text { synapses }\end{array}$ & $\begin{array}{c}\text { represses } h b l-1 \text {, } \\
\text { Ir } x-1\end{array}$ & $\begin{array}{l}\text { Seven } \\
\text { Up }\end{array}$ & $\begin{array}{l}\text { neurogenesis, } \\
\text { cardiac } \\
\text { development }\end{array}$ & $\begin{array}{c}\text { COUP-TF1/ } \\
\text { NR2F1 } \\
\text { COUP-TF2/ } \\
\text { NR2F2 }\end{array}$ & $\begin{array}{c}\text { cardiovascular } \\
\text { development, } \\
\text { angiogenesis, } \\
\text { neural } \\
\text { development, } \\
\text { pituitary and } \\
\text { reproductive } \\
\text { function, } \\
\text { metabolism }\end{array}$ \\
\hline NHR-25 & $\begin{array}{l}\text { intestine, } \\
\text { hypodermis, } \\
\text { vulva, } \\
\text { pharyngeal } \\
\text { and rectal } \\
\text { epithelial }\end{array}$ & $\begin{array}{c}\text { molting, } \\
\text { epidermal } \\
\text { differentiation, } \\
\text { developmental } \\
\text { timing, fat } \\
\text { metabolism }\end{array}$ & $\begin{array}{l}\text { apl-1, acn-1, } \\
\text { mlt-10, nas-37 }\end{array}$ & FTZ-F1 & $\begin{array}{c}\text { early } \\
\text { embryonic } \\
\text { patterning and } \\
\text { larval molting } \\
\text { and } \\
\text { metamorphosis }\end{array}$ & SF-1/ NR5A1 & $\begin{array}{c}\text { regulates } \\
\text { sexual } \\
\text { development } \\
\& \\
\text { development } \\
\text { of }\end{array}$ \\
\hline
\end{tabular}




\begin{tabular}{|c|c|c|c|c|c|c|c|}
\hline $\begin{array}{c}\mathrm{Ce} \\
\text { receptor }\end{array}$ & Expression & Function & $\begin{array}{l}\text { Regulated } \\
\text { Genes }\end{array}$ & $\begin{array}{c}\text { Dm } \\
\text { receptor }\end{array}$ & Function & $\begin{array}{l}\mathrm{Hs} / \mathrm{Mm} \\
\text { receptor }\end{array}$ & Function \\
\hline & $\begin{array}{l}\text { cells, } \\
\text { somatic } \\
\text { gonad, } \\
\text { germline }\end{array}$ & & & & & & $\begin{array}{l}\text { steroidogenic } \\
\text { tissues }\end{array}$ \\
\hline & & & & & & LRH/ NR5A2 & $\begin{array}{c}\text { cholesterol, } \\
\text { bile acid, } \\
\text { glucose and } \\
\text { fatty acid } \\
\text { metabolism, } \\
\text { inflammation, } \\
\text { pluripotentency } \\
\text { of embryonic } \\
\text { stem cells, gut } \\
\text { stem cell } \\
\text { renewal }\end{array}$ \\
\hline NHR-23 & $\begin{array}{l}\text { hypodermis, } \\
\text { pharynx, } \\
\text { germline, } \\
\text { intestine? }\end{array}$ & $\begin{array}{l}\text { molting, } \\
\text { maturational } \\
\text { timing in } \\
\text { response to } \\
\text { nutrients }\end{array}$ & $\begin{array}{c}\text { dpy-2,3,5,7,8,10, } \\
\text { wrt-1,2,3, } \\
\text { mlt-8,9,10,11, } \\
\text { ptc-3, acn-1, } \\
\text { nhr- } 60\end{array}$ & DHR3 & $\begin{array}{c}\text { ecdysone } \\
\text { inducible, } \\
\text { prepupal to } \\
\text { pupal } \\
\text { transition, } \\
\text { metamorphosis, } \\
\text { adult } \\
\text { differentiation, } \\
\text { molting, } \\
\text { cellular } \\
\text { growth }\end{array}$ & $\begin{array}{l}\text { ROR } \alpha / \text { NR1F1, } \\
\text { ROR } \beta / \text { NR1F2, } \\
\text { ROR } \gamma / \text { NR1F3 }\end{array}$ & $\begin{array}{l}\text { circadian } \\
\text { clock, } \\
\text { cerebellum } \\
\text { development, } \\
\text { immunity, } \\
\text { lipid, } \\
\text { cholesterol, } \\
\text { and glucose } \\
\text { metabolism }\end{array}$ \\
\hline NHR-41 & $\begin{array}{l}\text { seam cell, } \\
\text { hyodermis, } \\
\text { rectal } \\
\text { epithelium, } \\
\text { excretory } \\
\text { cell, head } \\
\text { neuron, } \\
\text { excretory } \\
\text { cell, vulva }\end{array}$ & Dauer molt & & DHR78 & $\begin{array}{c}\text { ecdysone } \\
\text { inducible, } \\
\text { larval growth, } \\
\text { metamorphosis, } \\
\text { tracheal } \\
\text { development }\end{array}$ & $\begin{array}{l}\text { TR2/ NR2C1, } \\
\text { TR4/ NR2C2 }\end{array}$ & $\begin{array}{c}\text { recruits } \\
\text { corepressors, } \\
\text { role in early } \\
\text { embryonic } \\
\text { development, } \\
\text { and stem cells }\end{array}$ \\
\hline NHR-85 & \begin{tabular}{|} 
excretory \\
duct cell, \\
hypodermis, \\
rectal \\
epithelium, \\
vulva
\end{tabular} & $\begin{array}{c}\text { dauer molt, egg } \\
\text { laying, }\end{array}$ & & E75 & $\begin{array}{l}\text { ecdysone } \\
\text { inducible, } \\
\text { covalently } \\
\text { modified by } \\
\text { heme and } \\
\text { regulated by } \\
\text { nitic oxide } \\
\text { which } \\
\text { regulates } \\
\text { association } \\
\text { with DHR3 }\end{array}$ & $\begin{array}{l}\text { REV-ERB } \alpha / \\
\text { NR1D1, } \\
\text { REV-ERB } \beta \\
\text { NR1D2 }\end{array}$ & $\begin{array}{l}\text { heme binding, } \\
\text { circadian } \\
\text { rhythm, } \\
\text { adipogenesis }\end{array}$ \\
\hline SEX-1 & $\begin{array}{l}\text { ubiquitous } \\
\text { nuclear } \\
\text { staining in } \\
\text { embryo }\end{array}$ & $\begin{array}{c}\text { sex } \\
\text { determination }\end{array}$ & xol-1 & E78 & $\begin{array}{c}\text { Ecdysone } \\
\text { inducible, } \\
\text { Repressed by } \\
\text { DHR3 }\end{array}$ & “ & “ \\
\hline NHR-67 & $\begin{array}{l}\text { head } \\
\text { neurons, }\end{array}$ & $\begin{array}{c}\text { epidermal } \\
\text { morphogenesis, }\end{array}$ & $\begin{array}{l}\text { egl-17/FGF, } \\
\text { egl-26/LRAT, }\end{array}$ & Tailless & $\begin{array}{l}\text { inhibits } \\
\text { embryonic }\end{array}$ & $\begin{array}{l}\text { TLX/ NR2E1, } \\
\text { TLL/ NR2E2 }\end{array}$ & $\begin{array}{c}\text { nervous } \\
\text { system and }\end{array}$ \\
\hline
\end{tabular}




\begin{tabular}{|c|c|c|c|c|c|c|c|}
\hline $\begin{array}{c}\text { Ce } \\
\text { receptor }\end{array}$ & Expression & Function & $\begin{array}{c}\text { Regulated } \\
\text { Genes }\end{array}$ & $\begin{array}{c}\text { Dm } \\
\text { receptor }\end{array}$ & Function & $\begin{array}{l}\text { Hs/Mm } / M m \\
\text { receptor }\end{array}$ & Function \\
\hline & $\begin{array}{l}\text { hypodermis, } \\
\text { vulva, } \\
\text { somatic } \\
\text { gonad, } \\
\text { excretory } \\
\text { cell }\end{array}$ & $\begin{array}{c}\text { vulval and } \\
\text { gonadal } \\
\text { development, } \\
\text { neuronal cell } \\
\text { fate, excretory } \\
\text { canal } \\
\text { morphogenesis }\end{array}$ & $\begin{array}{c}\text { pax-2, zmp-1, } \\
\text { unc-5 (LC), } \\
\text { hlh-8, crh-2, } \\
\text { sphk-1, trpa-1, } \\
\text { che-1 }\end{array}$ & & $\begin{array}{l}\text { segmentation, } \\
\text { promotes } \\
\text { terminal fates, } \\
\text { neurogenesis }\end{array}$ & & $\begin{array}{c}\text { visual } \\
\text { development, } \\
\text { embryonic } \\
\text { and adult } \\
\text { neural stem } \\
\text { maintenance }\end{array}$ \\
\hline FAX-1 & $\begin{array}{c}\mathrm{AVK}, \\
\text { various } \\
\text { interneurons }\end{array}$ & $\begin{array}{l}\text { interneuron fate } \\
\text { specification, } \\
\text { axon } \\
\text { outgrowth, } \\
\text { neurotransmitter } \\
\text { expression }\end{array}$ & $\begin{array}{c}\text { flp-1, opt-3, } \\
n c s-1\end{array}$ & DHR51 & $\begin{array}{l}\text { mushroom } \\
\text { body } \\
\text { development, } \\
\text { wing } \\
\text { expansion } \\
\text { fertility }\end{array}$ & PNR/ NR2E3 & $\begin{array}{l}\text { photoreceptor } \\
\text { rods and } \\
\text { cones }\end{array}$ \\
\hline NHR-6 & $\begin{array}{c}\text { ASI, } \\
\text { spermatheca }\end{array}$ & $\begin{array}{l}\text { spermathecal } \\
\text { organogenesis }\end{array}$ & $\operatorname{cog}-1$, let-502 & DHR38 & \begin{tabular}{|c|} 
molting and \\
metamorphosis, \\
glycogen \\
storage, \\
carbohydrate \\
metabolism
\end{tabular} & $\begin{array}{l}\text { Nurr77/NR4A1, } \\
\text { Nurr1/NR4A2, } \\
\text { NOR1/NR4A3 }\end{array}$ & \begin{tabular}{|} 
immediate \\
early \\
response, \\
neural \\
development, \\
specification \\
of midbrain \\
dopaminergic \\
neurons, \\
immunity and \\
inflammation, \\
atherogenesis, \\
adrenal \\
steroidogenesis, \\
and glucose \\
and \\
mitochondrial \\
metabolism
\end{tabular} \\
\hline NHR-91 & \begin{tabular}{|c|} 
neurons, \\
seam cells, \\
vulva, \\
excretory \\
cell, \\
spermatheca,
\end{tabular} & $\begin{array}{l}\text { regulates stem } \\
\text { blast cell } \\
\text { quiescence and } \\
\text { progression in } \\
\text { response to } \\
\text { nutrients }\end{array}$ & & DHR4 & $\begin{array}{l}\text { controls the } \\
\text { timing of } \\
\text { ecdysone } \\
\text { pulses and } \\
\text { larval } \\
\text { maturation, } \\
\text { through } \\
\text { negative } \\
\text { feedback }\end{array}$ & GCNF/NR6A1 & $\begin{array}{l}\text { transcriptional } \\
\text { repressor } \\
\text { required for } \\
\text { vertebrate } \\
\text { stem cell } \\
\text { differentiation, } \\
\text { embryogenesis } \\
\text { and neural } \\
\text { differentiation }\end{array}$ \\
\hline
\end{tabular}


Table 2. Spotlight on functionally characterized HNF4-related receptors.

\begin{tabular}{|c|c|c|c|}
\hline Receptor & Tissue Expression & Function & Regulated genes \\
\hline NHR-62 & $\begin{array}{l}\text { neurons, intestine, } \\
\text { hypodermis, pharynx, } \\
\text { spermatheca, excretory cell }\end{array}$ & $\begin{array}{l}\text { Promotes: dietary } \\
\text { restriction mediated } \\
\text { longevity }\end{array}$ & $\begin{array}{l}\text { acdh-2, lbp-8, vit-1-6 } \\
\text { col-91, gst-21, lgg-1 }\end{array}$ \\
\hline NHR-49 & $\begin{array}{l}\text { neurons, intestine, } \\
\text { hypodermis, pharynx, body } \\
\text { muscle }\end{array}$ & $\begin{array}{l}\text { Promotes: FA } \beta \text { oxidation, } \\
\text { FA desaturation, transport, } \\
\text { adult reproductive diapause }\end{array}$ & $\begin{array}{l}\text { fat-5, fat-6, fat-7, lbp-8 } \\
\text { cpt-5, ech-1, acs-2, acs-11, } \\
\text { hacd-1, gei-7, acid } \\
\text { ceramidase F27e5.1, } \\
\text { glycosylhydrolase } \\
\text { E02H9.5, spl B0222.4, } \\
\text { ZK167.2 lipase, W02b12.1 } \\
\text { lipase }\end{array}$ \\
\hline NHR-80 & $\begin{array}{l}\text { neurons, intestine, head } \\
\text { muscle }\end{array}$ & $\begin{array}{l}\text { Promotes: FA desaturation, } \\
\beta \text {-oxidation, gonadal } \\
\text { longevity }\end{array}$ & $\begin{array}{l}\text { fat-5, fat-6, fat-7, cpt-5, } \\
\text { ech-1 }\end{array}$ \\
\hline NHR-66 & $\begin{array}{l}\text { neurons in anterior, lateral, } \\
\text { retrovesicular ganglia, seam } \\
\text { cells, hypodermis, intestine, } \\
\text { body muscle }\end{array}$ & $\begin{array}{l}\beta \text { oxidation, Represses: } \\
\text { sphingolipid metabolism }\end{array}$ & $\begin{array}{l}\text { ceramidase F27e5.1, } \\
\text { glycosylhydrolase } \\
\text { E02H9.5, spl B0222.4, } \\
\text { ZK167.2 lipase, W02b12.1 } \\
\text { lipase }\end{array}$ \\
\hline NHR-13 & ubiquitous, intestine & Promotes: FA desaturation & fat-5, fat-6, fat-7, ech-1 \\
\hline NHR-76 & $\begin{array}{l}\text { body muscle, vulval } \\
\text { muscle, excretory gland, } \\
\text { intestine, seam cell }\end{array}$ & $\begin{array}{l}\text { Promotes: FA lipolysis in } \\
\text { response to serotonin }\end{array}$ & atgl-1 \\
\hline NHR-64 & $\begin{array}{l}\text { neurons of head, tail, } \\
\text { ventral cord, intestine, } \\
\text { hypodermis, pharynx }\end{array}$ & $\begin{array}{l}\text { Promotes: FA synthesis } \\
\text { Prevents: FA catabolism }\end{array}$ & $\begin{array}{l}\text { acs-1-5, elo-5, elo-6, pod-2 } \\
\text { up, acyl-CoA-oxidase } \\
\text { F08A8.4 down }\end{array}$ \\
\hline NHR-69 & $\begin{array}{l}\text { ASI neuron, tail neurons, } \\
\text { Intestine, hypodermis, } \\
\text { pharynx, uterus, rectal } \\
\text { epithelium }\end{array}$ & $\begin{array}{l}\text { Glucose metabolism, } \\
\text { TGF- } \beta \text { \& Insulin signaling, } \\
\text { Dauer formation, longevity }\end{array}$ & $\exp -2$ \\
\hline NHR-31 & excretory cell & $\begin{array}{l}\text { Excretory cell } \\
\text { morphogenesis, Fluid } \\
\text { Balance }\end{array}$ & Vacuolar-ATPase subunits \\
\hline NHR-114 & $\begin{array}{l}\text { intestine, hypodermis, } \\
\text { germline }\end{array}$ & $\begin{array}{l}\text { Germ Cell Maintenance, } \\
\text { Xenobiotic Metabolism }\end{array}$ & $\begin{array}{l}\text { cyp-35b2, cyp-35B1, } \\
\text { clec-61, clec-169, gst-8, } \\
\text { acs-10, ugt-63 }\end{array}$ \\
\hline NHR-40 & $\begin{array}{l}\text { neurons, body muscle, } \\
\text { pharynx, vulval muscle, } \\
\text { rectal glands, P ectoblasts }\end{array}$ & $\begin{array}{l}\text { Embryonic muscle } \\
\text { development }\end{array}$ & myo-2, act-1, unc-52 \\
\hline NHR-60 & $\begin{array}{l}\text { VC4 -, VC5 } \\
\text {-motor-neurons, pharyngeal } \\
\text { gland, seam cell, male ray } \\
\text { UV1 uterine cells }\end{array}$ & $\begin{array}{l}\text { Ventral closure, } \\
\text { embryogenesis }\end{array}$ & \\
\hline
\end{tabular}




\section{Acknowledgements}

I thank Dan Magner and Philipp Jäger for critical reading of the manuscript and Moritz Horn, Christoph Geisen, and Sabine Finkler for help with figures. I thank the Max Planck Society, Deutsche Forschungsgemeinschaft (SFB635 \& Cluster of Excellence: Cellular Stress Responses in Aging-Associated Diseases (CECAD)), and the German Bundesministerium für Bildung und Forschung (Gerontosys; Sybacol) for their generous support.

\section{References}

Abbott, A.L., Alvarez-Saavedra, E., Miska, E.A., Lau, N.C., Bartel, D.P., Horvitz, H.R., and Ambros, V. (2005). The let-7 MicroRNA family members mir-48, mir-84, and mir-241 function together to regulate developmental timing in Caenorhabditis elegans. Dev. Cell 9, 403-414. Abstract Article

Ambros, V., and Horvitz, H.R. (1984). Heterochronic mutants of the nematode C. elegans. Science 226, 409-416. Abstract Article

Anbalagan, M., Huderson, B., Murphy, L., and Rowan, B.G. (2012). Post-translational modifications of nuclear receptors and human disease. Nucl. Recept. Signal. 10, e001. Abstract Article

Angelo, G., and Van Gilst, M.R. (2009). Starvation protects germline stem cells and extends reproductive longevity in C. elegans. Science 326, 954-958. Abstract Article

Antebi, A. (2006). Nuclear hormone receptors in C. elegans (January 03, 2006), WormBook, ed. The C. elegans Research Community, WormBook, doi/10.1895/wormbook.1.64.1, http://www.wormbook.org. Article

Antebi, A., Culotti, J.G., and Hedgecock, E.M. (1998). daf-12 regulates developmental age and the dauer alternative in Caenorhabditis elegans. Development 125, 1191-1205. Abstract

Antebi, A., Yeh, W.H., Tait, D., Hedgecock, E.M., and Riddle, D.L. (2000). daf-12 encodes a nuclear receptor that regulates the dauer diapause and developmental age in C. elegans. Genes Dev. 14, 1512-1527. Abstract

Ao, W., Gaudet, J., Kent, W.J., Muttumu, S., and Mango, S.E. (2004). Environmentally induced foregut remodeling by PHA-4/FoxA and DAF-12/NHR. Science 305, 1743-1746. Abstract Article

Apfeld, J., O'Connor, G., McDonagh, T., DiStefano, P.S., and Curtis, R. (2004). The AMP-activated protein kinase AAK-2 links energy levels and insulin-like signals to lifespan in C. elegans. Genes Dev. 18, 3004-3009. Abstract Article

Arantes-Oliveira, N., Apfeld, J., Dillin, A., and Kenyon, C. (2002). Regulation of life-span by germ-line stem cells in Caenorhabditis elegans. Science 295, 502-505. Abstract Article

Arda, H.E., Taubert, S., MacNeil, L.T., Conine, C.C., Tsuda, B., Van Gilst, M., Sequerra, R., Doucette-Stamm, L., Yamamoto, K.R., and Walhout, A.J. (2010). Functional modularity of nuclear hormone receptors in a Caenorhabditis elegans metabolic gene regulatory network. Mol. Syst. Biol. 6, 367. Abstract Article

Asahina, M., Ishihara, T., Jindra, M., Kohara, Y., Katsura, I., and Hirose, S. (2000). The conserved nuclear receptor Ftz-F1 is required for embryogenesis, moulting and reproduction in Caenorhabditis elegans. Genes Cells 5, 711-723. Abstract Article

Asahina, M., Valenta, T., Silhankova, M., Korinek, V., and Jindra, M. (2006). Crosstalk between a nuclear receptor and $\beta$-catenin signaling decides cell fates in the C. elegans somatic gonad. Dev. Cell 11, 203-211. Abstract Article

Ashrafi, K., Chang, F.Y., Watts, J.L., Fraser, A.G., Kamath, R.S., Ahringer, J., and Ruvkun, G. (2003). Genome-wide RNAi analysis of Caenorhabditis elegans fat regulatory genes. Nature 421, 268-272. Abstract Article

Atherton, H.J., Jones, O.A., Malik, S., Miska, E.A., and Griffin, J.L. (2008). A comparative metabolomic study of NHR-49 in Caenorhabditis elegans and PPAR- $\alpha$ in the mouse. FEBS Lett. 582, 1661-1666. Abstract Article 
Bargmann, C.I., and Horvitz, H.R. (1991). Control of larval development by chemosensory neurons in C. elegans. Science 251, 1243-1246. Abstract Article

Barna, J., Princz, A., Kosztelnik, M., Hargitai, B., Takacs-Vellai, K., and Vellai, T. (2012). Heat shock factor-1 intertwines insulin/IGF-1, TGF- $\beta$ and cGMP signaling to control development and aging. BMC Dev. Biol. 12, 32. Abstract Article

Baugh, L.R., and Sternberg, P.W. (2006). DAF-16/FOXO regulates transcription of $c k i-1 / \mathrm{Cip} / \mathrm{Kip}$ and repression of lin-4 during C. elegans L1 arrest. Curr. Biol. 16, 780-785. Abstract Article

Benito-Sipos, J., Ulvklo, C., Gabilondo, H., Baumgardt, M., Angel, A., Torroja, L., and Thor, S. (2011). Seven up acts as a temporal factor during two different stages of neuroblast 5-6 development. Development 138, 5311-5320. Abstract Article

Bento, G., Ogawa, A., and Sommer, R.J. (2010). Co-option of the hormone-signalling module dafachronic acid-DAF-12 in nematode evolution. Nature 466, 494-497. Abstract Article

Bethke, A., Fielenbach, N., Wang, Z., Mangelsdorf, D.J., and Antebi, A. (2009). Nuclear hormone receptor regulation of microRNAs controls developmental progression. Science 324, 95-98. Abstract Article

Bhat-Nakshatri, P., Wang, G., Collins, N.R., Thomson, M.J., Geistlinger, T.R., Carroll, J.S., Brown, M., Hammond, S., Srour, E.F., Liu, Y., et al. (2009). Estradiol-regulated microRNAs control estradiol response in breast cancer cells. Nucleic Acids Res. 37, 4850-4861. Abstract Article

Birnby, D.A., Link, E.M., Vowels, J.J., Tian, H., Colacurcio, P.L., and Thomas, J.H. (2000). A transmembrane guanylyl cyclase (DAF-11) and Hsp90 (DAF-21) regulate a common set of chemosensory behaviors in Caenorhabditis elegans. Genetics 155, 85-104. Abstract

Boehm, M., and Slack, F. (2005). A developmental timing microRNA and its target regulate life span in C. elegans. Science 310, 1954-1957. Abstract Article

Brock, T.J., Browse, J., and Watts, J.L. (2006). Genetic regulation of unsaturated fatty acid composition in $C$. elegans. PLoS Genet. 2, e108. Abstract Article

Brooks, D.R., Appleford, P.J., Murray, L., and Isaac, R.E. (2003). An essential role in molting and morphogenesis of Caenorhabditis elegans for ACN-1, a novel member of the angiotensin-converting enzyme family that lacks a metallopeptidase active site. J. Biol. Chem. 278, 52340-52346. Abstract Article

Brozova, E., Simeckova, K., Kostrouch, Z., Rall, J.E., and Kostrouchova, M. (2006). NHR-40, a Caenorhabditis elegans supplementary nuclear receptor, regulates embryonic and early larval development. Mech. Dev. 123, 689-701. Abstract Article

Butcher, R.A., Fujita, M., Schroeder, F.C., and Clardy, J. (2007). Small-molecule pheromones that control dauer development in Caenorhabditis elegans. Nat. Chem. Biol. 3, 420-422. Abstract Article

Byerly, L., Cassada, R.C., and Russell, R.L. (1976). The life cycle of the nematode Caenorhabditis elegans. I. Wild-type growth and reproduction. Dev. Biol. 51, 23-33. Abstract Article

Calkin, A.C., and Tontonoz, P. (2012). Transcriptional integration of metabolism by the nuclear sterol-activated receptors LXR and FXR. Nat. Rev. Mol. Cell Biol. 13, 213-224. Abstract Article

Carmi, I., Kopczynski, J.B., and Meyer, B.J. (1998). The nuclear hormone receptor SEX-1 is an X-chromosome signal that determines nematode sex. Nature 396, 168-173. Abstract Article

Cassada, R., and Russell, R. (1975). The dauer-larva: a post-embryonic developmental variant of the nematode $C$. elegans. Dev. Biol. 46, 326-342. Abstract Article

Chawla, G., and Sokol, N.S. (2012). Hormonal activation of let-7-C microRNAs via EcR is required for adult Drosophila melanogaster morphology and function. Development 139, 1788-1797. Abstract Article 
Chen, Z., Eastburn, D.J., and Han, M. (2004). The Caenorhabditis elegans nuclear receptor gene $n h r-25$ regulates epidermal cell development. Mol. Cell. Biol. 24, 7345-7358. Abstract Article

Clancy, D.J., Gems, D., Harshman, L.G., Oldham, S., Stocker, H., Hafen, E., Leevers, S.J., and Partridge, L. (2001). Extension of life-span by loss of CHICO, a Drosophila insulin receptor substrate protein. Science 292, $104-106$. Abstract Article

Cochella, L., and Hobert, O. (2012). Embryonic priming of a miRNA locus predetermines postmitotic neuronal left/right asymmetry in C. elegans. Cell 151, 1229-1242. Abstract Article

Cohen, M., Reale, V., Olofsson, B., Knights, A., Evans, P., and de Bono, M. (2009). Coordinated regulation of foraging and metabolism in C. elegans by RFamide neuropeptide signaling. Cell Metab. 9, 375-385. Abstract Article

Colman, R.J., Beasley, T.M., Kemnitz, J.W., Johnson, S.C., Weindruch, R., and Anderson, R.M. (2014). Caloric restriction reduces age-related and all-cause mortality in rhesus monkeys. Nat. Commun. 5, 3557. Abstract Article

Cypser, J.R., Tedesco, P., and Johnson, T.E. (2006). Hormesis and aging in Caenorhabditis elegans. Exp. Gerontol. 41, 935-939. Abstract Article

Davis, M.W., Birnie, A.J., Chan, A.C., Page, A.P., and Jorgensen, E.M. (2004). A conserved metalloprotease mediates ecdysis in Caenorhabditis elegans. Development 131,6001-6008. Abstract Article

Dieterich, C., Clifton, S.W., Schuster, L.N., Chinwalla, A., Delehaunty, K., Dinkelacker, I., Fulton, L., Fulton, R., Godfrey, J., Minx, P., et al. (2008). The Pristionchus pacificus genome provides a unique perspective on nematode lifestyle and parasitism. Nat. Genet. 40, 1193-1198. Abstract Article

Ding, L., Spencer, A., Morita, K., and Han, M. (2005). The developmental timing regulator AIN-1 interacts with miRISCs and may target the argonaute protein ALG-1 to cytoplasmic P bodies in C. elegans. Mol. Cell 19, $437-447$. Abstract Article

Dixon, S.J., Alexander, M., Chan, K.K., and Roy, P.J. (2008). Insulin-like signaling negatively regulates muscle arm extension through DAF-12 in Caenorhabditis elegans. Dev. Biol. 318, 153-161. Abstract Article

Dumas, K.J., Guo, C., Shih, H.J., and Hu, P.J. (2013). Influence of steroid hormone signaling on life span control by Caenorhabditis elegans insulin-like signaling. G3 (Bethesda) 3, 841-850. Abstract Article

Dumas, K.J., Guo, C., Wang, X., Burkhart, K.B., Adams, E.J., Alam, H., and Hu, P.J. (2010). Functional divergence of dafachronic acid pathways in the control of C. elegans development and lifespan. Dev. Biol. 340, 605-612. Abstract Article

Esquela-Kerscher, A., Johnson, S.M., Bai, L., Saito, K., Partridge, J., Reinert, K.L., and Slack, F.J. (2005). Post-embryonic expression of $C$. elegans microRNAs belonging to the lin-4 and let-7 families in the hypodermis and the reproductive system. Dev. Dyn. 234, 868-877. Abstract Article

Essers, M.A., de Vries-Smits, L.M., Barker, N., Polderman, P.E., Burgering, B.M., and Korswagen, H.C. (2005). Functional interaction between $\beta$-catenin and FOXO in oxidative stress signaling. Science 308, 1181-1184. Abstract Article

Farboud, B., Nix, P., Jow, M.M., Gladden, J.M., and Meyer, B.J. (2013). Molecular antagonism between X-chromosome and autosome signals determines nematode sex. Genes Dev. 27, 1159-1178. Abstract Article

Fernandes, J.S., and Sternberg, P.W. (2007). The tailless ortholog $n h r-67$ regulates patterning of gene expression and morphogenesis in the C. elegans vulva. PLoS Genet. 3, e69. Abstract Article

Fernandez-Marcos, P.J., Auwerx, J., and Schoonjans, K. (2011). Emerging actions of the nuclear receptor LRH-1 in the gut. Biochim. Biophys. Acta 1812, 947-955. Abstract Article

Ferraz-de-Souza, B., Lin, L., and Achermann, J.C. (2011). Steroidogenic factor-1 (SF-1, NR5A1) and human disease. Mol. Cell. Endocrinol. 336, 198-205. Abstract Article 
Fielenbach, N., and Antebi, A. (2008). C. elegans dauer formation and the molecular basis of plasticity. Genes Dev. 22, 2149-2165. Abstract Article

Fielenbach, N., Guardavaccaro, D., Neubert, K., Chan, T., Li, D., Feng, Q., Hutter, H., Pagano, M., and Antebi, A. (2007). DRE-1: an evolutionarily conserved F box protein that regulates C. elegans developmental age. Dev. Cell 12, 443-455. Abstract Article

Fisher, A.L., and Lithgow, G.J. (2006). The nuclear hormone receptor DAF-12 has opposing effects on Caenorhabditis elegans lifespan and regulates genes repressed in multiple long-lived worms. Aging Cell 5, 127-138. Abstract Article

Flatt, T., Min, K.J., D'Alterio, C., Villa-Cuesta, E., Cumbers, J., Lehmann, R., Jones, D.L., and Tatar, M. (2008). Drosophila germ-line modulation of insulin signaling and lifespan. Proc. Natl. Acad. Sci. U. S. A. 105, 6368-6373. Abstract Article

Frand, A.R., Russel, S., and Ruvkun, G. (2005). Functional genomic analysis of C. elegans molting. PLoS Biol. 3, e312. Abstract Article

Fredens, J., Engholm-Keller, K., Giessing, A., Pultz, D., Larsen, M.R., Hojrup, P., Moller-Jensen, J., and Faergeman, N.J. (2011). Quantitative proteomics by amino acid labeling in C. elegans. Nat. Methods 8, 845-847. Abstract Article

Fukuyama, M., Rougvie, A.E., and Rothman, J.H. (2006). C. elegans DAF-18/PTEN mediates nutrient-dependent arrest of cell cycle and growth in the germline. Curr. Biol. 16, 773-779. Abstract Article

Gems, D., Sutton, A.J., Sundermeyer, M.L., Albert, P.S., King, K.V., Edgley, M.L., Larsen, P.L., and Riddle, D.L. (1998). Two pleiotropic classes of daf-2 mutation affect larval arrest, adult behavior, reproduction and longevity in C. elegans. Genetics 150, 129-155. Abstract

Gerisch, B., and Antebi, A. (2004). Hormonal signals produced by DAF-9/cytochrome P450 regulate C. elegans dauer diapause in response to environmental cues. Development 131, 1765-1776. Abstract Article

Gerisch, B., Rottiers, V., Li, D., Motola, D.L., Cummins, C.L., Lehrach, H., Mangelsdorf, D.J., and Antebi, A. (2007). A bile acid-like steroid modulates Caenorhabditis elegans lifespan through nuclear receptor signaling. Proc. Natl. Acad. Sci. U. S. A. 104, 5014-5019. Abstract Article

Gerisch, B., Weitzel, C., Kober-Eisermann, C., Rottiers, V., and Antebi, A. (2001). A hormonal signaling pathway influencing C. elegans metabolism, reproductive development, and life span. Dev. Cell 1, 841-851. Abstract Article

Gissendanner, C.R., Cardin, D., Dubose, C.J., El Sayed, M., Harmson, J.S., Praslicka, B., and Rowan, B.G. (2013). C. elegans nuclear receptor NHR-6 functionally interacts with the jun-1 transcription factor during spermatheca development. Genesis 52, 29-38. Abstract Article

Gissendanner, C.R., Crossgrove, K., Kraus, K.A., Maina, C.V., and Sluder, A.E. (2004). Expression and function of conserved nuclear receptor genes in Caenorhabditis elegans. Dev. Biol. 266, 399-416. Abstract Article

Gissendanner, C.R., Kelley, K., Nguyen, T.Q., Hoener, M.C., Sluder, A.E., and Maina, C.V. (2008). The Caenorhabditis elegans NR4A nuclear receptor is required for spermatheca morphogenesis. Dev. Biol. 313, 767-786. Abstract Article

Gissendanner, C.R., and Sluder, A.E. (2000). $n h r-25$, the Caenorhabditis elegans ortholog of $f t z-f 1$, is required for epidermal and somatic gonad development. Dev. Biol. 221, 259-272. Abstract Article

Goh, G.Y., Martelli, K.L., Parhar, K.S., Kwong, A.W., Wong, M.A., Mah, A., Hou, N.S., and Taubert, S. (2013). The conserved Mediator subunit MDT-15 is required for oxidative stress responses in Caenorhabditis elegans. Aging Cell 13, 70-79. Abstract Article

Goh, K.Y., Ng, N.W., Hagen, T., and Inoue, T. (2012). p21-activated kinase interacts with Wnt signaling to regulate tissue polarity and gene expression. Proc. Natl. Acad. Sci. U. S. A. 109, 15853-15858. Abstract Article 
Golden, J.W., and Riddle, D.L. (1984a). The C. elegans dauer larva: developmental effects of pheromone, food, and temperature. Dev. Biol. 102, 368-378. Abstract Article

Golden, J.W., and Riddle, D.L. (1984b). A pheromone-induced developmental switch in C. elegans: Temperature-sensitive mutants reveal a wild-type temperature-dependent process. Proc. Natl. Acad. Sci. U. S. A. 81, 819-823. Abstract Article

Gonzalez, F.J. (2008). Regulation of hepatocyte nuclear factor $4 \alpha$-mediated transcription. Drug Metab. Pharmacokinet. 23, 2-7. Abstract Article

Gottlieb, S., and Ruvkun, G. (1994). daf-2, daf-16 and daf-23: genetically interacting genes controlling Dauer formation in Caenorhabditis elegans. Genetics 137, 107-120. Abstract

Goudeau, J., Bellemin, S., Toselli-Mollereau, E., Shamalnasab, M., Chen, Y., and Aguilaniu, H. (2011). Fatty acid desaturation links germ cell loss to longevity through NHR-80/HNF4 in C. elegans. PLoS Biol. 9, e1000599. Abstract Article

Gracida, X., and Eckmann, C.R. (2013). Fertility and germline stem cell maintenance under different diets requires $n h r-114 / \mathrm{HNF} 4$ in C. elegans. Curr. Biol. 23, 607-613. Abstract Article

Grimaldi, B., Bellet, M.M., Katada, S., Astarita, G., Hirayama, J., Amin, R.H., Granneman, J.G., Piomelli, D., Leff, T., and Sassone-Corsi, P. (2010). PER2 controls lipid metabolism by direct regulation of PPARgamma. Cell Metab. 12, 509-520. Abstract Article

Grosshans, H., Johnson, T., Reinert, K.L., Gerstein, M., and Slack, F.J. (2005). The temporal patterning microRNA let-7 regulates several transcription factors at the larval to adult transition in C. elegans. Dev. Cell 8, $321-330$. Abstract Article

Gui, H., Li, M.L., and Tsai, C.C. (2011). A tale of tailless. Dev. Neurosci. 33, 1-13. Abstract Article

Guittard, E., Blais, C., Maria, A., Parvy, J.P., Pasricha, S., Lumb, C., Lafont, R., Daborn, P.J., and Dauphin-Villemant, C. (2011). CYP18A1, a key enzyme of Drosophila steroid hormone inactivation, is essential for metamorphosis. Dev. Biol. 349, 35-45. Abstract Article

Hada, K., Asahina, M., Hasegawa, H., Kanaho, Y., Slack, F.J., and Niwa, R. (2010). The nuclear receptor gene $n h r-25$ plays multiple roles in the Caenorhabditis elegans heterochronic gene network to control the larva-to-adult transition. Dev. Biol. 344, 1100-1109. Abstract Article

Haerty, W., Artieri, C., Khezri, N., Singh, R.S., and Gupta, B.P. (2008). Comparative analysis of function and interaction of transcription factors in nematodes: extensive conservation of orthology coupled to rapid sequence evolution. BMC Genomics 9, 399. Abstract Article

Hahn-Windgassen, A., and Van Gilst, M.R. (2009). The Caenorhabditis elegans HNF4alpha Homolog, NHR-31, mediates excretory tube growth and function through coordinate regulation of the vacuolar ATPase. PLoS Genet. 5, e1000553. Abstract Article

Hajduskova, M., Jindra, M., Herman, M.A., and Asahina, M. (2009). The nuclear receptor NHR-25 cooperates with the Wnt/ $\beta$-catenin asymmetry pathway to control differentiation of the T seam cell in C. elegans. J. Cell Sci. 122, 3051-3060. Abstract Article

Hammell, C.M., Karp, X., and Ambros, V. (2009). A feedback circuit involving let-7-family miRNAs and DAF-12 integrates environmental signals and developmental timing in Caenorhabditis elegans. Proc. Natl. Acad. Sci. U. S. A. 106, 18668-18673. Abstract Article

Hansen, M., Chandra, A., Mitic, L.L., Onken, B., Driscoll, M., and Kenyon, C. (2008). A role for autophagy in the extension of lifespan by dietary restriction in C. elegans. PLoS Genet. 4, e24. Abstract Article 
Hayes, G.D., Frand, A.R., and Ruvkun, G. (2006). The mir-84 and let-7 paralogous microRNA genes of Caenorhabditis elegans direct the cessation of molting via the conserved nuclear hormone receptors NHR-23 and NHR-25. Development 133, 4631-4641. Abstract Article

Hedgecock, E.M., Culotti, J.G., and Hall, D.H. (1990). The unc-5, unc-6, and unc-40 genes guide circumferential migrations of pioneer axons and mesodermal cells on the epidermis in C. elegans. Neuron 4, 61-85. Abstract Article

Hedgecock, E.M., and White, J.G. (1985). Polyploid tissues in the nematode C. elegans. Dev. Biol. 107, $128-133$. Abstract Article

Heestand, B.N., Shen, Y., Liu, W., Magner, D.B., Storm, N., Meharg, C., Habermann, B., and Antebi, A. (2013). Dietary restriction induced longevity is mediated by nuclear receptor NHR-62 in Caenorhabditis elegans. PLoS Genet. 9, e1003651. Abstract Article

Held, J.M., White, M.P., Fisher, A.L., Gibson, B.W., Lithgow, G.J., and Gill, M.S. (2006). DAF-12-dependent rescue of dauer formation in Caenorhabditis elegans by (25S)-cholestenoic acid. Aging Cell 5, 283-291. Abstract Article

Hobert, O., Mori, I., Yamashita, Y., Honda, H., Ohshima, Y., Liu, Y., and Ruvkun, G. (1997). Regulation of interneuron function in the $C$. elegans thermoregulatory pathway by the $t$ tx-3 LIM homeobox gene. Neuron 19 , 345-357. Abstract Article

Hochbaum, D., Zhang, Y., Stuckenholz, C., Labhart, P., Alexiadis, V., Martin, R., Knolker, H.J., and Fisher, A.L. (2011). DAF-12 regulates a connected network of genes to ensure robust developmental decisions. PLoS Genet. 7, e1002179. Abstract Article

Holzenberger, M., Dupont, J., Ducos, B., Leneuve, P., Geloen, A., Even, P.C., Cervera, P., and Le Bouc, Y. (2003). IGF-1 receptor regulates lifespan and resistance to oxidative stress in mice. Nature 421, 182-187. Abstract Article

Horner, M.A., Pardee, K., Liu, S., King-Jones, K., Lajoie, G., Edwards, A., Krause, H.M., and Thummel, C.S. (2009). The Drosophila DHR96 nuclear receptor binds cholesterol and regulates cholesterol homeostasis. Genes Dev. 23, 2711-2716. Abstract Article

Hornsten, A., Lieberthal, J., Fadia, S., Malins, R., Ha, L., Xu, X., Daigle, I., Markowitz, M., O'Connor, G., Plasterk, R., et al. (2007). APL-1, a Caenorhabditis elegans protein related to the human $\beta$-amyloid precursor protein, is essential for viability. Proc. Natl. Acad. Sci. U. S. A. 104, 1971-1976. Abstract Article

Hsin, H., and Kenyon, C. (1999). Signals from the reproductive system regulate the lifespan of C. elegans. Nature 399, 362-366. Abstract Article

Hu, P.J. Dauer (August 08, 2007), WormBook, ed. The C. elegans Research Community, WormBook, doi/10.1895/wormbook.1.144.1, http://www.wormbook.org. Abstract Article

Huang, X., and Zhang, H. (2011). The zinc-finger protein SEA-2 regulates larval developmental timing and adult lifespan in C. elegans. Development 138, 2059-2068. Abstract Article

Janowski, B.A., Willy, P.J., Devi, T.R., Falck, J.R., and Mangelsdorf, D.J. (1996). An oxysterol signalling pathway mediated by the nuclear receptor $\operatorname{LXR} \alpha$. Nature 383, 728-731. Abstract Article

Jeon, M., Gardner, H.F., Miller, E.A., Deshler, J., and Rougvie, A.E. (1999). Similarity of the C. elegans developmental timing protein LIN-42 to circadian rhythm proteins. Science 286, 1141-1146. Abstract Article

Jia, K., Albert, P.S., and Riddle, D.L. (2002). DAF-9, a cytochrome P450 regulating C. elegans larval development and adult longevity. Development 129, 221-231. Abstract

Jia, K., Chen, D., and Riddle, D.L. (2004). The TOR pathway interacts with the insulin signaling pathway to regulate C. elegans larval development, metabolism and life span. Development 131, 3897-3906. Abstract Article 
Johnson, T.E., Mitchell, D.H., Kline, S., Kemal, R., and Foy, J. (1984). Arresting development arrests aging in the nematode Caenorhabditis elegans. Mech. Ageing Dev. 28, 23-40. Abstract Article

Johnston, R.J., and Hobert, O. (2003). A microRNA controlling left/right neuronal asymmetry in Caenorhabditis elegans. Nature 426,845-849. Abstract Article

Jurutka, P.W., Thompson, P.D., Whitfield, G.K., Eichhorst, K.R., Hall, N., Dominguez, C.E., Hsieh, J.C., Haussler, C.A., and Haussler, M.R. (2005). Molecular and functional comparison of 1,25-dihydroxyvitamin $\mathrm{D}(3)$ and the novel vitamin D receptor ligand, lithocholic acid, in activating transcription of cytochrome P450 3A4. J. Cell. Biochem. 94, 917-943. Abstract Article

Kanai, M.I., Okabe, M., and Hiromi, Y. (2005). seven-up controls switching of transcription factors that specify temporal identities of Drosophila neuroblasts. Dev. Cell 8, 203-213. Abstract Article

Kasuga, H., Fukuyama, M., Kitazawa, A., Kontani, K., and Katada, T. (2013). The microRNA miR-235 couples blast-cell quiescence to the nutritional state. Nature 497, 503-506. Abstract Article

Kato, M., and Sternberg, P.W. (2009). The C. elegans tailless/Tlx homolog nhr-67 regulates a stage-specific program of linker cell migration in male gonadogenesis. Development 136, 3907-3915. Abstract Article

Keisala, T., Minasyan, A., Lou, Y.R., Zou, J., Kalueff, A.V., Pyykko, I., and Tuohimaa, P. (2009). Premature aging in vitamin D receptor mutant mice. J. Steroid Biochem. Mol. Biol. 115, 91-97. Abstract Article

Kenyon, C.J. (2010). The genetics of ageing. Nature 464, 504-512. Abstract Article

Kenyon, C., Chang, J., Gensch, E., Rudner, A., and Tabtiang, R. (1993). A C. elegans mutant that lives twice as long as wild type. Nature 366, 461-464. Abstract Article

Kimble, J., and Hirsh, D. (1979). The postembryonic cell lineages of the hermaphrodite and male gonads in $C$. elegans. Dev. Biol. 70, 396-417. Abstract Article

Klass, M.R. (1977). Aging in the nematode C. elegans: major biological and environmental factors influencing life span. Mech. Ageing Dev. 6, 413-429. Abstract Article

Kleemann, G., Jia, L., and Emmons, S.W. (2008). Regulation of Caenorhabditis elegans male mate searching behavior by the nuclear receptor DAF-12. Genetics 180, 2111-2122. Abstract Article

Kniazeva, M., Crawford, Q.T., Seiber, M., Wang, C.Y., and Han, M. (2004). Monomethyl branched-chain fatty acids play an essential role in Caenorhabditis elegans development. PLoS Biol. 2, E257. Abstract Article

Kostrouchova, M., Krause, M., Kostrouch, Z., and Rall, J.E. (1998). CHR3: a Caenorhabditis elegans orphan nuclear hormone receptor required for proper epidermal development and molting. Development 125, 1617-1626. Abstract

Kostrouchova, M., Krause, M., Kostrouch, Z., and Rall, J.E. (2001). Nuclear hormone receptor CHR3 is a critical regulator of all four larval molts of the nematode Caenorhabditis elegans. Proc. Natl. Acad. Sci. U. S. A., pp. 7360-7365. Abstract Article

Kouns, N.A., Nakielna, J., Behensky, F., Krause, M.W., Kostrouch, Z., and Kostrouchova, M. (2011). NHR-23 dependent collagen and hedgehog-related genes required for molting. Biochem. Biophys. Res. Commun. 413, 515-520. Abstract Article

Krylova, I.N., Sablin, E.P., Moore, J., Xu, R.X., Waitt, G.M., MacKay, J.A., Juzumiene, D., Bynum, J.M., Madauss, K., Montana, V., et al. (2005). Structural analyses reveal phosphatidyl inositols as ligands for the NR5 orphan receptors SF-1 and LRH-1. Cell 120,343-355. Abstract Article

Kucherenko, M.M., Barth, J., Fiala, A., and Shcherbata, H.R. (2012). Steroid-induced microRNA let-7 acts as a spatio-temporal code for neuronal cell fate in the developing Drosophila brain. EMBO J. 31, 4511-4523. Abstract Article 
Kulalert, W., and Kim, D.H. (2013). The unfolded protein response in a pair of sensory neurons promotes entry of C. elegans into dauer diapause. Curr. Biol. 23, 2540-2545. Abstract Article

Lakowski, B., and Hekimi, S. (1998). The genetics of caloric restriction in Caenorhabditis elegans. Proc. Natl. Acad. Sci. U. S. A. 95, 13091-13096. Abstract Article

Lanjuin, A., VanHoven, M.K., Bargmann, C.I., Thompson, J.K., and Sengupta, P. (2003). Otx/otd homeobox genes specify distinct sensory neuron identities in C. elegans. Dev. Cell 5, 621-633. Abstract Article

Lapierre, L.R., De Magalhaes Filho, C.D., McQuary, P.R., Chu, C.C., Visvikis, O., Chang, J.T., Gelino, S., Ong, B., Davis, A.E., Irazoqui, J.E., et al. (2013). The TFEB orthologue HLH-30 regulates autophagy and modulates longevity in Caenorhabditis elegans. Nat. Commun. 4, 2267. Abstract Article

Lapierre, L.R., Gelino, S., Melendez, A., and Hansen, M. (2011). Autophagy and lipid metabolism coordinately modulate life span in germline-less C. elegans. Curr. Biol. 21, 1507-1514. Abstract Article

Lee, J., Kim, K.Y., and Paik, Y.K. (2014). Alteration in cellular acetylcholine influences dauer formation in Caenorhabditis elegans. BMB Rep. 47, 80-85. Abstract Article

Lee, J.M., Lee, Y.K., Mamrosh, J.L., Busby, S.A., Griffin, P.R., Pathak, M.C., Ortlund, E.A., and Moore, D.D. (2011). A nuclear-receptor-dependent phosphatidylcholine pathway with antidiabetic effects. Nature 474, 506-510. Abstract Article

Lee, R.C., Feinbaum, R.L., and Ambros, V. (1993). The C. elegans heterochronic gene lin-4 encodes small RNAs with antisense complementarity to lin-14. Cell 75, 843-854. Abstract Article

Lee, S.J., and Kenyon, C. (2009). Regulation of the longevity response to temperature by thermosensory neurons in Caenorhabditis elegans. Curr. Biol. 19, 715-722. Abstract Article

Li, S., Armstrong, C.M., Bertin, N., Ge, H., Milstein, S., Boxem, M., Vidalain, P.O., Han, J.D., Chesneau, A., Hao, T., et al. (2004). A map of the interactome network of the metazoan C. elegans. Science 303, 540-543. Abstract Article

Li, W., Kennedy, S.G., and Ruvkun, G. (2003). daf-28 encodes a C. elegans insulin superfamily member that is regulated by environmental cues and acts in the DAF-2 signaling pathway. Genes Dev. 17, 844-858. Abstract Article

Li, Y., and Paik, Y.K. (2011). A potential role for fatty acid biosynthesis genes during molting and cuticle formation in Caenorhabditis elegans. BMB Rep. 44, 285-290. Abstract Article

Liang, B., Ferguson, K., Kadyk, L., and Watts, J.L. (2010). The role of nuclear receptor NHR-64 in fat storage regulation in Caenorhabditis elegans. PloS One 5, e9869. Abstract Article

Lin, F.J., Qin, J., Tang, K., Tsai, S.Y., and Tsai, M.J. (2011). Coup d'Etat: an orphan takes control. Endocr. Rev. 32, 404-421. Abstract Article

Luciani, G.M., Magomedova, L., Puckrin, R., Urbanus, M.L., Wallace, I.M., Giaever, G., Nislow, C., Cummins, C.L., and Roy, P.J. (2011). Dafadine inhibits DAF-9 to promote dauer formation and longevity of Caenorhabditis elegans. Nat. Chem. Biol. 7, 891-893. Abstract Article

Ludewig, A.H., Kober-Eisermann, C., Weitzel, C., Bethke, A., Neubert, K., Gerisch, B., Hutter, H., and Antebi, A. (2004). A novel nuclear receptor/coregulator complex controls C. elegans lipid metabolism, larval development, and aging. Genes Dev. 18, 2120-2133. Abstract Article

MacNeil, L.T., Watson, E., Arda, H.E., Zhu, L.J., and Walhout, A.J. (2013). Diet-induced developmental acceleration independent of TOR and insulin in C. elegans. Cell 153, 240-252. Abstract Article 
Magner, D.B., Wollam, J., Shen, Y., Hoppe, C., Li, D., Latza, C., Rottiers, V., Hutter, H., and Antebi, A. (2013). The NHR-8 nuclear receptor regulates cholesterol and bile acid homeostasis in C. elegans. Cell Metab. 18, $212-224$. Abstract Article

Mahanti, P., Bose, N., Bethke, A., Judkins, J.C., Wollam, J., Dumas, K.J., Zimmerman, A.M., Campbell, S.L., Hu, P.J., Antebi, A., et al. (2014). Comparative metabolomics reveals endogenous ligands of DAF-12, a nuclear hormone receptor, regulating C. elegans development and lifespan. Cell Metab. 19, 73-83. Abstract Article

Mair, W., and Dillin, A. (2008). Aging and survival: the genetics of life span extension by dietary restriction. Annu. Rev. Biochem. 77, 727-754. Abstract Article

Mak, H.Y., and Ruvkun, G. (2004). Intercellular signaling of reproductive development by the C. elegans DAF-9 cytochrome P450. Development 131, 1777-1786. Abstract Article

Makishima, M., Okamoto, A.Y., Repa, J.J., Tu, H., Learned, R.M., Luk, A., Hull, M.V., Lustig, K.D., Mangelsdorf, D.J., and Shan, B. (1999). Identification of a nuclear receptor for bile acids. Science 284, 1362-1365. Abstract Article

Mangelsdorf, D.J., Thummel, C., Beato, M., Herrlich, P., Schutz, G., Umesono, K., Blumberg, B., Kastner, P., Mark, M., Chambon, P., et al. (1995). The nuclear receptor superfamily: the second decade. Cell 83, 835-839. Abstract Article

Mattison, J.A., Roth, G.S., Beasley, T.M., Tilmont, E.M., Handy, A.M., Herbert, R.L., Longo, D.L., Allison, D.B., Young, J.E., Bryant, M., et al. (2012). Impact of caloric restriction on health and survival in rhesus monkeys from the NIA study. Nature 489, 318-321. Abstract Article

McCormick, M., Chen, K., Ramaswamy, P., and Kenyon, C. (2012). New genes that extend Caenorhabditis elegans ${ }^{6}$ lifespan in response to reproductive signals. Aging Cell 11, 192-202. Abstract Article

McCulloch, D., and Gems, D. (2007). Sex-specific effects of the DAF-12 steroid receptor on aging in Caenorhabditis elegans. Ann. N. Y. Acad. Sci. 1119, 253-259. Abstract Article

McDonnell, D.P., Mangelsdorf, D.J., Pike, J.W., Haussler, M.R., and O'Malley, B.W. (1987). Molecular cloning of complementary DNA encoding the avian receptor for vitamin D. Science 235, 1214-1217. Abstract Article

McKay, J.P., Raizen, D.M., Gottschalk, A., Schafer, W.R., and Avery, L. (2004). eat-2 and eat-18 are required for nicotinic neurotransmission in the Caenorhabditis elegans pharynx. Genetics 166, 161-169. Abstract Article

McKenna, N.J., and O'Malley, B.W. (2010a). SnapShot: Nuclear receptors I. Cell 142, 822-822 e821. Abstract Article

McKenna, N.J., and O'Malley, B.W. (2010b). SnapShot: Nuclear receptors II. Cell 142, 986 e981. Abstract Article

Meli, V.S., Osuna, B., Ruvkun, G., and Frand, A.R. (2010). MLT-10 defines a family of DUF644 and proline-rich repeat proteins involved in the molting cycle of Caenorhabditis elegans. Mol. Biol. Cell 21, 1648-1661. Abstract Article

Merris, M., Wang, T., Soteropoulos, P., and Lenard, J. (2007). Differential gene expression of Caenorhabditis elegans grown on unmethylated sterols or $4 \alpha$-methylsterols. J. Lipid Res. 48, 1159-1166. Abstract Article

Min, K.J., Lee, C.K., and Park, H.N. (2012). The lifespan of Korean eunuchs. Curr. Biol. 22, R792-793. Abstract Article

Miskowski, J., Li, Y., and Kimble, J. (2001). The sys-1 gene and sexual dimorphism during gonadogenesis in Caenorhabditis elegans. Dev. Biol. 230, 61-73. Abstract Article

Mizutani, A., Koinuma, D., Tsutsumi, S., Kamimura, N., Morikawa, M., Suzuki, H.I., Imamura, T., Miyazono, K., and Aburatani, H. (2011). Cell type-specific target selection by combinatorial binding of Smad2/3 proteins and hepatocyte nuclear factor $4 \alpha$ in HepG2 cells. J. Biol. Chem. 286, 29848-29860. Abstract Article 
Monje, J.M., Brokate-Llanos, A.M., Perez-Jimenez, M.M., Fidalgo, M.A., and Munoz, M.J. (2011). pkc-1 regulates daf-2 insulin/IGF signalling-dependent control of dauer formation in Caenorhabditis elegans. Aging Cell 10, 1021-1031. Abstract Article

Monsalve, G.C., and Frand, A.R. (2012). Toward a unified model of developmental timing: A "molting" approach. Worm 1, 221-230. Abstract Article

Monsalve, G.C., Van Buskirk, C., and Frand, A.R. (2011). LIN-42/PERIOD controls cyclical and developmental progression of C. elegans molts. Curr. Biol. 21, 2033-2045. Abstract Article

Mooijaart, S.P., Kuningas, M., Westendorp, R.G., Houwing-Duistermaat, J.J., Slagboom, P.E., Rensen, P.C., and van Heemst, D. (2007). Liver X receptor alpha associates with human life span. J. Gerontol. A Biol. Sci. Med. Sci. 62, 343-349. Abstract Article

Moss, E.G., Lee, R.C., and Ambros, V. (1997). The cold shock domain protein LIN-28 controls developmental timing in C. elegans and is regulated by the lin-4 RNA. Cell 88, 637-646. Abstract Article

Motola, D.L., Cummins, C.L., Rottiers, V., Sharma, K.K., Li, T., Li, Y., Suino-Powell, K., Xu, H.E., Auchus, R.J., Antebi, A., et al. (2006). Identification of ligands for DAF-12 that govern dauer formation and reproduction in $C$. elegans. Cell 124, 1209-1223. Abstract Article

Much, J.W., Slade, D.J., Klampert, K., Garriga, G., and Wightman, B. (2000). The fax-1 nuclear hormone receptor regulates axon pathfinding and neurotransmitter expression. Development 127, 703-712. Abstract

Mullaney, B.C., Blind, R.D., Lemieux, G.A., Perez, C.L., Elle, I.C., Faergeman, N.J., Van Gilst, M.R., Ingraham, H.A., and Ashrafi, K. (2010). Regulation of C. elegans fat uptake and storage by acyl-CoA synthase-3 is dependent on NR5A family nuclear hormone receptor $n h r-25$. Cell Metab. 12, 398-410. Abstract Article

Nanji, M., Hopper, N.A., and Gems, D. (2005). LET-60 RAS modulates effects of insulin/IGF-1 signaling on development and aging in Caenorhabditis elegans. Aging Cell 4, 235-245. Abstract Article

Nelson, M.D., Zhou, E., Kiontke, K., Fradin, H., Maldonado, G., Martin, D., Shah, K., and Fitch, D.H. (2011). A bow-tie genetic architecture for morphogenesis suggested by a genome-wide RNAi screen in Caenorhabditis elegans. PLoS Genet. 7, e1002010. Abstract Article

Noble, T., Stieglitz, J., and Srinivasan, S. (2013). An integrated serotonin and octopamine neuronal circuit directs the release of an endocrine signal to control C. elegans body fat. Cell Metab. 18, 672-684. Abstract Article

Nolan, K.M., Sarafi-Reinach, T.R., Horne, J.G., Saffer, A.M., and Sengupta, P. (2002). The DAF-7 TGF- $\beta$ signaling pathway regulates chemosensory receptor gene expression in C. elegans. Genes Dev. 16, 3061-3073. Abstract Article

O'Rourke, E.J., Kuballa, P., Xavier, R., and Ruvkun, G. (2013). $\omega-6$ Polyunsaturated fatty acids extend life span through the activation of autophagy. Genes Dev. 27, 429-440. Abstract Article

O'Rourke, E.J., and Ruvkun, G. (2013). MXL-3 and HLH-30 transcriptionally link lipolysis and autophagy to nutrient availability. Nat. Cell Biol. 15, 668-676. Abstract Article

O'Rourke, E.J., Soukas, A.A., Carr, C.E., and Ruvkun, G. (2009). C. elegans major fats are stored in vesicles distinct from lysosome-related organelles. Cell Metab. 10, 430-435. Abstract Article

Ogawa, A., Streit, A., Antebi, A., and Sommer, R.J. (2009). A conserved endocrine mechanism controls the formation of dauer and infective larvae in nematodes. Curr. Biol. 19, 67-71. Abstract Article

Ong, K.K., Elks, C.E., Li, S., Zhao, J.H., Luan, J., Andersen, L.B., Bingham, S.A., Brage, S., Smith, G.D., Ekelund, U., et al. (2009). Genetic variation in LIN28B is associated with the timing of puberty. Nat. Genet. 41, 729-733. Abstract Article 
Ou, Q., and King-Jones, K. (2013). What goes up must come down: transcription factors have their say in making ecdysone pulses. Curr. Top. Dev. Biol. 103, 35-71. Abstract Article

Ouellet, J., Li, S., and Roy, R. (2008). Notch signalling is required for both dauer maintenance and recovery in $C$. elegans. Development 135, 2583-2592. Abstract Article

Paradis, S., and Ruvkun, G. (1998). C. elegans Akt/PKB transduces insulin receptor-like signals from AGE-1 PI3 kinase to the DAF-16 transcription factor. Genes Dev. 12, 2488-2498. Abstract Article

Park, D., Jones, K.L., Lee, H., Snutch, T.P., Taubert, S., and Riddle, D.L. (2012). Repression of a potassium channel by nuclear hormone receptor and TGF- $\beta$ signaling modulates insulin signaling in Caenorhabditis elegans. PLoS Genet. 8, e1002519. Abstract Article

Parks, D.J., Blanchard, S.G., Bledsoe, R.K., Chandra, G., Consler, T.G., Kliewer, S.A., Stimmel, J.B., Willson, T.M., Zavacki, A.M., Moore, D.D., et al. (1999). Bile acids: natural ligands for an orphan nuclear receptor. Science 284, 1365-1368. Abstract Article

Patel, D.S., Fang, L.L., Svy, D.K., Ruvkun, G., and Li, W. (2008). Genetic identification of HSD-1, a conserved steroidogenic enzyme that directs larval development in Caenorhabditis elegans. Development 135, 2239-2249. Abstract Article

Pathare, P.P., Lin, A., Bornfeldt, K.E., Taubert, S., and Van Gilst, M.R. (2012). Coordinate regulation of lipid metabolism by novel nuclear receptor partnerships. PLoS Genet. 8, e1002645. Abstract Article

Perkins, L.A., Hedgecock, E.M., Thomson, J.N., and Culotti, J.G. (1986). Mutant sensory cilia in the nematode Caenorhabditis elegans. Dev. Biol. 117, 456-487. Abstract Article

Petersen, S.C., Watson, J.D., Richmond, J.E., Sarov, M., Walthall, W.W., and Miller, D.M., 3rd (2011). A transcriptional program promotes remodeling of GABAergic synapses in Caenorhabditis elegans. J. Neurosci. 31, 15362-15375. Abstract Article

Pohludka, M., Simeckova, K., Vohanka, J., Yilma, P., Novak, P., Krause, M.W., Kostrouchova, M., and Kostrouch, Z. (2008). Proteomic analysis uncovers a metabolic phenotype in C. elegans after $n h r-40$ reduction of function. Biochem. Biophys. Res. Commun. 374, 49-54. Abstract Article

Potthoff, M.J., Kliewer, S.A., and Mangelsdorf, D.J. (2012). Endocrine fibroblast growth factors 15/19 and 21: from feast to famine. Genes Dev. 26, 312-324. Abstract Article

Rae, R., Sinha, A., and Sommer, R.J. (2012). Genome-wide analysis of germline signaling genes regulating longevity and innate immunity in the nematode Pristionchus pacificus. PLoS Pathog. 8, e1002864. Abstract Article

Raizen, D.M., Zimmerman, J.E., Maycock, M.H., Ta, U.D., You, Y.J., Sundaram, M.V., and Pack, A.I. (2008). Lethargus is a Caenorhabditis elegans sleep-like state. Nature 451, 569-572. Abstract Article

Ranhotra, H.S. (2012). The interplay between retinoic acid receptor-related orphan receptors and human diseases. J. Recept. Signal. Transduct. Res. 32, 181-189. Abstract Article

Reiner, D.J., Ailion, M., Thomas, J.H., and Meyer, B.J. (2008). C. elegans anaplastic lymphoma kinase ortholog SCD-2 controls dauer formation by modulating TGF- $\beta$ signaling. Curr. Biol. 18, 1101-1109. Abstract Article

Reinhart, B.J., Slack, F.J., Basson, M., Pasquinelli, A.E., Bettinger, J.C., Rougvie, A.E., Horvitz, H.R., and Ruvkun, G. (2000). The 21-nucleotide let-7 RNA regulates developmental timing in C. elegans. Nature 403, 901-906. Abstract Article

Ren, P., Lim, C.S., Johnsen, R., Albert, P.S., Pilgrim, D., and Riddle, D.L. (1996). Control of C. elegans larval development by neuronal expression of a TGF- $\beta$ homolog. Science 274, 1389-1391. Abstract Article

Riddle, D.L., Swanson, M.M., and Albert, P.S. (1981). Interacting genes in nematode dauer larva formation. Nature 290, 668-671. Abstract Article 
Robinson-Rechavi, M., Maina, C.V., Gissendanner, C.R., Laudet, V., and Sluder, A. (2005). Explosive lineage-specific expansion of the orphan nuclear receptor HNF4 in nematodes. J. Mol. Evol. 60, 577-586. Abstract Article

Rottiers, V., Motola, D.L., Gerisch, B., Cummins, C.L., Nishiwaki, K., Mangelsdorf, D.J., and Antebi, A. (2006). Hormonal control of $C$. elegans dauer formation and life span by a Rieske-like oxygenase. Dev. Cell 10, $473-482$. Abstract Article

Ruaud, A.F., Lam, G., and Thummel, C.S. (2011). The Drosophila NR4A nuclear receptor DHR38 regulates carbohydrate metabolism and glycogen storage. Mol. Endocrinol. 25, 83-91. Abstract Article

Russell, D.W. (2003). The enzymes, regulation, and genetics of bile acid synthesis. Annu. Rev. Biochem. 72, 137-174. Abstract Article

Salisbury, T.B., Binder, A.K., Grammer, J.C., and Nilson, J.H. (2007). Maximal activity of the luteinizing hormone $\beta$-subunit gene requires $\beta$-catenin. Mol. Endocrinol. 21, 963-971. Abstract Article

Sarin, S., Antonio, C., Tursun, B., and Hobert, O. (2009). The C. elegans Tailless/TLX transcription factor $n h r-67$ controls neuronal identity and left/right asymmetric fate diversification. Development 136, 2933-2944. Abstract Article

Sarin, S., O'Meara, M.M., Flowers, E.B., Antonio, C., Poole, R.J., Didiano, D., Johnston, R.J., Jr., Chang, S., Narula, S., and Hobert, O. (2007). Genetic screens for Caenorhabditis elegans mutants defective in left/right asymmetric neuronal fate specification. Genetics 176, 2109-2130. Abstract Article

Schaedel, O.N., Gerisch, B., Antebi, A., and Sternberg, P.W. (2012). Hormonal signal amplification mediates environmental conditions during development and controls an irreversible commitment to adulthood. PLoS Biol. 10, e1001306. Abstract Article

Schleit, J., Wall, V.Z., Simko, M., and Kaeberlein, M. (2011). The MDT-15 subunit of mediator interacts with dietary restriction to modulate longevity and fluoranthene toxicity in Caenorhabditis elegans. PloS One 6, e28036. Abstract Article

Schmutz, I., Ripperger, J.A., Baeriswyl-Aebischer, S., and Albrecht, U. (2010). The mammalian clock component PERIOD2 coordinates circadian output by interaction with nuclear receptors. Genes Dev. 24, 345-357. Abstract Article

Schorderet, D.F., and Escher, P. (2009). NR2E3 mutations in enhanced S-cone sensitivity syndrome (ESCS), Goldmann-Favre syndrome (GFS), clumped pigmentary retinal degeneration (CPRD), and retinitis pigmentosa (RP). Hum. Mutat. 30, 1475-1485. Abstract Article

Schwarz, E.M., Kato, M., and Sternberg, P.W. (2012). Functional transcriptomics of a migrating cell in Caenorhabditis elegans. Proc. Natl. Acad. Sci. U. S. A. 109, 16246-16251. Abstract Article

Schwarz, J., Lewandrowski, I., and Bringmann, H. (2011). Reduced activity of a sensory neuron during a sleep-like state in Caenorhabditis elegans. Curr. Biol. 21, R983-984. Abstract Article

Seydoux, G., and Greenwald, I. (1989). Cell autonomy of lin-12 function in a cell fate decision in C. elegans. Cell 57, 1237-1245. Abstract Article

Shaw, W.M., Luo, S., Landis, J., Ashraf, J., and Murphy, C.T. (2007). The C. elegans TGF- $\beta$ dauer pathway regulates longevity via insulin signaling. Curr. Biol. 17, 1635-1645. Abstract Article

Shen, Y., Wollam, J., Magner, D., Karalay, O., and Antebi, A. (2012). A steroid receptor-microRNA switch regulates life span in response to signals from the gonad. Science 338, 1472-1476. Abstract Article

Shi, C., and Murphy, C.T. (2013). Mating induces shrinking and death in Caenorhabditis mothers. Science 343, 536-540. Abstract Article 
Shmookler Reis, R.J., Xu, L., Lee, H., Chae, M., Thaden, J.J., Bharill, P., Tazearslan, C., Siegel, E., Alla, R., Zimniak, P., et al. (2011). Modulation of lipid biosynthesis contributes to stress resistance and longevity of $C$. elegans mutants. Aging (Albany NY) 3, 125-147. Abstract

Shostak, Y., Van Gilst, M.R., Antebi, A., and Yamamoto, K.R. (2004). Identification of C. elegans DAF-12-binding sites, response elements, and target genes. Genes Dev. 18, 2529-2544. Abstract Article

Sieber, M.H., and Thummel, C.S. (2012). Coordination of triacylglycerol and cholesterol homeostasis by DHR96 and the Drosophila LipA homolog magro. Cell Metab. 15, 122-127. Abstract Article

Siegfried, K.R., Kidd, A.R., 3rd, Chesney, M.A., and Kimble, J. (2004). The sys-1 and sys-3 genes cooperate with Wnt signaling to establish the proximal-distal axis of the Caenorhabditis elegans gonad. Genetics 166, $171-186$. Abstract Article

Siegfried, K.R., and Kimble, J. (2002). POP-1 controls axis formation during early gonadogenesis in C. elegans. Development 129, 443-453. Abstract

Silhankova, M., Jindra, M., and Asahina, M. (2005). Nuclear receptor NHR-25 is required for cell-shape dynamics during epidermal differentiation in Caenorhabditis elegans. J. Cell Sci. 118, 223-232. Abstract Article

Simeckova, K., Brozova, E., Vohanka, J., Pohludka, M., Kostrouch, Z., Krause, M.W., Rall, J.E., and Kostrouchova, M. (2007). Supplementary nuclear receptor NHR-60 is required for normal embryonic and early larval development of Caenorhabditis elegans. Folia Biol. (Praha) 53, 85-96. Abstract

Simon, A.F., Shih, C., Mack, A., and Benzer, S. (2003). Steroid control of longevity in Drosophila melanogaster. Science 299, 1407-1410. Abstract Article

Song, C., and Liao, S. (2000). Cholestenoic acid is a naturally occurring ligand for liver $\mathrm{X}$ receptor $\alpha$. Endocrinology 141, 4180-4184. Abstract Article

Sulston, J.E., and Horvitz, H.R. (1977). Post-embryonic cell lineages of the nematode, C. elegans. Dev. Biol. 56, 110-156. Abstract Article

Sze, J.Y., Victor, M., Loer, C., Shi, Y., and Ruvkun, G. (2000). Food and metabolic signalling defects in a $C$. elegans serotonin-synthesis mutant. Nature 403, 560-564. Abstract Article

Tatar, M., Kopelman, A., Epstein, D., Tu, M.P., Yin, C.M., and Garofalo, R.S. (2001). A mutant Drosophila insulin receptor homolog that extends life-span and impairs neuroendocrine function. Science 292, 107-110. Abstract Article

Taubert, S., Hansen, M., Van Gilst, M.R., Cooper, S.B., and Yamamoto, K.R. (2008). The Mediator subunit MDT-15 confers metabolic adaptation to ingested material. PLoS Genet. 4, e1000021. Abstract Article

Taubert, S., Van Gilst, M.R., Hansen, M., and Yamamoto, K.R. (2006). A Mediator subunit, MDT-15, integrates regulation of fatty acid metabolism by NHR-49-dependent and -independent pathways in C. elegans. Genes Dev. 20, 1137-1149. Abstract Article

Tennessen, J.M., Gardner, H.F., Volk, M.L., and Rougvie, A.E. (2006). Novel heterochronic functions of the Caenorhabditis elegans period-related protein LIN-42. Dev. Biol. 289, 30-43. Abstract Article

Tennessen, J.M., Opperman, K.J., and Rougvie, A.E. (2010). The C. elegans developmental timing protein LIN-42 regulates diapause in response to environmental cues. Development 137, 3501-3511. Abstract Article

Tennessen, J.M., and Thummel, C.S. (2011). Coordinating growth and maturation-insights from Drosophila. Curr. Biol. 21, R750-757. Abstract Article

Thomas, J.H., Birnby, D.A., and Vowels, J.J. (1993). Evidence for parallel processing of sensory information controlling dauer formation in Caenorhabditis elegans. Genetics 134, 1105-1117. Abstract 
Thompson-Peer, K.L., Bai, J., Hu, Z., and Kaplan, J.M. (2012). HBL-1 patterns synaptic remodeling in C. elegans. Neuron 73, 453-465. Abstract Article

Uchida, O., Nakano, H., Koga, M., and Ohshima, Y. (2003). The C. elegans che-1 gene encodes a zinc finger transcription factor required for specification of the ASE chemosensory neurons. Development 130, 1215-1224. Abstract Article

Urs, A.N., Dammer, E., Kelly, S., Wang, E., Merrill, A.H., Jr., and Sewer, M.B. (2007). Steroidogenic factor-1 is a sphingolipid binding protein. Mol. Cell. Endocrinol. 265-266, 174-178. Abstract Article

Van Buskirk, C., and Sternberg, P.W. (2007). Epidermal growth factor signaling induces behavioral quiescence in Caenorhabditis elegans. Nat. Neurosci. 10, 1300-1307. Abstract Article

Van Gilst, M.R., Hadjivassiliou, H., Jolly, A., and Yamamoto, K.R. (2005a). Nuclear hormone receptor NHR-49 controls fat consumption and fatty acid composition in C. elegans. PLoS Biol. 3, e53. Abstract Article

Van Gilst, M.R., Hadjivassiliou, H., and Yamamoto, K.R. (2005b). A Caenorhabditis elegans nutrient response system partially dependent on nuclear receptor NHR-49. Proc. Natl. Acad. Sci. U. S. A. 102, 13496-13501. Abstract Article

Verghese, E., Schocken, J., Jacob, S., Wimer, A.M., Royce, R., Nesmith, J.E., Baer, G.M., Clever, S., McCain, E., Lakowski, B., et al. (2011). The tailless ortholog $n h r-67$ functions in the development of the C. elegans ventral uterus. Dev. Biol. 356, 516-528. Abstract Article

Vilchez, D., Morantte, I., Liu, Z., Douglas, P.M., Merkwirth, C., Rodrigues, A.P., Manning, G., and Dillin, A. (2012). RPN-6 determines C. elegans longevity under proteotoxic stress conditions. Nature 489, 263-268. Abstract Article

Viswanathan, S.R., Daley, G.Q., and Gregory, R.I. (2008). Selective blockade of microRNA processing by Lin28. Science 320, 97-100. Abstract Article

Vowels, J.J., and Thomas, J.H. (1992). Genetic analysis of chemosensory control of dauer formation in Caenorhabditis elegans. Genetics 130, 105-123. Abstract

Wang, M.C., Min, W., Freudiger, C.W., Ruvkun, G., and Xie, X.S. (2011). RNAi screening for fat regulatory genes with SRS microscopy. Nat. Methods 8, 135-138. Abstract Article

Wang, M.C., O'Rourke, E.J., and Ruvkun, G. (2008). Fat metabolism links germline stem cells and longevity in $C$. elegans. Science 322, 957-960. Abstract Article

Wang, Q., and Cooney, A.J. (2013). The role of nuclear receptors in embryonic stem cells. Adv. Exp. Med. Biol. 786, 287-306. Abstract Article

Wang, Y., Kumar, N., Solt, L.A., Richardson, T.I., Helvering, L.M., Crumbley, C., Garcia-Ordonez, R.D., Stayrook, K.R., Zhang, X., Novick, S., et al. (2010). Modulation of retinoic acid receptor-related orphan receptor $\alpha$ and $\gamma$ activity by 7-oxygenated sterol ligands. J. Biol. Chem. 285, 5013-5025. Abstract Article

Wang, Z., Zhou, X.E., Motola, D.L., Gao, X., Suino-Powell, K., Conneely, A., Ogata, C., Sharma, K.K., Auchus, R.J., Lok, J.B., et al. (2009). Identification of the nuclear receptor DAF-12 as a therapeutic target in parasitic nematodes. Proc. Natl. Acad. Sci. U. S. A. 106, 9138-9143. Abstract Article

Ward, J.D., Bojanala, N., Bernal, T., Ashrafi, K., Asahina, M., and Yamamoto, K.R. (2013). Sumoylated NHR-25/NR5A regulates cell fate during C. elegans vulval development. PLoS Genet. 9, e1003992. Abstract Article

Watson, E., MacNeil, L.T., Arda, H.E., Zhu, L.J., and Walhout, A.J. (2013). Integration of metabolic and gene regulatory networks modulates the C. elegans dietary response. Cell 153, 253-266. Abstract Article 
Wiese, M., Antebi, A., and Zheng, H. (2010). Intracellular trafficking and synaptic function of APL-1 in Caenorhabditis elegans. PloS One 5, e12790. Abstract Article

Wightman, B., Ebert, B., Carmean, N., Weber, K., and Clever, S. (2005). The C. elegans nuclear receptor gene fax-1 and homeobox gene unc-42 coordinate interneuron identity by regulating the expression of glutamate receptor subunits and other neuron-specific genes. Dev. Biol. 287, pp. 74-85. Abstract Article

Wightman, B., Ha, I., and Ruvkun, G. (1993). Posttranscriptional regulation of the heterochronic gene lin-14 by lin-4 mediates temporal pattern formation in C. elegans. Cell 75, 855-862. Abstract Article

Willcox, B.J., Donlon, T.A., He, Q., Chen, R., Grove, J.S., Yano, K., Masaki, K.H., Willcox, D.C., Rodriguez, B., and Curb, J.D. (2008). FOXO3A genotype is strongly associated with human longevity. Proc. Natl. Acad. Sci. U. S. A. 105, 13987-13992. Abstract Article

Williams, B.D., and Waterston, R.H. (1994). Genes critical for muscle development and function in Caenorhabditis elegans identified through lethal mutations. J. Cell Biol. 124, 475-490. Abstract Article

Wollam, J., Magner, D.B., Magomedova, L., Rass, E., Shen, Y., Rottiers, V., Habermann, B., Cummins, C.L., and Antebi, A. (2012). A novel 3-hydroxysteroid dehydrogenase that regulates reproductive development and longevity. PLoS Biol. 10, e1001305. Abstract Article

Wollam, J., Magomedova, L., Magner, D.B., Shen, Y., Rottiers, V., Motola, D.L., Mangelsdorf, D.J., Cummins, C.L., and Antebi, A. (2011). The Rieske oxygenase DAF-36 functions as a cholesterol 7-desaturase in steroidogenic pathways governing longevity. Aging Cell 10, 879-884. Abstract Article

Yamawaki, T.M., Berman, J.R., Suchanek-Kavipurapu, M., McCormick, M., Maria Gaglia, M., Lee, S.J., and Kenyon, C. (2010). The somatic reproductive tissues of $C$. elegans promote longevity through steroid hormone signaling. PLoS Biol. 8. Abstract Article

Yang, F., Vought, B.W., Satterlee, J.S., Walker, A.K., Jim Sun, Z.Y., Watts, J.L., DeBeaumont, R., Saito, R.M., Hyberts, S.G., Yang, S., et al. (2006). An ARC/Mediator subunit required for SREBP control of cholesterol and lipid homeostasis. Nature 442, 700-704. Abstract Article

Yochem, J., Tuck, S., Greenwald, I., and Han, M. (1999). A gp330/megalin-related protein is required in the major epidermis of Caenorhabditis elegans for completion of molting. Development 126, 597-606. Abstract

Yoshiyama, T., Namiki, T., Mita, K., Kataoka, H., and Niwa, R. (2006). Neverland is an evolutionally conserved Rieske-domain protein that is essential for ecdysone synthesis and insect growth. Development 133, $2565-2574$. Abstract Article

Yoshiyama-Yanagawa, T., Enya, S., Shimada-Niwa, Y., Yaguchi, S., Haramoto, Y., Matsuya, T., Shiomi, K., Sasakura, Y., Takahashi, S., Asashima, M., et al. (2011). The conserved Rieske oxygenase DAF-36/Neverland is a novel cholesterol-metabolizing enzyme. J. Biol. Chem. 286, 25756-25762. Abstract Article

Zhang, Y., Xie, Y., Berglund, E.D., Coate, K.C., He, T.T., Katafuchi, T., Xiao, G., Potthoff, M.J., Wei, W., Wan, Y., et al. (2012). The starvation hormone, fibroblast growth factor-21, extends lifespan in mice. eLife 1, e00065. Abstract Article

Zhao, Y., and Bruemmer, D. (2010). NR4A orphan nuclear receptors: transcriptional regulators of gene expression in metabolism and vascular biology. Arterioscler Thromb Vasc Biol 30, 1535-1541. Abstract Article

Zhao, Z., Fang, L.L., Johnsen, R., and Baillie, D.L. (2004). ATP-binding cassette protein E is involved in gene transcription and translation in Caenorhabditis elegans. Biochem. Biophys. Res. Commun. 323, 104-111. Abstract Article

Zhi, X., Zhou, X.E., Melcher, K., Motola, D.L., Gelmedin, V., Hawdon, J., Kliewer, S.A., Mangelsdorf, D.J., and $\mathrm{Xu}$, H.E. (2012). Structural conservation of ligand binding reveals a bile acid-like signaling pathway in nematodes. J. Biol. Chem. 287, 4894-4903. Abstract Article 
Zhou, H.M., and Walthall, W.W. (1998). UNC-55, an orphan nuclear hormone receptor, orchestrates synaptic specificity among two classes of motor neurons in Caenorhabditis elegans. J. Neurosci. 18, 10438-10444. Abstract

Zhu, H., Shen, H., Sewell, A.K., Kniazeva, M., and Han, M. (2013). A novel sphingolipid-TORC1 pathway critically promotes postembryonic development in Caenorhabditis elegans. eLife 2, e00429. Abstract Article

Zugasti, O., Rajan, J., and Kuwabara, P.E. (2005). The function and expansion of the Patched- and Hedgehog-related homologs in C. elegans. Genome Res. 15, 1402-1410. Abstract Article

All WormBook content, except where otherwise noted, is licensed under a Creative SOMAERIGHISRESERVED COMmons Attribution License. 